\title{
The thigh and leg of Homo naledi
}

Damiano Marchi ${ }^{\text {a, b, * }}$, Christopher S. Walker ${ }^{\mathrm{c}, \mathrm{d}, \mathrm{b}}$, Pianpian Wei ${ }^{\mathrm{e}, \mathrm{f}, \mathrm{b}}$, Trenton W. Holliday ${ }^{\mathrm{g}, \mathrm{b}}$, Steven E. Churchill ${ }^{\text {d, b }}$, Lee R. Berger ${ }^{\text {b }}$, Jeremy M. DeSilva ${ }^{\text {h, b }}$

${ }^{a}$ Department of Biology, University of Pisa, Via Derna 1, Pisa, 56126, Italy.

${ }^{\mathrm{b}}$ Evolutionary Studies Institute and Centre for Excellence in PalaeoSciences, University of the Witwatersrand, Private Bag 3, Wits 2050, South Africa.

${ }^{c}$ Department of Molecular Biomedical Sciences, College of Veterinary Medicine, North Carolina State University, 1060 William Moore Drive, Raleigh, NC, 27607 USA.

d Department of Evolutionary Anthropology, Box 90383, Duke University, Durham, NC 27708, USA.

${ }^{\mathrm{e}}$ Key Laboratory of Vertebrate Evolution and Human Origins, Institute of Vertebrate Paleontology and Paleoanthropology, Chinese Academy of Sciences, Beijing 100044, China.

${ }^{\mathrm{f}}$ Department of Geoscience, University of Chinese Academy of Sciences, Beijing 100049, China.

${ }^{\mathrm{g}}$ Department of Anthropology, Tulane University, New Orleans, LA 70118, USA.

${ }^{\mathrm{h}}$ Department of Anthropology, Dartmouth College, Hanover, NH 03755, USA.

* Corresponding author.

E-mail address: damiano.marchi@unipi.it (D. Marchi)

Keywords: Bipedal locomotion; Femur; Patella; Tibia; Fibula; South Africa 


\begin{abstract}
This paper describes the 108 femoral, patellar, tibial, and fibular elements of a new species of Homo (Homo naledi) discovered in the Dinaledi chamber of the Rising Star cave system in South Africa. Homo naledi possesses a mosaic of primitive, derived, and unique traits functionally indicative of a bipedal hominin adapted for long distance walking and possibly running. Traits shared with australopiths include an anteroposteriorly compressed femoral neck, a mediolaterally compressed tibia, and a relatively circular fibular neck. Traits shared with Homo include a well-marked linea aspera, anteroposteriorly thick patellae, relatively long tibiae, and gracile fibulae with laterally oriented lateral malleoli. Unique features include the presence of two pillars on the superior aspect of the femoral neck and a tubercular distal insertion of the pes anserinus on the tibia. The mosaic morphology of the $H$. naledi thigh and leg appears most consistent with a species intermediate between Australopithecus spp. and Homo erectus and, accordingly, may offer insight into the nature of the earliest members of genus Homo. These fossils also expand the morphological diversity of the Homo lower limb, perhaps indicative of locomotor diversity in our genus.
\end{abstract}




\section{Introduction}

The transition from Australopithecus to Homo probably involved changes to the postcranial skeleton (Bramble and Lieberman, 2004; Antón et al., 2014), but the limited number of postcranial remains assigned to early Homo has limited efforts to clarify the transition between the genera. There are isolated remains, such as KNM-ER 1472 (Leakey, 1973), KNM-ER 1481 (Kennedy, 1983), KNM-ER 5881 (Ward et al., 2015), and others (Wood and Leakey, 2011) that likely belong to Homo, however, given both the taxonomic diversity in early Homo (Leakey et al., 2012; Spoor et al., 2015; but see van Arsdale and Wolpoff, 2012; Lordkipanidze et al., 2013) and the spatial and temporal overlap between early Homo and the robust australopiths, attribution of isolated fossils to a species of early Homo remains speculative and controversial (e.g., Moyà-Solà et al., 2008). South African localities, in particular, have yielded very little postcranial material confidently attributed to Homo (but see McHenry, 1994; Susman et al., 2001).

The most complete specimens attributed to early Homo, which preserve both craniodental and lower limb remains, include OH 62 (Johanson et al., 1987; although the attribution of this specimen to Homo has been questioned, see Berger et al., 2010), KNM-ER 3735 (Leakey and Walker, 1985), and the H. erectus fossils from Dmanisi, Georgia (Lordkipanidze et al., 2007). It has been suggested that the OH 62 femur is relatively short (Johanson et al., 1987; but see Haeusler and McHenry, 2004), with a long, anteroposteriorly compressed neck. Yet, both OH 62 and KNM-ER 3735 have well-developed femoral pilasters and levels of femoral diaphyseal robusticity that are more human-like than those of australopiths, such as the A. afarensis partial skeleton A.L. 288-1 (Haeusler and McHenry, 2004, 2007). The diaphysis of the OH 62 femur, however, is not as mediolaterally expanded at the level below the lesser trochanter as is the A.L. 288-1 femur (Johanson et al., 1987). Limb proportions and general morphology of the Dmanisi lower limb are more human-like, 
although the Dmanisi remains also exhibit some primitive features in the foot and upper limb (Lordkipanidze et al., 2007; Pontzer et al., 2010). No other early Homo specimens are complete enough to provide an unambiguous attribution, making it difficult to characterize the lower limb of early members of our own genus.

Here, we describe the femora, patellae, tibiae, and fibulae of Homo naledi (Berger et al., 2015). Although the Dinaledi deposit is not yet dated, the overall cranial and postcranial morphology of $H$. naledi is most similar to Pleistocene fossils attributed to members of the genus Homo (Berger et al., 2015; Dembo et al., 2016).

\section{Materials and methods}

\section{The Dinaledi and comparative sample}

The thigh and leg remains of the Dinaledi assemblage consist of 108 femoral, patellar, tibial, and fibular elements (Table 1). Elements are defined as identifiable fossils (regardless of size or completeness) that do not clearly conjoin with any other known elements in the assemblage as it currently stands. The minimum number of individuals (MNI) and the maturity of the elements in the present sample were assessed using size, side, morphology, and epiphyseal fusion. Bone siding and anatomical overlap were the primary methods by which individuals in the postcranial assemblage were differentiated. Though the assemblage is remarkably homogenous morphologically, variation between bones of comparable size and from opposite sides was used in rare cases to distinguish unique individuals. State of epiphyseal fusion was used preferentially, wherever possible, in grouping elements into two broad developmental categories: mature (fused epiphyses), or immature (unfused epiphyses; no elements in the thigh and leg assemblage recovered to date have partially fused 
epiphyses). Size was used secondarily to estimate the maturity of fragmentary, isolated elements (not preserving epiphyses or metaphyses) and as a factor in differentiating individuals. Specimens that fell within or over the size range of elements determined to be mature by epiphyseal fusion, were deemed mature. Elements markedly smaller than comparative mature specimens were designated immature. Maturity was not estimated for specimens of intermediate size. Overall, specimens sorted by size alone do not feature prominently in this work and are used primarily for classification purposes, whereas the most complete (typically preserving epiphyses or metaphyses) and thereby diagnostic elements of the assemblage are featured disproportionately in the present descriptions and analyses.

The femoral sample represents a minimum of eight mature and three immature individuals, while three mature individuals have been identified from the patellae. Seven mature and two immature individuals are known from the tibiae, and eight mature, two immature, and one individual of unknown developmental state are represented by the fibulae (Table 2). Descriptions of the most complete specimens are included in the main text. Descriptions of less anatomically informative fragments are presented in the Supplementary Online Material (SOM). The immature sample is pictured and described: it is largely morphologically consistent with the mature sample, but these specimens are excluded from diagnoses and analyses due to the potential for ontogenetic variation that cannot be fully evaluated at this time and is the subject of ongoing study. The comparative samples used in the analyses are listed in SOM Tables S1 and S2. In summary, it includes the following groups: among the extant species Homo sapiens, Chimpanzee (Pan troglodytes) and Gorilla (Gorilla gorilla), among fossil species Orrorin tugenensis, Australopithecus (which includes A. afarensis, A. africanus, A. sediba, A. robustus and A. boisei), Hominin indet. (see table S1 for the specimens included), Early Homo (see table S1 for the specimens included) and Homo erectus. 


\section{Femur methods}

Measurements taken on the proximal femur include the maximum superoinferior (SI) diameter of the femoral head, the minimum SI diameter of the neck (taken such that the measurement was orthogonal to the long axis of the bone), and the anteroposterior (AP) diameter of the neck (taken orthogonal to the SI diameter of the neck). These measures followed measurement numbers 1-3 in McHenry and Corruccini (1978) and repeated in other hominin femoral studies (e.g., Reed et al., 1993). Because no femora preserved both the head and the greater trochanter, biomechanical neck length was not measured. Instead, the neck was measured as the maximum length along the main axis from the lateralmost edge of the femoral head to the intertrochanteric crest (measurement number 7 in McHenry and Corruccini [1978]). No H. naledi femora are complete, so femoral anteversion could not be measured using the traditional method (Kingsley and Olmsted, 1948). Instead, femoral neck anterversion was quantified as the angle formed by the longitudinal axes of the neck and the proximal shaft, with the shaft positioned so that the linea aspera distal to the point of convergence between the spiral line and the gluteal line is the most posterior part of the bone (Fig. 1). Digital photos were taken with the lens in line with the bone and perpendicular to the superior view of the femur (Fig. 1b). The photograph obtained is shown in Figure 1c. ImageJ (http://rsb.info.nih.gov/ij/) was used to measure anteversion angle on the digital photos, which were measured as the angles between the longitudinal axis of the neck and the sagittal plane (Fig. 1c). Angles greater than $90^{\circ}$ indicate femoral neck anterversion. A typical modern human angle is lower than $90^{\circ}$ (Fig. 1c).

Femoral neck external outlines in sagittal view (Fig. 2) were taken at the neck-shaft junction on three-dimensional (3D) digital scan reconstructions. Three-dimensional digital 
scans were captured using a 3D HD Next Engine Scanner in wide mode: $380 \mu \mathrm{m}$ accuracy and 6 points per $\mathrm{mm}$. The subtrochanteric dimensions were measured as the maximum mediolateral (ML) diameter of the shaft below the lesser trochanter and the AP diameter of the bone perpendicular to the ML diameter as described in McHenry and Corrucini (1978; measurements 4 and 5) and Gilbert (2008). Ratios were used to characterize the shape of the femoral neck (AP/SI*100) and the platymeric index (AP/ML*100). Relative neck length was assessed by dividing the neck length by the square root of the product of the ML and AP subtrochanteric dimensions. To justify the use of ratios, reduced major axis (RMA) regressions were used to demonstrate that the $95 \%$ C.I. of the slope of the line characterizing the scaling relationship between the two variables used in the ratio included 1.0.

Medical computed tomography (CT) scanning of three mature femoral diaphyses (U.W. 101-003, UW. 101-012, and U.W. 101-268) was performed at Johannesburg Hospital (Johannesburg, South Africa) on a Philips Brilliance 16P medical CT scanner (Philips Healthcare, Andover, MA); pixel dimensions 0.98 x $0.98 \mathrm{~mm}$ ). Following data acquisition, image stacks were segmented to produce isosurfaces using Avizo 8 software (Visualization Sciences Group, Mérignac, France). In order to create diaphyseal cross-sections, the medullary spaces must be identified and matrix needs to be subtracted by manual segmentation. Because of the low resolution of the images, it was not possible to accurately isolate the cortical shell of specimens U.W. 101-003 and U.W. 101-012. U.W. 101-268 did not present matrix in the medullary cavity, thus allowing segmentation. Due to the fragmentary nature of U.W. 101-268, midshaft level was first estimated on the more complete U.W. 101-003 and then estimated on U.W. 101-268 by positioning the two bones parallel to each other. Given that the two femoral diaphyses roughly represent the same portion of the femur (see descriptions below) this approach is justified by evidence for low variability in cross-sectional geometry around the midshaft in modern humans (Sládek et al., 2010). Cross- 
sectional images obtained with Avizo 8 were imported into Image $\mathbf{J}$ and analyzed using MomentMacro 1.3 (http://www.hopkinsmedicine.org/FAE/mmacro.html).

A linear discriminant function analysis (DFA) was performed to classify the Dinaledi femora relative to known hominin femora. Five measurements of the proximal femur described earlier were used in DFA: neck SI, neck AP, subtrochanteric AP, subtrochanteric ML, and neck length. The five variables were size- adjusted by dividing each variable by the geometric mean of the five proximal femoral measurements (Mosimann, 1970; Richmond and Jungers, 2008). In the first DFA, the Dinaledi femora were entered as unknowns alongside Homo sapiens, Australopithecus, fossil Homo, and hominin indet. This last grouping consisted of five femora (KNM-ER 738, KNM-ER 815, KNM-ER 1463, KNM-ER 3728, and KNM-ER 5880) that could either be from early Homo or robust Australopithecus. Because of this taxonomic uncertainty, a second DFA was performed without these hominin indet. specimens. The DFA was performed using IMB SPSS Statistics Version 20.

\section{Patella methods}

Patella measurements included the maximum superoinferior diameter of the bone (M1), the maximum ML breadth (M2), and the maximum AP thickness (M3) following Martin and Saller (1957). The relative AP thickness of the patella was assessed as: (AP/ML*100).

\section{Tibia methods}

The tibial nutrient foramen and midshaft dimensions were measured as the maximum AP diameter of the shaft at the nutrient foramen and midshaft, respectively, and the ML diameter of the bone perpendicular to the AP diameters. Distal tibia measurements included the 
maximum ML thickness of the medial malleolus, the maximum ML diameter of the anterior and posterior rims of the talar articular surface, and the ML diameter of the midpoint of the talar facet following the methods described in DeSilva (2008).

Tibia length (intended as total length, M1 [Martin and Saller, 1957]) obtained from the only nearly complete mature specimen (U.W. 101-484) was estimated using two methods: 1) a comparative measure obtained from a human tibia (Khoe-san) at the University of the Witwatersrand fossil lab of approximately the same size as U.W. 101-484 (Fig. 3; yielding an estimated length of $325 \mathrm{~mm}$ ), and 2) a measure derived from Wright and Vásquez's (2003) regression formulae obtained from a Guatemalan population. Forensic-based regressions using articular dimensions to estimate bone length (Chibba and Bidmos, 2007) are not applicable given that U.W. 101-484 lacks complete epiphyses, however, regressions based on diaphyseal dimensions can be applied (Steele and McKern, 1969; Jacobs, 1992; Wright and Vásquez, 2008). We are aware that these formulae are population specific (Wright and Vásquez, 2008) and can vary with muscular activity patterns and intensity (Jacobs, 1992). Nevertheless, the formulae developed for the Guatemalan population can be tentatively used, given the diminutive stature and relatively gracile skeletons of this population, similar to that seen in H. naledi. U.W. 101-484 includes the most proximal point of the tibial tuberosity to the proximal margin of the tibiotalar articular surface (called T1-T6 in Wright and Vásquez, 2008), and is related to total tibial length by the equation:

$$
\text { T1-T6 }=8.847+0.873 \times \text { tibia length }\left(\mathrm{R}^{2}=0.965 ; N=89 ; \mathrm{SE}=5.92\right) .
$$

U.W. 101-484 does not preserve enough of the articular surface distally (or any of the proximal articular surface) to compare the length to the weight bearing joints of this individual. Thus, to assess the relative length of the tibia, we performed a bootstrapping analysis that produced normal distributions for tibial length compared to the femoral head diameter in humans and great apes. The femoral head SI measurement for U.W. 101-484 
along with the diameter of two mature femoral heads (U.W. 101-271 [35.8 mm] and U.W. $101-1300[35.2 \mathrm{~mm}])$ were used in this analysis. Tibial lengths from humans $(n=122)$, lowland gorillas $(n=16)$, chimpanzees $(n=24)$, and orangutans $(n=12)$ were compared with femoral head diameters from humans $(n=308)$, lowland gorillas $(n=112)$, chimpanzees $(n=$ 125), and orangutans ( $n=23$ ) (see Table $S 3$ in SOM) using the resampling macro in Microsoft Excel (Resampling Stats Excel Add-in Version 4). In humans, a single tibial length was randomly selected and divided by the average of two randomly sampled femoral head diameters. This was repeated 5,000 times, and then repeated for the great apes using an exact randomization approach given the smaller sample sizes. Normal distributions of tibial length: femoral head diameter resulted and we assessed the likelihood of sampling the ratio found in the Dinaledi sample to that constructed for humans and great apes.

\section{Fibula methods}

Fibula measurements included AP (M4c) and ML (M4b) neck diameter, where the neck is the region of the proximal fibular diaphysis of lowest circumference, and midshaft AP [(M3(2)] and ML [(M3(1)] diameters following Martin and Saller (1957). The linear measurements were used to compute the neck robusticity index and the midshaft robusticity index of the fibula: (ML/AP*100).

U.W. 101-1037 is the most complete fibula of the Dinaledi assemblage and is preserved from the level of the neck to just inferior to the most proximal part of the insertion of the interosseous ligament. Unfortunately, no data are available in the literature to estimate fibula length from fragmentary bones. Accordingly, we developed a new length estimation method using two landmarks on the fibular diaphysis: the proximal neck and the most proximal part of the subcutaneous triangular surface (STS). We measured neck-STS distance (intended as the distance, parallel to the longitudinal axis of the fibula, between the neck and 
the most proximal part of the STS) and fibular total length (M1, Martin and Saller, 1957) from a South African sample housed at the Dart Collection, University of the Witwatersrand. The sample includes 31 non-pathological adult individuals. A regression formula was obtained to estimate fibular total length:

fibula length $(\mathrm{mm})=62.761+1.282 \times$ neck-STS $\left(\mathrm{R}^{2}=0.735 ; N=31 ; \mathrm{SEE}=9.7\right)$.

The angle between the fibulotalar surface area and STS was measured following Stern and Susman (1983). The fibulotalar articular surface has been divided into two functional surfaces: the proximal portion, which articulates with the vertical part of the lateral articular surface of the talus, and the distal portion that articulates with the flaring part of the lateral articular surface of the talus (Marchi, 2015). The AP and SI diameters of the proximal and distal portions of the fibulotalar articulation were measured and used to calculate the areas of the two articular surfaces (Marchi, 2015).

\section{Descriptions of Dinaledi thigh and leg remains}

\section{Femur}

Dimensions for the H. naledi femur sample are listed in Table 3. Femur specimens are depicted in Figures 4 - 11 (3D surface scans available at www.morphosource.org).

U.W. 101-002 (Fig. 4a) is a mature right proximal femur preserved from the proximal end of the eroded head to a clean break in the shaft. Posteriorly, there is a ring of cortex around the damaged head that flares gradually and is fenestrated with vascular foramina demarcating the head-neck junction. The neck is well preserved posteriorly, but has some damage anteriorly. It is AP compressed. The femoral head and neck are anteverted relative to the long axis of the shaft. There is a palpable obturator externus groove across the posterior neck. Superiorly, 
along the neck, there are two ML oriented pillars of bone (see Fig. 5 for examples). One is more inferior and posterior, the other is more superior and anterior. These contribute to torsion of the head and neck relative to the long axis of the shaft. Anteriorly, the neck is smooth without any evidence of an intertrochanteric line. Anterolaterally, there is a palpable depression for $\mathrm{m}$. vastus lateralis. The underlying trabecular bone is all that remains of the badly damaged greater trochanter, which is $25.3 \mathrm{~mm}$ AP and $23.2 \mathrm{~mm} \mathrm{ML}$. At the superior junction of the neck and the greater trochanter, there is a part of the trochanteric fossa preserved in which there are several vascular foramina. In anterior view, the inferior aspect of the greater trochanter flares laterally. The lesser trochanter is badly eroded, though the overall dimensions are about $14.3 \mathrm{~mm}$ SI and $13.6 \mathrm{~mm}$ ML. It is positioned posteriorly and cannot be seen in anterior view, likely because of erosion. The center of the lesser trochanter is 28.8 $\mathrm{mm}$ from the inferolateral edge of the femoral head. Just inferior to the lesser trochanter, the shaft is platymeric. Descending straight, from the edge of the greater trochanter posterolaterally, is a well-developed third trochanter. Lateral and inferior to the gluteal line is a concave depression - the hypotrochanteric fossa. Lateral to that is a thickening of the cortex that begins anterolaterally and spirals inferiorly to merge with the gluteal line just inferior to the hypotrochanteric fossa. The central part of the posterior shaft is abraded and the pectineal and spiral lines are barely detectable. Inferiorly, the lines merge into a well-developed linea aspera. Anteriorly, the shaft is convex, posteriorly it is relatively flat. The shaft at the point of break is circular: $20.0 \mathrm{~mm}$ ML and $20.6 \mathrm{~mm}$ AP. Here, the medial cortex is thicker $(6.7 \mathrm{~mm})$ than the lateral cortex $(6.3 \mathrm{~mm})$.

U.W. 101-003 (Fig. 6) is a large right femoral shaft, from a break just below the lesser trochanter to a break in the shaft that precedes the supracondylar split of the linea aspera. It is platymeric near the subtrochanteric region. The ML narrowest part of the shaft appears to be quite distal, near the break. Proximally and posterolaterally there is a rugose gluteal line 
lateral to which is the base of the hypotrochanteric fossa. Just medial to the gluteal line is a pectineal line that merges with the gluteal line $23.5 \mathrm{~mm}$ inferior to the break in the proximal shaft. The spiral line can be traced proximomedially down the shaft and merges with the other two muscle markings $58.2 \mathrm{~mm}$ down the shaft to form a linea aspera that runs the length of the preserved bone. Distolaterally, the shaft has a weak concavity, just lateral to the linea aspera. Anteriorly, the shaft is quite flat proximally and becomes more rounded distally. Proximally and medially there is a depression that runs to approximately midshaft between the convex anterior and medial aspects of the bone, which is likely a consequence of the torsion of the proximal diaphysis. In medial and lateral view, the bone is AP curved. The dimensions at the point of the distal break are $25.3 \mathrm{~mm}$ AP and $21.7 \mathrm{~mm}$ ML.

U.W. 101-012 (Fig. 6) is a right femoral shaft. It is AP broad throughout, meaning that its proximal break is likely more distally positioned than the subtrochanteric region, which is platymeric in the Dinaledi femora. A break in the bone distally has internal trabeculae indicating proximity to the knee region. Proximally, the shaft is $21.8 \mathrm{~mm} \mathrm{AP}$ and $19.9 \mathrm{~mm}$ ML. Here, the medial cortex is thicker $(6.7 \mathrm{~mm})$ than the lateral cortex $(5.7 \mathrm{~mm})$. At the distal break, it is $25.1 \mathrm{~mm}$ AP and $20.1 \mathrm{~mm}$ ML. In medial and lateral views, there is some AP curvature to the shaft. In anterior view, the shaft is somewhat bowed ML (convex medially).

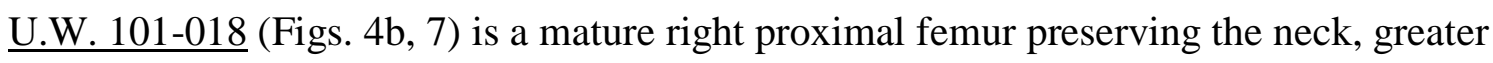
trochanter, and proximal shaft. The head is not preserved and the neck is too badly damaged to measure dimensions. The break in the neck reveals internal trabeculae and asymmetrical cortical bone at the neck/shaft junction, measuring (approximately) $1.5 \mathrm{~mm}$ superiorly and $9.5 \mathrm{~mm}$ inferiorly in thickness. There is erosion around the perimeters of the lesser and greater trochanters revealing trabecular bone. There is some abrasion along the shaft, but the cortex is preserved well enough to detect muscle markings. Posteriorly, the neck is smooth without an obvious obturator externus groove. Superiorly, the neck is bordered by a 
prominent bar of bone lateral to which is a well-developed trochanteric fossa. Anteriorly, the neck is damaged and exposed trabeculae extend from the greater trochanter to the femoral neck. There is a palpable depression for $\mathrm{m}$. vastus lateralis. Just medial to the depression is the inferior extent of the intertrochanteric line that continues medial and inferior to the lesser trochanter. The greater trochanter is complete, though there are exposed trabeculae around the perimeter of the structure. Small patches of cortex are visible laterally and superiorly, allowing the general extent of the greater trochanter to be discerned. It is relatively low and exhibits weak lateral flaring from the axis of the shaft. The lesser trochanter is eroded, exposing internal trabeculae, however, it is visible in anterior view (dimensions approximately $16.0 \mathrm{SI}$ and $10.9 \mathrm{~mm} \mathrm{ML}$ ). Inferomedial to the lesser trochanter is a prominent shelf that continues medially to a ridge of bone that extends inferolaterally from the lesser trochanter. The subtrochanteric region is platymeric. Along the posterolateral shaft is a prominent third trochanter, which descends inferiorly in the form of a gluteal line and lateral to which is a hypotrochanteric fossa. There is a pectineal line just medial to the third trochanter. The pectineal line and spiral line merge $24.3 \mathrm{~mm}$ from the distal break in the shaft. This line remains separate from the gluteal line in the preserved part of the shaft. At the break, the shaft is still somewhat platymeric: $22.3 \mathrm{~mm}$ ML and $18.4 \mathrm{~mm}$ AP. Here, the medial and lateral cortical shells are equally thick $(6.5 \mathrm{~mm})$.

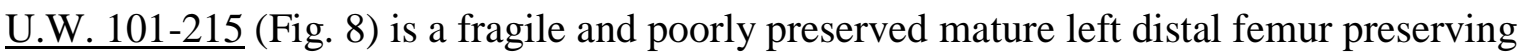
the distal and posterior part of the bone. The anterior portion of the femur has sheared away, exposing trabeculae throughout. The preserved subchondral bone is quite thin $(<1 \mathrm{~mm})$. The medial condyle was recovered in a fragmentary state and has been attached to the bone. In lateral view, the lateral condyle is flat and becomes convex posteriorly. The lateral edge is eroded, but there is a preserved pit for m. popliteus and a flexion groove that extends 11.9 $\mathrm{mm}$ posteriorly. The lateral condyle is a minimum of $20.6 \mathrm{~mm}$ wide; the height cannot be 
taken because of erosion. The lateral part of the intercondylar notch is preserved and is pocked with many vascular foramina. The anterior part of the intercondylar notch is smooth. The estimated biepicondylar width is $57.0 \mathrm{~mm}$ ML. There is a carrying angle, but its magnitude cannot be estimated because of the incompleteness of the diaphysis posteriorly and laterally and the imperfect match of the medial condyle with the diaphysis. The medial condyle is convex and is at least $18.8 \mathrm{~mm}$ ML. The intercondylar notch is $19.3 \mathrm{~mm} \mathrm{ML}$. The medial aspect of the condyle is eroded, but the lateral aspect has a preserved edge. There are several fragments that may rejoin with this specimen.

U.W. 101-268 (Fig. 6)_is a left femoral shaft. Proximally, the shaft is broken just inferior to the lesser trochanter and is platymeric. At the level of the proximal break the shaft exhibits torsion similar to that found in U.W. 101-003, which results in anteversion of the proximal part of the bone. At the ML narrowest part of the preserved shaft, the dimensions are 24.6 mm AP and 22.1 mm ML. Distally, the medial and posterior parts of the bone are not preserved at all. Anteriorly, the shaft is flat proximally and becomes rounded distally. There is heavy surface etching of the cortex making it difficult to discern any details of the bone. Posteriorly, there is a well-developed linea aspera that begins laterally and becomes centered distally. Proximomedially, there is a weak depression just medial to the linea aspera. Around midshaft, a rugosity perhaps for the insertion of the adductors appears medially and merges with the linea aspera that continues to descend distally.

U.W. 101-271 (Fig. 9) is a mature femoral head. Only the inferior part of the neck/head junction is preserved and covered with several foramina. Posteriorly there is minor surface abrasion exposing underlying trabeculae, though the cortex is generally well-preserved on this side of the bone. Superiorly and anteriorly the cortex is entirely stripped away, revealing trabeculae. Laterally, the head has sheared straight from the neck exposing trabeculae and only a very small ( $15 \mathrm{~mm}$ ML) portion of the neck inferiorly. 


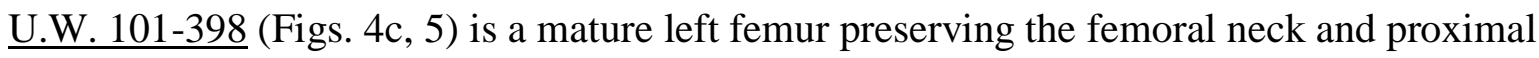
shaft. The head and greater trochanter have eroded away. The lesser trochanter is wellpreserved. The primary fossil is U.W. 101-398; U.W. 101-226 is a $30 \mathrm{~mm}$ fragment refit to the distal shaft. Distally, the shaft extends further on the posterior than the anterior side due to a $21.4 \mathrm{~mm}$ SI piece of bone missing anteriorly. The shaft at the point of the distal break is $21.8 \mathrm{~mm} \mathrm{ML}$ and $20.1 \mathrm{~mm}$ AP. The head is not preserved at all, though $23.5 \mathrm{~mm} \mathrm{SI}, 20.5 \mathrm{~mm}$ $\mathrm{AP}$, and $14.5 \mathrm{~mm} \mathrm{ML}$ of a mass of trabeculae remains without any covering cortex delineating edges. However, there is a flaring, preserved ring of cortex, fenestrated with vascular foramina around the trabeculae, marking the neck/head junction. The neck is very well-preserved and is AP compressed. In lateral, medial, or superior view, the femoral head and neck deflect anteriorly. Posteriorly, there is a palpable and even visible obturator externus groove $3.6 \mathrm{~mm}$ wide (in the SI plane) running along the inferior margin of the neck. Posteriorly, there is a well-developed intertrochanteric crest connecting the lesser trochanter to the eroded greater trochanter: $17.6 \mathrm{~mm}$ of it is preserved SI. Superiorly, along the neck, there are two ML oriented pillars of bone positioned inferoposteriorly and superoanteriorly (Fig. 5). They are $9.1 \mathrm{~mm}$ away from one another and separated by a highly vascularized groove, especially laterally. Anteriorly, the neck is smooth and there is a very faint intertrochanteric line running superolaterally to inferomedially. Just lateral to the intertrochanteric line is a palpable depression (m. vastus lateralis). In anterior or posterior view, the inferior base of the greater trochanter flares laterally. The lesser trochanter measures $15.4 \mathrm{~mm}$ SI and $12.6 \mathrm{~mm}$ ML. It is positioned posteriorly, though in anterior view a small part of it can be seen medially. The center of the lesser trochanter is $36.1 \mathrm{~mm}$ from the inferolateral edge of the femoral head. Just inferior to the lesser trochanter, the shaft is platymeric. There is a strong bar of bone descending from the base of the lesser trochanter and continuing inferolaterally. Descending straight from the edge of the greater trochanter 
posterolaterally is a rugose gluteal line. Proximally, it is well-developed as a third trochanter. Lateral to the gluteal line is a region that becomes concave inferiorly (the hypotrochanteric fossa). Medial to the gluteal line is a well-developed pectineal line that merges with the gluteal line just medial to the inferior edge of the hypotrochanteric fossa. Medially, there is a detectable spiral line that runs inferior to the lesser trochanter. These muscle markings merge into a linea aspera inferiorly near a foramen that is just superior to the break in the shaft. Anteriorly, the shaft is convex; posteriorly, it is relatively flat.

U.W. 101-421 (Fig. 9) is a mature left proximal femur and partial head that are currently separate, but refit cleanly. The neck is well-preserved and is AP compressed. The greater trochanter has been sheared away and the point of break in the shaft does not preserve any of the lesser trochanter save for a very small portion of trabeculae superiorly. The head is badly damaged, with cortex stripped from most of the head except for some small patches superiorly and posteriorly. The preserved SI diameter from the preserved cortex of the superior head to the broken head/neck rim inferiorly is $33.5 \mathrm{~mm}$, which is a minimum head diameter in this individual. Anteriorly, the neck is smooth, though a faint intertrochanteric line descends inferomedially. Just lateral to the intertrochanteric line is a concave depression for the m. vastus lateralis. Posteriorly, there is a faint but palpable obturator externus groove running along the inferior neck. Superiorly, there is a small trochanteric fossa preserved, which is filled with large vascular foramina. The head and neck exhibit torsion, resulting in a ML oriented posterior bar of bone more inferiorly positioned than the anterior bar of bone (which is superior).

U.W. 101-545 (Fig. 10) is a right distal femoral shaft. The anterior part of the shaft is wellpreserved save for some longitudinal cracking. It is convex and flattens distally. At the far distal end of the preserved bone, there is the superior end of the sustrochlear hollow, which is depressed into the bone and filled with several foramina. It is slightly medial to center. The 
lateral shaft is a bit flatter than the medial, which remains convex. Posteriorly, there is less bone preserved, ca. $71.5 \mathrm{~mm}$ SI. Superiorly, a linea aspera descends distally $23.3 \mathrm{~mm}$ before splitting into lateral and medial supracondylar lines that gradually diverge down the shaft to the point of break. At the break, there are exposed trabeculae. Superiorly, the shaft is 22.4 $\mathrm{mm} \mathrm{AP}$ and $20.5 \mathrm{~mm}$ ML. At the origin of the supracondylar lines, the shaft is $22.6 \mathrm{~mm} \mathrm{AP}$ and $20.2 \mathrm{~mm}$ ML. There is no discernable wasting of the shaft.

U.W. 101-938 (Fig. 11) is an immature right femur preserving the femoral neck, the metaphyseal surface of the femoral head, part of the epiphysal cap, some of the metaphyseal surface for the greater and lesser trochanters, and the majority of the shaft. There is erosional damage along the intertrochanteric crest and along the rims of the metaphyses. The fossil was found in four pieces. The most proximal piece is SI $88.4 \mathrm{~mm}$ from the proximal end of the eroded head to a jagged break in the shaft. Two shaft fragments approximately $63 \mathrm{~mm}$ and $100 \mathrm{~mm}$ in length each refit cleanly, as does a small $(\sim 24 \mathrm{~mm})$ fragment of the popliteal surface of the posterior distal femur. The head is damaged around the margin of the metaphysis, preserving a minimum of $20.6 \mathrm{~mm} \mathrm{AP}$, but without any delineating edges. The epiphyseal cap fits cleanly onto the metaphyseal surface. There is considerable erosion around the epiphyseal surface, but enough cortical bone is present to measure an approximate femoral head SI of $25.9 \mathrm{~mm}$. The neck is well-preserved though there is some erosion of the cortical surface superiorly, exposing trabeculae. The neck is AP compressed. In lateral, medial, and superior view, the femoral head and neck deflect anteriorly. The posterior neck is smooth and there is a barely detectable obturator externus groove running along the inferior margin of the neck. Superiorly, along the neck, there are two weakly developed ML running pillars of bone, contributing to head/neck torsion relative to the long axis of the shaft. There is also considerable femoral anteversion relative to the linea aspera. Anteriorly, the neck is smooth, without any evidence of an intertrochanteric line. Laterally and superiorly is the 
surface for the apophysis of the greater trochanter. It is inferolaterally angled relative to the superior aspect of the neck. The metaphysis for the greater trochanter advances quite medially and is only $16.5 \mathrm{~mm}$ ML from the most lateral metaphyseal surface for the femoral head. In posterior view, there is weak lateral flare at the base of the greater trochanter. The lesser trochanter is preserved medially with a small patch (5.9 mm SI, $4.0 \mathrm{~mm} \mathrm{ML})$ of metaphyseal surface surrounded laterally and distally by exposed trabeculae. The lesser trochanter is positioned posteriorly, though in anterior view a small part of it can be seen medially, as is the case with most other femora in the assemblage. The center of the lesser trochanter is $28.6 \mathrm{~mm}$ from the inferolateral edge of the femoral head. Just inferior to the lesser trochanter, the shaft is platymeric. Descending from the base of the lesser trochanter and continuing inferolaterally to form the pectineal line is a prominent bar of bone. The pectineal line merges distally ( $\sim 38 \mathrm{~mm}$ from the base of the lesser trochanter) with the gluteal line. The two are separated by a groove that narrows inferiorly. Lateral to the gluteal line is a flattened region, the hypotrochanteric fossa. Anteriorly, the shaft is convex and there are several longitudinal cracks along the shaft, though they do not alter the anatomy of the bone. Along the posterior shaft is a linea aspera that is most strongly developed from the midshaft distally. Here, the linea aspera weakens and splits into barely detectable supracondylar lines. At approximately midshaft, the shaft is $17 \mathrm{~mm}$ AP and $15 \mathrm{~mm}$ ML. The narrowest ML region of the shaft is $14.6 \mathrm{~mm}$ ML and only $15 \mathrm{~mm}$ distal to the midshaft, indicating femoral wasting.

U.W. 101-1000/1098 (Fig. 11) is an immature right proximal femur preserving the metaphyseal surface of the head, the neck, and a fragmentary proximal shaft. The metaphyseal surface for the greater trochanter is badly eroded, though there is a small patch of undifferentiated bone anteromedially. The metaphysis for the head is well-preserved. There is some erosion around the perimeter, though a maximum AP dimension of $25.7 \mathrm{~mm}$ 
can be measured, which matches the $25.7 \mathrm{~mm}$ AP of the associated epiphyseal head (U.W. 101-1098). There are metaphyseal grooves and furrows around the perimeter and a pit located centrally. The posterior neck is smooth and preserves about $19 \mathrm{~mm}$ of cortex from the lateral edge of the head to a break in the bone that exposes trabeculae. There is no evidence for an obturator externus groove. Anteriorly, the neck is better preserved and is smooth, grading laterally into a small pit for $\mathrm{m}$. vastus lateralis. An intertrochanteric line is not present. The neck is AP compressed. Superiorly, the neck is $14.6 \mathrm{~mm}$ long, from the lateral edge of the head metaphysis to the medial edge of the metaphysis for the greater trochanter. Only a small patch (14.5 mm ML, $8.8 \mathrm{~mm} \mathrm{AP)} \mathrm{of} \mathrm{the} \mathrm{metaphyseal} \mathrm{surface} \mathrm{of} \mathrm{the} \mathrm{greater} \mathrm{trochanter} \mathrm{is}$ preserved and is moderately angled inferolaterally relative to the long axis of the neck. There is a $66.5 \mathrm{~mm}$ piece of the lateral shaft that conjoins posterolaterally to U.W. 101-1000, but anteriorly there is no clean fit.

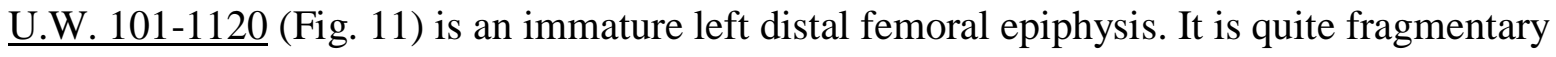
with exposed trabeculae medially. The lateral condyle was not recovered. With the metaphyseal surface horizontal, 33.5 mm ML is preserved. There is preserved cortex along the inferior rim of the medial condyle, which is convex. The intercondylar notch is reasonably well-preserved and pocked with vascular foramina. In inferior view, it is $13.3 \mathrm{~mm}$ SI, but the ML diameter cannot be assessed because the lateral condyle was not recovered. The patellar surface has preserved cortex $13.5 \mathrm{~mm} \mathrm{ML}$ and is moderately concave medially, but exhibits the beginning of a lateral patellar lip, especially in inferior view. While there is topography to the metaphyseal surface, it lacks a deep ML groove.

U.W. 101-1136 (Fig. 4d) is a right proximal femur preserved from a break along the superior neck and head to a break in the shaft. The head, greater trochanter, and lesser trochanter are not preserved and there are exposed trabeculae in those regions. The shaft has some exfoliated cortex and cracking throughout. Because of the flaking of the cortex, it is difficult 
to discern any muscle markings along the shaft, with the possible exception of a hypotrochanteric fossa along the posterolateral part of the shaft. The neck is poorly preserved. The SI dimensions are unknown because of damage superiorly. Features of hominin neck anatomy, like the obturator externus groove or the intertrochanteric line, are not detectable because of surface erosion. The neck is anteriorly shifted relative to the shaft and the neck has experienced torsion. The subtrochanteric dimensions are platymeric. At the point of the distal break in the shaft, the dimensions are $17.3 \mathrm{~mm}$ AP and $17.1 \mathrm{~mm}$ ML.

U.W. 101-1300 (Fig. 9) is an unsided femoral head. It is sheared laterally. It is unclear if the anterior part of a right or the posterior part of a left femoral head is preserved. The fovea is well-preserved and is $8.6 \mathrm{~mm}$ SI and 6.6 mm ML. It is deeply pitted with several foramina in the interior.

U.W. 101-1391 (Figs. 4e, 5) is a mature right femur preserving part of the head, the femoral neck, some of the greater and lesser trochanters, and a large portion of the proximal shaft. There is erosional damage around the perimeter of the femoral head, along the greater trochanter and on the lesser trochanter, exposing trabecular bone. The bone was recovered in two pieces, separated by a break below the lesser trochanter; the two pieces of the proximal femur and the shaft are glued back together cleanly. At the distal break, a triangular fragment has been glued back into place. The head is damaged circumferentially. Only a small patch of cortex is preserved medially and another small patch posteriorly, preventing an estimate of femoral head diameter. The neck is well-preserved and AP compressed. In lateral, medial, or superior view, the femoral head and neck deflect anteriorly. Posteriorly, there is a detectable obturator externus groove running along the inferior margin of the neck. Superiorly along the neck there are two ML oriented pillars of bone positioned inferoposteriorly and superoanteriorly (Fig. 5), resulting in head/neck torsion relative to the long axis of the shaft. Anteriorly, there is a weakly developed intertrochanteric line descending from a palpable 
femoral tubercle. It continues around the inferior part of the neck and descends as the spiral line down the posterior shaft. Superiorly, the neck grades into a trochanteric fossa that is angled towards the posterior part of the bone. There are two large foramina medial to a pit. In posterior view, the shaft begins to flare laterally at the base of the greater trochanter. The lesser trochanter is eroded, though the cortical ring around the trabeculae indicates that the lesser trochanter would have been about $13.3 \mathrm{~mm}$ SI and $10 \mathrm{~mm}$ ML. The lesser trochanter is positioned posteriorly, though in anterior view a small part of it can be seen medially. The center of the lesser trochanter is $35.8 \mathrm{~mm}$ from the inferolateral edge of the femoral head. Medial to the lesser trochanter, there is a strong ridge of bone producing an indentation between the projecting lesser trochanter and the spiral line. Just inferior to the lesser trochanter, the shaft is platymeric. A prominent bar of bone descends from the base of the lesser trochanter and continues inferolaterally to form the pectineal line. The pectineal line merges distally ( $42 \mathrm{~mm}$ from the base of the lesser trochanter) with the gluteal line and the beginnings of the linea aspera are detectable at the distal break in the shaft. Proximally, the gluteal line is well-developed as a third trochanter. The pectineal line and the gluteal line are separated by a groove that narrows inferiorly. Lateral to the gluteal line is a flattened region, the hypotrochanteric fossa, inferior to which is a laterally bulging rugosity. Anteriorly, the shaft is convex. The shaft at the point of break is $19.5 \mathrm{~mm}$ ML and $22.5 \mathrm{~mm}$ AP. Here, the medial cortex is thicker $(6.3 \mathrm{~mm})$ than the lateral cortex $(4.6 \mathrm{~mm})$.

U.W. 101-1475 (Fig. 4f) is a mature left proximal femur preserving the neck, eroded greater trochanter, and proximal shaft. The neck is broken in a manner that preserves the inferior, anterior, and posterior portions, but the superior and medial aspect is missing. A break in the neck reveals internal trabeculae and thick cortex along the inferior margin. There is erosion around the perimeters of the lesser and greater trochanters revealing trabecular bone. Posteriorly along the neck there is a weakly developed obturator externus groove (especially 
laterally). Anteriorly, the neck is quite smooth with little evidence for an intertrochanteric line. Inferior to the neck, there is the start of a palpable spiral line that twists posteriorly and inferiorly. It merges with the pectineal line $25.2 \mathrm{~mm}$ inferior to the lesser trochanter. The greater trochanter is badly damaged, though inferiorly it exhibits weak lateral flaring from the axis of the shaft. It is separated from the lesser trochanter by an intertrochanteric crest that preserves only $15.4 \mathrm{~mm}$ in the SI plane of the cortex. The lesser trochanter is eroded, though it can be seen projecting medially in anterior view and the dimensions can be measured (16.6 $\mathrm{mm}$ SI and $12.1 \mathrm{~mm} \mathrm{ML).} \mathrm{Just} \mathrm{inferior} \mathrm{to} \mathrm{the} \mathrm{lesser} \mathrm{trochanter,} \mathrm{the} \mathrm{shaft} \mathrm{is} \mathrm{platymeric.} \mathrm{Medial}$ to the lesser trochanter there is a prominent pillar of bone that runs proximoanteriorly to distoposteriorly and contributes to the anterior torsion of this proximal femur. Along the posterolateral shaft is a prominent third trochanter, which descends inferiorly in the form of a gluteal line and lateral to which is a hypotrochanteric fossa. There is a pectineal line just medial to the third trochanter. At the point of break, the shaft is platymeric: $26.3 \mathrm{~mm} \mathrm{ML}$ and $20.3 \mathrm{~mm}$ AP. Here, the medial cortex is thicker $(9.7 \mathrm{~mm})$ than the lateral cortex $(7.3 \mathrm{~mm})$.

U.W. 101-1482 (Fig. 10) is a left femoral shaft fragment preserved from a break in the shaft inferior to the lesser trochanter to a break in the midshaft region. The proximal break is oblique, running proximomedial to distolateral. The subtrochanteric region is platymeric. The cortex is roughened making identification of muscular insertions difficult, however, there is a detectable spiral line descending from the lesser trochanteric region and a faint impression of the pectineal line. Distally, a well-developed linea aspera descends the length of the remainder of the shaft. At the break in the shaft, the bone is $23.2 \mathrm{~mm}$ AP and $25.1 \mathrm{~mm}$ ML. Here, the medial cortex is thicker $(8.4 \mathrm{~mm})$ than the lateral cortex $(7.6 \mathrm{~mm})$. 
Homo naledi patella dimensions are listed in Table 4, with material depicted in Figure 12.

U.W. 101-852 (Fig. 12) is a right patella preserving some of the base, the anterior surface, and the posterior contact with the distal femur, especially laterally. The medial side of the bone and the apex were not recovered, making height and length measurements impossible. However, the bone is $18.3 \mathrm{~mm}$ thick AP. The minimum SI diameter from the tip of the base to the break inferiorly is $24.9 \mathrm{~mm}$. The minimum distance ML from the lateral edge to a break medially is $27.8 \mathrm{~mm}$. Posteriorly the facet for the distal femur is strongly ML curved. From the height of the femoral surface, the lateral facet strongly slopes anteriorly and is moderately concave at the most lateral point. The lateral facet is $20.7 \mathrm{~mm}$ ML. Medially, the facet is preserved for only $7.1 \mathrm{~mm}$ and is flat, with a less steep slope. Internally, the patella is filled with trabeculae that are exposed medially and inferiorly. Proximally, the base is relatively smooth and somewhat eroded along the most proximal rim. It is deflected posteriorly relative to the anterior aspect of the patella, which is vascular and has several vertical striations.

U.W. 101-1404 (Fig. 12) is a right patella preserving some of the base, the anteromedial surface, and a small portion of the lateral femoral surface. A piece of the patellar surface is broken away from the anterior part of the bone, but the two fragments refit. Much of the lateral side of the bone and the apex were not recovered, preventing an SI diameter measure. The ML length of the specimen is $\sim 30 \mathrm{~mm}$ and the AP thickness is $16.2 \mathrm{~mm}$. The minimum SI diameter from the tip of the base to the break inferiorly is $26.0 \mathrm{~mm}$, though this patella would have been taller. Posteriorly the facet for the distal femur is preserved only laterally. It rises from a high central region and slopes anteriorly, forming a rather flat ML facet. The lateral facet preserves $21.3 \mathrm{~mm}$ ML and $16.2 \mathrm{~mm}$ SI. Internally, the fragment is filled with 
trabeculae. Proximally, the base deflects posteriorly relative to the anterior aspect of the patella, which has several vertical striations.

Tibia

Homo naledi tibia dimensions are listed in Table 5, with material depicted in Figures 13 - 16 (3D surface scans available at www.morphosource.org). The dimension of T1-T6 (after Wright and Vásquez, 2008) in U.W. 101-484 is $293 \mathrm{~mm}$, resulting in an estimated total tibial length of $325.5 \mathrm{~mm}$ (SEE $5.92 \mathrm{~mm}$ ). Given that nearly the same value was obtained with the comparative and mathematical methods, we estimate that the length of the tibia U.W. 101-484 is approximately $325 \mathrm{~mm}$.

U.W. 101-213 (Fig. 13) is a right proximal tibial shaft fragment. It is constituted by the association of three fragments: U.W. 101-213, U.W. 101-214, and U.W. 101-312. The anterior part of the bone, including the tibial tuberosity, has been stripped away. Posteriorly, the soleal line descends superolaterally to inferomedially across the shaft for $66 \mathrm{~mm}$. The vertical line is not visible. There is a depression laterally between the soleal line and the interosseous crest (mm. flexor digitorum longus and tibialis posterior). The anterior border curves from anteromedially to distolaterally and is rounded. Distally the diaphysis flares in anterior and posterior view and the cross-section is less triangular than it is proximally. At the proximal point of the break (where the soleal line is no longer visible), the bone is $22.7 \mathrm{~mm}$ AP and $16.8 \mathrm{~mm}$ ML.

U.W. 101-420 (Fig. 14) is a mature left distal tibia preserved from the rims of the tibial plafond to a break in the tibial shaft. There is damage to the distomedial part of the metaphysis, though it is AP expanded. The tibiotalar articular surface is well-preserved, though the medial malleolus has been sheared away. There is a gentle AP-oriented keel 
dividing the facet into a lateral (11.9 $\mathrm{mm} \mathrm{ML})$ and medial (9.5 $\mathrm{mm}$ minimum ML) region. The lateral part of the facet is slightly concave ML and more concave AP; the medial part is flat ML and concave AP. In the coronal plane, the tibiotalar articular surface is orthogonal to the long axis of the tibial shaft, as is common in bipedal hominins. Anteriorly, the rim of the tibiotalar surface possesses a small squatting facet that is $3.9 \mathrm{~mm}$ SI. Its ML extent is unclear because the medial malleolus has been sheared away from the bone, taking with it a portion of the anteromedial shaft. Anteromedially, a pillar of bone extends proximolaterally to the break in the shaft. Anteriorly, the break is $59.7 \mathrm{~mm}$ from the tibiotalar articular surface. At this point of the shaft, the dimensions are $21.7 \mathrm{~mm}$ AP and $20.4 \mathrm{~mm}$ ML. Medially, the shaft is flat and bordered anteriorly and posteriorly by thickened bony pillars. The posterior shaft is convex with a thick pillar of bone running down its length. Laterally, there is a wellpreserved and large posterior tuberosity for the posterior tibiofibular ligament. Laterally, the crest for the interosseous membrane descends anterodistally and terminates in a small anterior tubercle. This crest is well-marked, elevated, and rough. There is no detectable posterior component to this crest. The fibular facet has eroded away. In lateral view, the posterior rim of the tibial plafond is more distally projecting than the anterior rim.

U.W. 101-484 (Fig. 15) is a mature right tibia preserved from a break in the proximal shaft just proximal to the tibial tuberosity to a small preserved patch of the talar articular surface. The tibial tuberosity itself is not preserved, but the vertical striations just distal to it are. The shaft is reasonably well preserved, though there is post-mortem damage along its length. The shaft was discovered in three pieces, two similarly sized proximal elements and a longer distal piece: individual lengths are approximately $93 \mathrm{~mm}$ for the proximal portion, $85 \mathrm{~mm}$ for the middle fragment, and $115 \mathrm{~mm}$ for the distal fragment. Each contacts the previous piece cleanly and has left a crack around the perimeter of the shaft. Anteriorly, the shaft is dominated by a sharp crest that is smooth distally and grades into the base of the tibial 
tuberosity proximally. At the base of the tuberosity, the shaft is $33.1 \mathrm{~mm}$ AP and $20.2 \mathrm{~mm}$ ML. In medial or lateral view, the posterior part of the shaft flares posteriorly at the point of break of the fossil. Just medial to the tibial tuberosity is a hollow depression, posterior to which is a rugose area of bone for the pes anserinus (the common tendon for $\mathrm{m}$. sartorius, $\mathrm{m}$. gracilis and $\mathrm{m}$. semitendinosus). Laterally, the bone is quite flat and distally the interosseous crest forms and progresses down the length of the shaft becoming most rugose distally. Near the midshaft, there is a concavity between the interosseous crest and the anterior part of the bone for the attachment of $\mathrm{m}$. tibialis anterior. Medially, the bone is relatively flat along its length. On the medial side of the bone there is a border running from superoanteriorly to inferoposteriorly, marking a large attachment of $\mathrm{m}$. flexor digitorum longus. The proximal attachment of $\mathrm{m}$. tibialis posterior is more posteriorly positioned than is typical in modern humans. Posteriorly, the bone is convex and flattens distally. Progressing superolaterally to inferomedially across the proximal part of the posterior shaft is a soleal line. Just medial to the soleal line is a nutrient foramen. On most human tibiae (and on other Dinaledi hominin tibiae), the foramen is lateral to the soleal line. The distal tibia is heavily eroded. Only a small patch of thin subchondral bone is preserved in the tibial plafond, which otherwise has exposed trabeculae. Although the tibiotalar surface is damaged, in lateral view the posterior rim of the tibial plafond is more distally projecting than the anterior rim.

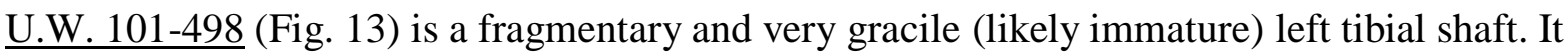
does not preserve the tibial tuberosity and the soleal line is barely detectable posteriorly. Just distal to the nutrient foramen, near the distal extent of the soleal line, the bone is $19.8 \mathrm{~mm} \mathrm{AP}$ and $14.2 \mathrm{~mm}$ ML.

U.W. 101-500 (Fig. 13) is a large left proximal tibial shaft. It is broken just distal to the tibial tuberosity, though there are no preserved vertical striations anteriorly and thus it is broken more distally than U.W. 101-484. Only $94.6 \mathrm{~mm}$ SI on the anterior part of the shaft is 
preserved; the majority of preserved bone is posterior. Laterally, there is a well-developed superoanteriorly to inferoposteriorly directed interosseous crest that progresses down the shaft. Between the anterior border and interosseous crest is a concavity that runs the length of the preserved shaft for m. tibialis anterior. Posteriorly, the distal extent of the soleal line is preserved and elevated, progressing superolaterally to inferomedially. Medially, the bone is convex-flattening anteriorly, with a slight concavity down the length of the shaft posteriorly. Aligning the bones by the soleal line and the interosseous crest, the U.W. 101500 shaft is $32.2 \mathrm{~mm}$ AP and $20.5 \mathrm{ML}$ just distal to the tibial tuberosity, making it roughly the same size as that of U.W. 101-484.

U.W. 101-571 (Fig. 13) is a right proximal tibial shaft. The proximal plateau is sheared away, leaving only the vaguest impression of the inferior vertical striations of the tibial tuberosity. Posteriorly, the bone is damaged, leaving only $50.3 \mathrm{~mm}$ SI of the distal portion of the preserved shaft. Laterally, there is a superoanterior to inferoposteriorly running interosseous crest, anterior to which is a depression for the origin of $\mathrm{m}$. tibialis anterior. Medially and most proximally, there is a preserved depression just medial to the tibial tuberosity (which is sheared away) posterior to which there is a rugose area for the pes anserinus (the common insertion of mm. sartorius, gracilis and semitendinosus). Distally, the medial shaft is quite flat. The shaft is $23.2 \mathrm{~mm}$ AP and $17.1 \mathrm{~mm} \mathrm{ML}$ at the distal break.

U.W. 101-711 (Fig. 14) is a fragmentary mature left distal tibia, preserved from the margins of the tibial plafond to a diagonal break in the tibial shaft. The malleolus has been sheared away, damaging the medial side of the bone. There is erosion around the distal rim of the bone, except for a small patch anteriorly where there is a large squatting facet $4.2 \mathrm{~mm}$ SI and a minimum of $7.3 \mathrm{~mm}$ ML. The distal metaphysis is AP flared. The talar articular surface is concave AP and mildly concave ML. Medially, there is weak AP keeling. The preserved anterior shaft is flat and there is (eroded) evidence for a large anterior tubercle for the anterior 
tibiofibular ligament. Medially, the shaft is flat, though there is a palpable pillar separating the anterior and medial portions of the shaft. Posteriorly, the shaft is convex and distolaterally there is a large (eroded) posterior tubercle for the posterior tibiofibular ligament. Laterally, there is a strong interosseous crest descending anterodistally. There is no detectable posterior crest. If there was a fibular facet, it is not preserved at all. In lateral view, the posterior rim of the tibial plafond is more distally projecting than the anterior rim.

U.W. 101-973 (Fig. 13) is a left tibial shaft preserved from a break just distal to the tibial tuberosity to the midshaft area. Just inferior to the tibial tuberosity, the shaft is $32.6 \mathrm{~mm} \mathrm{AP}$ and 19.3 mm ML, similar to the dimensions of U.W. 101-484 and U.W. 101-500. Just medial to the tibial tuberosity, there is a small hollow depression and, posterior to it, appears to be a raised area for the pes anserinus tendon, though there is considerable damage in this area. Laterally, there is an interosseous crest that begins anteriorly and progresses posteriorly down the shaft. A depression between the anterior crest and the interosseous crest for the $\mathrm{m}$. tibialis anterior runs the length of the shaft. Just posterior to the interosseous crest (laterally) is a nutrient foramen. Posteriorly, there is a well-marked and elevated soleal line running superolaterally to inferomedially.

U.W. 101-996 (Fig. 16) is an immature right tibia, preserved from the proximal metaphyseal surface to the distal metaphyseal surface. It is constituted by three fragments: U.W. 101-996, U.W. 101-1074, and U.W. 101-1077. Only the preservation of this specimen will be described; for anatomical descriptions, refer to the more complete antimere U.W. 101-1070 unless specified otherwise. The three conjoining pieces are (in length): $124.5 \mathrm{~mm}$ proximally, $83.7 \mathrm{~mm}$ middle, and $45.9 \mathrm{~mm}$ distally. The shaft of this specimen is better preserved than U.W. 101-1070. The proximal metaphysis preserves a small patch (9.0 mm ML, $8.5 \mathrm{~mm} \mathrm{AP)}$ of surface anterolaterally. It is damaged anteriorly and medially, exposing trabecular bone and the medullary cavity. The proximal shaft flares medially and is much straighter laterally. 
Distally, there is a very small patch of metaphyseal surface (2.8 mm ML, $4.3 \mathrm{~mm} \mathrm{AP})$ surrounded by trabecular bone.

U.W. 101-1070 (Fig. 16) is a nearly complete immature left tibia from the tip of the tibial spines to the distal extent of the medial malleolus. Both partially preserved epiphyses were discovered in situ, in articulation on the diaphysis and are presently (non-permanently) adhered to the shaft. The specimen is well-preserved overall, though there is some damage near the metaphyseal/epiphyseal junctions. The proximal metaphysis is damaged anteriorly and laterally, removing $\sim 16 \mathrm{~mm}$ SI of the bone. The lateral condyle is not preserved, but the medial condyle and the tibial spines are present and well-preserved. The distal metaphysis is damaged anteriorly and laterally, such that an $18 \mathrm{~mm}$ SI portion of the metaphysis is stripped away anteriorly and anterolaterally, exposing trabecular bone. The medial portion of the medial malleolus is not preserved. The shaft is broken in two locations, producing three parts of the bone: a proximal piece $70.4 \mathrm{~mm}$ SI, a middle piece $\sim 144 \mathrm{~mm} \mathrm{SI}$, and a distal piece $\sim 78$ $\mathrm{mm}$ SI (the sum of which exceeds total length because the diagonal breaks and lengths are maximums). The proximal epiphyseal plateau is $29.0 \mathrm{~mm}$ AP and a minimum of $28.0 \mathrm{~mm}$ ML from the medial edge of the surface to a break at the medial edge of the lateral epicondyle. It is $16.1 \mathrm{~mm}$ SI from the tip of the tibial spines to the inferior projection of the tibial tuberosity. The medial epicondyle is moderately concave and measures $23.9 \mathrm{~mm}$ AP and $15.5 \mathrm{~mm}$ ML. The tibial spines are raised $2.3 \mathrm{~mm}$ above the tibial plateau and are $6.7 \mathrm{~mm}$ ML apart. They are angled anterolaterally to posteromedially. Anteriorly, there is a small indentation for insertion of the anterior cruciate ligament. The pit for the posterior cruciate ligament is much better developed and is fenestrated with some vascular foramina. The tibial tuberosity is not well-preserved, especially superiorly. Inferiorly, there are vertical striations and in medial view, the base of the tibial tuberosity extends anteriorly. Here the shaft dimensions are $24.9 \mathrm{~mm}$ AP and 16.0 $\mathrm{mm} \mathrm{ML}$. In medial/lateral view, the tibial plateau 
exhibits retroversion of 15 degrees. Laterally, a faint interosseous crest begins proximally and continues posterodistally down the shaft. Just anterior to the crest is a weak depression proximally for the $\mathrm{m}$. tibialis anterior. Lateral to the crest, $75.3 \mathrm{~mm}$ from the tibial spines is a nutrient foramen. The anterior shaft is strongly convex and the medial surface is relatively flat, especially distally. Posteriorly, the shaft is strongly convex with a bar of bone running distally before flattening near the distal end. The distal end of the tibia is damaged laterally and anteriorly. In medial or lateral view, the posterior part of the bone flares. The AP dimension of the metaphysis is unknown due to damage. There is no preserved fibular facet. The distal epiphysis preserves $18.6 \mathrm{~mm}$ ML and $20.5 \mathrm{~mm}$ AP. The dimensions of the talar articular surface are not preserved laterally. The ML dimensions cannot be taken, nor can the lateral AP dimensions. The lateral side of the medial malleolus is quite flat. There is a weakly developed intercollicular groove posteriorly for the deltoid ligament and there is some minor erosion medially. Posteriorly, a $3.5 \mathrm{~mm}$ ML groove for the $\mathrm{m}$. tibialis posterior tendon runs inferomedially, which is the orientation of the medial malleolus relative to the tibial shaft. The tibial plafond is oriented perpendicular to the long axis of the shaft. In lateral view, the posterior rim of the tibial plafond is more inferiorly projecting than the anterior rim.

\section{U.W. 101-1416 (Fig. 14) is a fragmentary mature right distal tibia, preserved in two} conjoining pieces. One is a $44.1 \mathrm{~mm}$ SI fragment of a broken shaft and part of the lateral talar facet. The other piece joins distally and is part of the medial talar facet and the medial malleolus. U.W. 101-1416 is associated with the talus U.W. 101-1417, which belongs with the nearly complete foot 1 (Harcourt-Smith et al., 2015). The anteromedial part of the bone has been sheared away, leaving only a small (22.3 $\mathrm{mm}$ SI and $14.5 \mathrm{~mm} \mathrm{ML)} \mathrm{patch} \mathrm{of} \mathrm{cortex}$ anterolaterally. The lateral and posterior parts of the distal shaft are preserved, though the posterior rim is eroded away. The metaphysis flares AP distally. The ML diameter of the metaphysis is unknown due to damage medially. The talar surface is moderately wedged, 
concave AP, and has a very weak AP keel dividing the facet. The medial malleolus is preserved medially. It is flat, with some convexity anteriorly. Laterally, the medial malleolus is damaged and the cortex is stripped away exposing trabeculae. The medial malleolus is 11.4 $\mathrm{mm}$ SI and $7.1 \mathrm{~mm} \mathrm{ML}$. The AP dimension is difficult to measure because of damage posteriorly, but is at least $14.1 \mathrm{~mm}$. The preserved shaft has a large laterally positioned anterior tubercle for the anterior tibiofibular ligament. Posteriorly, the shaft is convex and distolaterally there is a large (eroded) posterior tubercle for the posterior tibiofibular ligament. Laterally, there is a strong interosseous crest descending anterodistally and a weak posterior crest. In lateral view, the posterior rim of the tibial plafond is more distally projecting than the anterior rim.

Fibula

Homo naledi fibula dimensions are listed in Table 6, with material depicted in Figures 17 and 18. The fibula neck-STS distance in U.W. 101-1037 is $207 \mathrm{~mm}$. Therefore, the complete length of U.W. 101-1037 is estimated to be $328.1 \mathrm{~mm}$. This estimation is based on the assumption that the insertion for the STS is human-like, being more proximal than in apes. Only two other early hominin fibulae are complete enough to use for reference, StW 356 and $\mathrm{OH} 35$. StW 356 does not include the distal articular surface, so the most proximal portion of the STS cannot be established with confidence. In $\mathrm{OH} 35$, the proximal portion of the STS is quite distal, far more so than in modern humans. Using the same regression formula used for $H$. naledi, the estimated length of the fibula for $\mathrm{OH} 35$ (neck-STS $=155$ $\mathrm{mm}$ ) is $261.5 \mathrm{~mm}$, almost identical to the $259 \mathrm{~mm}$ estimated by Susman and Stern (1982). Using a regression calibrated on apes (which have shorter proximal portions of the STS than humans: fibula length $(\mathrm{mm})=-19.57+1.673 \times$ neck-STS, $\left.\mathrm{R}^{2}=0.70 ; N=30 ; \mathrm{SEE}=8.8\right)$ 
produces an even shorter fibula length for $\mathrm{OH} 35$ (fibula length $=239.7 \mathrm{~mm}$ ). Therefore, we are confident the regression equation calibrated on humans is appropriate to estimate fibular length in $H$. naledi.

U.W. 101-817 (Fig. 17) is a proximal metaphysis and shaft fragment of an immature left fibula. There is considerable erosional damage leaving only a small portion of the metaphyseal surface of the proximal articulation preserved (11.3 mm AP, 7.5 mm ML, 26.5 $\mathrm{mm}$ in circumference). Part of the styloid process is preserved, but proximally and posteriorly there is erosional damage. The proximal articular surface is angled proximolaterally to distomedially $\left(125^{\circ}\right.$ to the longitudinal axis of the bone). The preserved shaft is ML compressed (10.3 mm AP, $6.2 \mathrm{~mm} \mathrm{ML).} \mathrm{The} \mathrm{anterolateral} \mathrm{and} \mathrm{posterolateral} \mathrm{borders} \mathrm{are}$ visible, but poorly defined. The anteromedial border is not visible. The posteromedial border is well-marked. The presence of a broken portion medially and many cracks potentially contribute to the less triangular appearance in cross-section of the shaft compared to the fragmentary specimens U.W. 101-1113 and U.W. 101-1451.

U.W. 101-1037 (Fig. 18) is a left fibular diaphyseal shaft ( 4/5 complete) constituted by two conjoining fragments, U.W. 101-1037 and U.W. 101-1498. The proximal end nears the level of the neck as suggested by the constriction of the diaphysis and the triangular cross-sectional shape. The flaring that occurs in fibulae just distal to the head is not observable in this specimen. The distal break presents trabecular bone indicating the break is near the malleolus. Distally, in posterior and anterior view, flaring characteristic of the origination of the malleolus is evident. The anterolateral border starts proximally, is well-marked and sharp, and becomes blunter distally. The border bifurcates $26.5 \mathrm{~mm}$ from the distal break, marking the beginning of the subcutaneous triangular surface (STS). Only a small portion of the STS is present. The lateral border of the STS is sharp and slightly convex posteriorly. The 
anteromedial border is not visible proximally. A distance of $29 \mathrm{~mm}$ distal to the proximal break, the anteromedial border is visible and runs parallel to the anterolateral border for $\sim 50$ $\mathrm{mm}$. The anteromedial border then diverges medially and is no longer visible $49 \mathrm{~mm}$ from the distal break, though erosion of the surface may contribute to the loss of this border. The posteromedial border is well-marked and sharp proximally, extending $48 \mathrm{~mm}$ from the proximal break. More distally, the posteromedial border remains well-marked, but it is not sharp. Distally, it becomes continuous with the area for interosseous ligament attachment. This area appears grooved and is $23.8 \mathrm{~mm}$ SI. The most proximal part of the interosseous ligament insertion is at the same level as the most proximal portion of the STS. The posterolateral border is damaged proximally. More distally, it is well-marked and rounded. The anterior surface is flat for its entire length. It is very narrow (2.6 mm ML) until midshaft and increases in breadth distally. The medial surface is distinctly grooved proximally (proximal insertion of $\mathrm{m}$. tibialis posterior) until about $50 \mathrm{~mm}$ from the proximal break. The groove becomes shallower approaching midshaft, where it becomes flat and then slightly convex distally. There is some erosional damage around midshaft and the mid-distal shaft. The lateral surface is grooved proximally until $74 \mathrm{~mm}$ from the proximal break. The groove decreases in depth and disappears at midshaft, where the surface becomes convex (for the proximal insertion of $\mathrm{m}$. fibularis brevis). This convexity increases distally. The surface is directed anterolaterally on the proximal portion, then spirals and is directed laterally on the distal portion. A section of cortex is missing around midshaft on the lateral surface. The posterior surface is slightly grooved proximally until $\sim 45 \mathrm{~mm}$ from the proximal break. Distally it is flat for the majority of the diaphysis. It becomes convex $63 \mathrm{~mm}$ from the distal break and becomes more convex distally. At the distal break, the dimensions are $11.8 \mathrm{~mm}$ AP, $8.3 \mathrm{~mm}$ ML, and $31.7 \mathrm{~mm}$ in circumference. 
U.W. 101-1045 is an immature left fibula consisting of three non-conjoining fragments. The proximal fragment (length $19.7 \mathrm{~mm}$ ) is badly damaged, with only a portion of the metaphyseal plate and some cortex visible. The metaphyseal surface is rectangular $(9.0 \mathrm{~mm}$ AP, $8.8 \mathrm{~mm} \mathrm{ML}$ ). A second proximal fragment (length $75.9 \mathrm{~mm}$ ) is platycnemic in crosssection proximally and triangular distally. The proximal break is jagged and the distal break is sheared cleanly. The diameters at the distal break are $8.6 \mathrm{~mm}$ AP and $7.1 \mathrm{~mm} \mathrm{ML}$. The lateral and posterior surfaces are eroded proximally. Some damage is present on the medial surface. The more distal fragment (length $112.2 \mathrm{~mm}$ ) is probably distal midshaft. There is damage to the posteromedial border and some erosion on the lateral surface. The proximal break of the distal fragment is jagged and its diameters are $8.3 \mathrm{~mm}$ AP and $7.2 \mathrm{~mm}$ ML. The distal break is jagged. The anterolateral border is well-marked along the entire shaft. It is sharp proximally and gradually becomes more rounded distally. Distally the bone is broken before the anterolateral border bifurcates to form the subcutaneous triangular surface. The anteromedial border is not visible. The posteromedial border is well-defined and moderately sharp proximally. It becomes more rounded distally. The posterolateral border is directed posteriorly and slightly laterally along its entire length. The medial surface is deeply grooved proximally, slightly convex around midshaft, and flat distally. Some erosion on the mid-distal portion makes it difficult to precisely define the appearance of the surface. The lateral surface of the bone is eroded proximally. It is flat from proximally to midshaft and slightly convex from midshaft distally. The posterior surface is flat. Erosion proximally makes it difficult to measure minimum diameter and circumference. The largest diameter of the cross section of the diaphysis changes from AP proximally, to ML at midshaft, to AP again distally. The diameter at the level of the proximal break of the distal fragment is $7.6 \mathrm{~mm} \mathrm{AP}$ and $7.5 \mathrm{~mm}$ ML. 
U.W. 101-1437 (Fig. 17) is a mature right distal fibula from the most distal part of the lateral malleolus to the proximal break. Only a small portion of the STS is preserved. The posterior part of the malleolus has been stripped away. The distal tibiofibular articulation is preserved: it is small, crescent-shaped, and oriented superiorly. The talofibular articulation is almost completely preserved. The proximal portion of the talofibular articulation is rectangular and a small part is missing posteriorly. The distal part of the talofibular articulation is preserved and triangular in shape. The malleolar fossa on the medial side of the articulation is deep, elongated anterosuperiorly to posteroinferiorly, and contains vascular foramina.

U.W. 101-1701 (Fig. 17) is a mature left distal fibula fragment, preserved from the most distal part of the lateral malleolus to the proximal break. The lateral side of the malleolus and part of the anterior side have been stripped away. Medially, the distal portion of the interosseous ligament insertion area is preserved $(15.6 \mathrm{~mm} \mathrm{SI})$ and the area is grooved. The AP diameter, superior to the fibulotalar articulation, is $17.2 \mathrm{~mm}$. The distal tibiofibular articulation on the medial aspect is small, eroded, and oriented superiorly. The superior part of the proximal part of fibulotalar articulation is eroded. The distal part of the fibulotalar articulation is preserved and triangular in shape. Only the anterior border of the malleolar fossa is preserved medially. The posterior portion of the malleolar fossa has been stripped away. The preserved malleolar fossa is deep and elongated anterosuperiorly to posteroinferiorly. Some vascular foramina are visible.

\section{Comparative anatomy (results and discussion)}


The femur of Homo naledi is represented by 26 proximal and diaphyseal elements, and three fragments of the distal femur, attributed to a minimum of eight mature and three immature individuals (Table 2). Table 3 lists $H$. naledi femoral dimensions compared to fossil hominins, extant humans, and apes. In the DFA (Fig. 19a) modern human femora are separated from hominin indet. along function 1, which accounts for the majority $(87.7 \%)$ of the variance. Grouped with the hominin indet. specimens are KNM-ER 1503 and OH 20, femora generally attributed to eastern African robust australopiths (Day, 1969; McHenry and Corruccini, 1978). The variables driving function 1 are neck length (longer to the right) and neck breadth (narrower to the left). Thus, the long, anteroposteriorly compressed necks of the eastern African robust australopiths cluster to the right. Fossils attributed to Homo align with modern humans along the first discriminant function, but fall below modern humans along function 2, which is being driven by neck SI diameter in the positive direction and neck length in the negative direction. Subtrochanteric AP is the only variable that does not make a significant contribution $(p=0.45)$ to the discriminant functions. Fossils of Australopithecus afarensis, Australopithecus africanus, Australopithecus robustus, Australopithecus sediba, and Homo floresiensis occupy the morphospace between modern humans, early Homo, and those presumed to belong to Australopithecus boisei. The Dinaledi femora span the gap between early Homo and Australopithecus with two femora (U.W. 101-002 and U.W. 101398) clustering with the australopiths and one femur (U.W. 101-1391) clustering with early Homo.

Because group membership is assumed a priori in DFA, we reran the analysis without the Hominin indet. femora and found similar results to the initial DFA (Fig. 19c). Again, the H. naledi femora cluster between femora attributed to fossil Homo and those attributed to Australopithecus. Group membership was predicted to be Australopithecus for 
U.W. 101-002 and fossil Homo for U.W. 101-398 and U.W. 101-1391, indicating the morphological mosaic of the Dinaledi femora.

Homo naledi femora possess a combination of traits found in both australopiths and early Homo (Tables 7 and 8). The femoral neck is relatively long, consistent with the flaring of the preserved ilium from the Dinaledi chamber (Berger at al., 2015; VanSickle et al., in review). Relative to the subtrochanteric dimensions (square root of the product of the AP and ML diameters), the femoral neck is long in australopiths and in early Homo (Fig. 20), with $H$. naledi femora falling within the overlapping ranges. However, the femoral necks are SI tall and AP compressed (Table 3), more similar to the morphology found in australopiths (Ruff and Higgins, 2013) and quite distinct from the femoral neck shape in specimens attributed to Homo (Fig. 21; Ward et al., 2015). The subtrochanteric region of the shaft is platymeric (Fig. 22), though not as platymeric as is typically found in H. erectus. However, this difference does not reach statistical significance (Student's $t$-test; $p=0.13$ ) with the current sample sizes. While the femoral shaft of $H$. erectus remains mediolaterally expanded at midshaft, the Dinaledi femora all become AP expanded inferior to the platymeric subtrochanteric region and remain AP expanded throughout the length of the shaft (see description of U.W. 101-012, for example). This shaft anatomy contrasts sharply with that found in $H$. erectus and is more similar to earlier Homo specimens, which are AP expanded at midshaft (Ward et al., 2015). The Dinaledi femora are characterized (especially in larger individuals, Fig. 4f) by considerable femoral anteversion, which contributes to an anterior set of the femoral neck relative to the proximal shaft (Fig. 4, medial views), as is found in australopiths and in early Homo (Fig. 23). While modern human femora exhibit a wide range of femoral neck anteversion, the neck is typically not torqued relative to the proximal shaft (Fig. 1c) and overall femoral neck anteversion is instead a reflection of the morphology of the distal diaphysis (Kingsley and Olmsted, 1948; Aiello and Dean, 2002). Other traits in the proximal 
femur that have been purported to distinguish Homo from australopiths, such as a lesser trochanter that is visible in anterior view (Pickford et al., 2002) or a sustrochlear hollow (Tardieu, 2010), are variably present in both Homo and Australopithecus, as well as in $H$. naledi. As with other hominin femora, the distribution of cortical bone in the femoral neck is asymmetrical (Ohman et al., 1997), there is a carrying angle at the knee, and the lateral condyle is flat and elongated (Lovejoy, 2007). Together, these anatomies are consistent with a hominin that practiced full extension of the leg during a human-like, striding bipedal gait.

Homo-like traits in the proximal diaphysis of the H. naledi femur include a welldefined posteriorly positioned gluteal tuberosity, a well-developed linea aspera, a variably present pilaster (see Fig. 10), and a thick diaphyseal cortex (Table 3; Fig. 4-6, 9). As in $H$. erectus femora (Gilbert, 2008), the cortex is thicker medially than laterally on all femoral shafts. Though, while thick cortex is generally thought to characterize the femora of early Homo (Gilbert, 2008), the femoral shaft of a recently described A. boisei skeleton, OH 80, also has thickened cortex (Domínguez-Rodrigo et al., 2013). In the Dinaledi femora, the base of the greater trochanter appears to flare laterally, as it does in other Homo femora. However, this observation remains qualitative and suffers from a lack of fully preserved greater trochanters on any of the Dinaledi femora. The immature femur U.W. 101-938 possesses an inferolaterally angled metaphyseal surface for the greater trochanter, like that found in the $H$. erectus juvenile KNM-WT 15000 and unlike immature australopith femora (Ward et al., 2012). Distal waisting is another femoral character that has been attributed to early Homo (Ruff, 1995), and H. erectus in particular (Gilbert, 2008; Puymerail et al., 2012). Though there are no complete femora from the Dinaledi chamber, specimen U.W. 101-003 is complete enough to demonstrate that shaft waisting occurs distally (see Fig. 6). U.W. 101003 gradually decreases in ML diameter distally down the shaft and is at its narrowest where 
the bone is broken distally and trabecular bone is exposed, indicating proximity to the distal metaphysis.

In our view, there is also a unique feature - consistently present in all $\mathrm{H}$. naledi proximal femora - not observed in other hominins: an elongated depression in the superior aspect of the neck that contributes to the presence of two mediolaterally-oriented pillars of bone, one inferoposterior and the other superoanterior. A depression between these two pillars is highly vascularized. Seen as a sagittal plane section along the neck-shaft boundary, the depression and resulting pillars are pronounced and distinct (Figs. 2 and 5). Subtle hints of this anatomy can be seen in some other hominin femora (e.g., U.W. 88-4 [A. sediba], KNM-ER 1472 [early Homo]) but none exhibit it to the extent found in all of the Dinaledi femora. While the consistency of this anatomy, among many others, supports our interpretation of the Dinaledi assemblage as a single species (Berger et al., 2015; Dirks et al., 2015), the functional implication of such a femoral architecture remains unknown. They may constitute bony reinforcement to bending forces across the superior neck, perhaps related to the flaring ilia of the pelvis of $H$. naledi (Berger et al., 2015). Their presence may therefore imply different biomechanics of the hip compared with other hominins. They may also be the by-product of a more medial insertion of $\mathrm{mm}$. obturator internus and gemelli, the function of which may therefore be subtly different in $H$. naledi compared with other hominins and with modern humans. The apparent presence of this feature in the immature specimens (i.e., U.W. 101-938) might signify that the anatomy is not the result of bony adaptation, and would therefore lend toward the latter hypothesis. Further research, however, is needed to test these hypotheses. 
There are very few fossil patellae of early hominins. The earliest is from A. sediba (DeSilva et al., 2013). Other patellae are known from the Dmanisi locality (Pontzer et al., 2010, $H$. erectus), Swartkrans (Susman et al., 2001, A. robustus), Gran Dolina (Carretero et al., 1999, H. antecessor), Sima de los Huesos (Carretero et al., 1999, H. heidelbergensis), Liang Bua (Jungers et al., 2009, H. floresiensis), and a variety of Neanderthal localities (compiled in Carretero et al., 1999). The H. naledi knee is represented by four partial patellae (Fig. 12, Table 4). They are strikingly thick anteroposteriorly, making them more human-like than patellae from A. sediba, A. robustus, and H. floresiensis (Fig. 24, Table 4). In absolute thickness $(16.2-18.3 \mathrm{~mm})$, the Dinaledi patellae are similar to the AP thick patellae from Dmanisi ( 18 mm; Rightmire, pers. comm.) and Gran Dolina (19.0-19.4 mm), and significantly thicker than patellae from Malapa $(13.1 \mathrm{~mm})$, Swartkrans $(13.3 \mathrm{~mm})$, and Liang Bua (12.2 mm). Additionally, the Dinaledi patellae are relatively thick (AP/ML *100) with values similar to those found in Middle Pleistocene Homo. A thicker patella increases the moment arm of m. quadriceps femoris, which may be a derived Homo trait (Lovejoy, 2007). Given the role that a thick patella has in reducing contractile forces of muscles crossing the knee, and therefore reducing joint reaction forces (Silveira et al., 2006), the thick patella of $H$. naledi may have conferred important selective advantages on a hominin walking, or even running (Bramble and Lieberman, 2004), long distances.

\section{Tibia}

The tibia of $H$. naledi is represented by 31 diaphyseal and distal elements (Fig. 13, Table 1), attributed to a minimum of seven mature and two immature individuals (Table 2). Homo naledi is characterized by a mediolaterally compressed tibial shaft (Figs. 13 and 15, Table 5), with an oval cross section at midshaft (observable from natural breaks in the bones) and a smooth anterior border. Although modern human tibial diaphyses often possess triangular cross sections, this feature is variable (Hrdlička, 1898) and some modern human (Jungers et 
al., 2009) and fossil (Trinkaus, 1983; Trinkaus and Ruff, 1999) hominin specimens have oval cross sections.

The proximal attachment for the $\mathrm{m}$. tibialis posterior is large and more posteriorly positioned than is typical in modern humans; the anterior border of the bone is round as in the OH 35 tibia (Susman and Stern, 1982; taxonomic attribution uncertain, but possibly $H$. habilis; Fig. 15). The platycnemic and midshaft indices of $H$. naledi are in the lower range of variability of modern humans and similar to the average of australopiths and early Homo (Table 5). The estimated length of an almost complete tibia (U.W. 101-484) is $325 \mathrm{~mm}$, shorter than that of the immature KNM-WT 15000 (380 mm, Walker and Leakey, 1993, $H$. erectus) and KSD-VP-1/1 (355 mm, Haile-Selassie et al., 2010, A. afarensis) but longer than the tibiae of OH 35 (259 mm, Susman and Stern, 1982), A.L. 288-1 (227-241 mm, HaileSelassie et al., 2010; Schmid, 1983, A. afarensis), and D3901 (306 mm, Lordkipanidze et al., 2007, H. erectus). Homo naledi has long tibiae relative to femoral head size, as assessed using a bootstrapping approach (Fig. 25). Compared to the size of the femoral heads in the $H$. naledi assemblage, the nearly complete tibia (U.W. 101-484) appears quite long and fits within the human distribution. All other known hominins also fit within the human distribution, though there is overlap between humans and apes (particularly chimpanzees) for this parameter (Fig. 25). Thus, in a similar fashion to early representative of the genus Homo (Pontzer et al., 2010; Holliday, 2012), H. naledi possessed relatively long lower limbs, which would have been energetically beneficial during long distance bipedal travel (Pontzer, 2007).

The soleal line of $H$. naledi is well-defined, indicating a strong medial attachment of m. soleus, an important muscle for bipedal locomotion (Myatt et al., 2011). Proximally and medially, H. naledi tibiae possess a tubercle for the pes anserinus (SOM Fig. S1), the common insertion of $\mathrm{mm}$. sartorius, gracilis and semitendinosus. Such a defined insertionquite distinct from the diffuse rugosity usually detectable in human or fossil hominin tibiae- 
may indicate an increased role of these muscles in stabilizing the knee of $H$. naledi (Noyes and Sonstergard, 1973). Distally the tibia is similar to other early hominins in possessing an orthogonal orientation of the talar facet relative to the long axis of the shaft (Latimer et al., 1987; DeSilva, 2009). Like other hominins, except $A$. sediba, H. naledi has a thin medial malleolus (Fig. 26). There are also long, well-marked insertions for the interosseous and anterior and posterior tibiofibular ligaments and the presence of squatting facets (Fig. 14).

\section{Fibula}

The fibula of $H$. naledi is represented by 42 proximal and diaphyseal elements and two partial distal fibulae (Table 1) attributed to a minimum of eight mature individuals, two immature individuals, and one individual of unknown developmental state (Table 2). The fibular diaphysis of $H$. naledi is gracile relative to its length in comparison to the $\mathrm{OH} 35$ (likely early Homo) fibula and to extant chimpanzees (Fig. 18). Estimated length of the most complete bone (U.W. 101-1037), obtained using a regression equation between fibular length and the distance between the neck and the most proximal part of the STS distally, is $328 \mathrm{~mm}$, longer than the $\mathrm{OH} 35$ fibula (estimated at $261.5 \mathrm{~mm}$ here and 259 by Susman and Stern, 1982) and in the lower range of modern humans. At the level of the neck, $H$. naledi fibulae are relatively robust (as expressed by ML/AP external diameter) similar to StW 356 (A. africanus), MH2 (A. sediba), and $\mathrm{OH} 35$, and more robust than modern humans (Table 6). Muscle markings are well-developed along the entirety of the diaphysis, as are the borders that separate the muscle compartments originating from the bone. The attachments of $\mathrm{mm}$. tibialis posterior and peroneus longus are characterized by deep grooves proximally on the medial and lateral surfaces of the fibula, respectively (Fig. 18). The area for the attachment of m.peroneus brevis is convex, as in OH 35 (Davies, 1964; Susman and Stern, 1982) and StW 356, unlike the flat surface seen in modern humans. Distally, a moderately grooved insertion area for the interosseous ligament is present, although the lack of the distal epiphysis on the specimen 
preserving this area (U.W. 101-1037) makes it difficult to assess its relative length. The most cranial portion of the subcutaneous triangular surface is at the same level as the most cranial portion of the interosseous ligament insertion, similar to the anatomy in the StW 356 and $\mathrm{OH}$ 35 fibulae. In modern humans, the most cranial portions of the two areas are more distant. The distal fibulae of $H$. naledi have a lateral malleolus facing less anteriorly than apes and within the range of modern humans (Table 6).

\section{Summary and conclusions}

The thigh and leg of $H$. naledi are characterized by a mosaic of primitive traits found in australopiths and shared-derived traits with early Homo (Tables 7 and 8). Although the geological age of the assemblage remains unknown, the anatomy is consistent with a Pleistocene transition from Australopithecus to early Homo. Thus, the Dinaledi assemblage may be a critically important site for characterizing the lower limb of the earliest members of the genus Homo. Alternatively, the assemblage may represent yet another "Homo-like" variant during what may have been an adaptive radiation of our genus (Jungers et al., 2009; Berger et al., 2010; Ward et al., 2015).

Primitive traits in the H. naledi thigh and leg include an australopith-like AP compressed femoral neck, a mediolaterally compressed tibia (Davies, 1964; Susman and Stern, 1982), a large proximal attachment for m. tibialis posterior (Davies, 1964), a relatively circular fibular neck, and a convex surface for the proximal attachment of the m. peroneus brevis on the fibula (Susman and Stern, 1982). Derived traits shared with Homo include strong muscle insertions for m. gluteus maximus, well-marked linea aspera, relatively anteroposteriorly thick patellae, a relatively long tibia, and relatively gracile fibulae with laterally oriented lateral malleoli (Davies, 1964, Stern and Susman, 1982; Lovejoy, 2007). 
Other features of the lower limb of $H$. naledi, including the presence of two pillars on the superior aspect of the femoral neck (perhaps as a result of a medially extended lateral attachment of the lateral rotators of the hip) and a strong distal attachment of the pes anserinus on the tibia, are unique to the taxon. All of these traits must be considered in the context of a derived foot anatomy (Harcourt-Smith et al., 2015) which together suggest that H. naledi was a bipedal hominin with adaptations for long distance walking and possibly endurance running (Bramble and Lieberman, 2004; Lieberman et al., 2006; e.g., long legs, enlarged m. gluteus maximus, locking calcaneocuboid joint [Harcourt-Smith et al., 2015]). As with the cranium (Berger et al., 2015), these traits suggest affinity with early Homo, including $H$. habilis and $H$. erectus. The largely australopith-like trunk, pelvis, and upper limb (Berger et al., 2015; Kivell et al., 2015) of $H$. naledi, however, demonstrate the mosaic morphology of the species. The significance of this pattern in the context of hominin evolution, though, is currently unknown, highlighting the importance of further analyses of the unique Dinaledi assemblage.

\section{Acknowledgments}

We thank the curators at the various museums where comparative data were collected:

L. Jellema and Y. Haile-Selassie (Cleveland Museum of Natural History), E. Westwig (American Museum of Natural History), J. Chupasko (Museum of Comparative Zoology), M. Morgan and D. Pilbeam (Peabody Museum of Archaeology and Ethnology), O. Lovejoy (Libben), E. Mbua (National Museums of Kenya), S. Potze (Ditsong Museum), B. Zipfel (Evolutionary Studies Institute, University of the Witwatersrand), B. Billings (School of Anatomical Sciences, University of the Witwatersrand), K. Isler and E. Langenegger (University of Zurich, Irchel, Switzerland), and G. Grupe and O. Röhrer-Ertl (University of Munich, Germany). We also thank the many funding agencies that supported various aspects 
of this work, including the L.S.B. Leakey Foundation and Boston University, but especially the National Geographic Society and the National Research Foundation of South Africa for particularly significant funding of the discovery, recovery, and analysis of this material. We would also like to thank the University of the Witwatersrand and the Evolutionary Studies Institute, as well as the South African National Centre of Excellence in PalaeoSciences for curating the material and hosting the authors while studying the material. We are grateful to the South African Heritage Resource Agency for the necessary permits to work on the Rising Star site; the Jacobs family for granting access; and Wilma Lawrence, Bonita De Klerk, Merrill Vanderwalt, and Justin Mukanku for their assistance during all phases of the project. 


\section{References}

Aiello, L.C., Dean, C., 2002. An introduction to human evolutionary anatomy. Academic Press, London.

Antón, S.C., Potts, R., Aiello, L.C., 2014. Evolution of early Homo: An integrated biological perspective. Science 345, 1236828-1-1236828-13.

Berger, L.R., de Ruiter, D., Churchill, S.E., Schmid, P., Carlson, K.J., Dirks, P.H.G.M., Kibii, J.B., 2010. Australopithecus sediba: a new species of Homo-like australopith from South Africa. Science 328, 195-204.

Berger, L.E., Hawks, J., de Ruiter, D.J., Churchill, S.E., Schmid, P., Delezene, L., Kivell, T., Garvin, H.M., Williams, S.A., DeSilva, J.M., Skinner, M.M., Musiba, C.M., Cameron, N., Holliday, T.W., Harcourt-Smith, W., Ackermann, R.R., Bastir, M., Bogin, B., Bolter, D., Brophy, J., Cofran, Z.D., Congdon, K.A., Deane, A.S., Dembo, M., Drapeau, M., Elliott, M., Feuerriegel, E.M., Garcia-Martinez, D., Green, D.J., Gurtov, A., Irish, J.D., Kruger, A., Laird, M.F., Marchi, D., Meyer, M.R., Nalla, S., Negash, E.W., Orr, C.M., Radovcic, D., Schroeder, L., Scott, J.E., Throckmorton, Z., Tocheri, M.W., VanSickle, C., Walker, C.S., Wei, P., Zipfel, B., 2015. A new species of the genus Homo from the Dinaledi Chamber, South Africa. eLIFE 4, e09560.

Bramble, D.M., Lieberman, D.E., 2004. Endurance running and the evolution of Homo. Nature 432, 345-352.

Carretero, J.M., Lorenzo, C., Arsuaga, J.L., 1999. Axial and appendicular skeleton of Homo antecessor. J. Hum. Evol. 37, 459-499.

Chibba, K., Bidmos, M.A., 2007. Using tibia fragments from South Africans of European descent to estimate maximum tibia length and stature. For. Sci. Int. 169, 145-151.

Davies, P.R., 1964. Hominid fossils from Bed I, Olduvai Gorge, Tanganyika. Nature 201, 967-968. 
Day, M.H., 1969. Femoral fragment of a robust australopithecine from Olduvai Gorge, Tanzania. Nature 221, 230-233.

DeGusta, D.A., 2004. Pliocene hominid postcranial fossils from the Middle Awash, Ethiopia. Ph.D. Dissertation, University of California, Berkeley.

Dembo, M., Radovčić, D., Garvin, H.M., Laird, M.F., Schroeder, L., Scott, J., Brophy, J., Ackerman, R.R., Musiba, C.M., de Ruiter, D.J., Mooers, A.Ø., 2016. The evolutionary relationships and age of Homo naledi: an assessment using dated Bayesian phylogenetic methods. J. Hum. Evol. 97, 17-26.

DeSilva, J.M., 2008. Vertical climbing adaptations in the anthropoid ankle and midfoot: implications for locomotion in Miocene catarrhines and Plio-Pleiostocene hominins. Ph.D. Dissertation, University of Michigan.

DeSilva, J.M., 2009. Functional morphology of the ankle and the likelihood of climbing in early hominins. Proc. Natl. Acad. Sci. 106, 6567-6572.

DeSilva, J.M., Holt, K.G., Churchill, S.E., Carlson, K.J., Walker, C.S., Zipfel, B., Berger, L.R., 2013. The lower limb and mechanics of walking in Australopithecus sediba. Science 340, 1232999-1-1232999-5.

Dirks, P.H.G.M., Berger, L.R., Roberts, E.M., Kramers, J., Hawks, J., Randolph-Quinney, P.S., Elliott, M., Musiba, C.M., Churchill, S.E., de Ruiter, D.J., Schmid, P., Backwell, L.R., Belyanin, G.A., Boshoff, P., Hunter, K.L., Feuerriegel, E.M., Gurtov, A., Harrison, J., Hunter, R., Kruger, A., Morris, H., Makhubela, T.V., Peixotto, B., Tucker, S., 2015. Geological and taphonomic context for the new hominin species Homo naledi from the Dinaledi Chamber, South Africa. eLife 4, e09561.

Domínguez-Rodrigo, M., Pickering, T.R., Baquedano, E., Mabulla, A., Mark, D.F., Musiba, C., Bunn, H.T., Uribelerrea, D., Smith, V., Diez-Martin, F., Pérez-González, A., 2013. 
First partial skeleton of a 1.34-million-year-old Paranthropus boisei from Bed II, Olduvai Gorge, Tanzania. PloS One 8, e80347.

Gilbert, W.H., 2008. Daka member hominid postcranial remains. In: Gilbert, W.H., Asfaw, B. (Eds.), Homo erectus: Pleistocene evidence from the Middle Awash, Ethiopia. Vol. 1. University of California Press, Cambridge, Berkeley, pp. 373-396.

Grine, F.E., Jungers, W.L., Tobias, P.V., Pearson, O.M., 1995. Fossil Homo femur from Berg Aukas, northern Namibia. Am. J. Phys. Anthropol. 97, 151-185.

Haeusler, M., McHenry, H.M., 2004. Body proportions of Homo habilis reviewed. J. Hum. Evol. 46, 433-465.

Haeusler, M., McHenry, H.M., 2007. Evolutionary reversals of limb proportions in early hominids? Evidence from KNM-ER 3735 (Homo habilis). J. Hum. Evol. 53, 383405.

Haile-Selassie, Y., Latimer, B.M, Alened, M., Deino, A.L., Gilbert, L., Melillo, S.M., Saylor, B.Z., Scott, G.R., Lovejoy, C.O., 2010. An early Australopithecus afarensis postcranium from Woranso-Mille, Ethiopia. Proc. Natl. Acad. Sci. 107, 12121-12126. Harcourt-Smith, W.E.H., Throckmorton, Z., Congdon, K.A., Zipfel, B., Deane, A.S., Drapeau, M.S.M., Churchill, S.E., Berger, L.R., DeSilva, J.M., 2015. The foot of Homo naledi. Nat. Commun. 6, 8432.

Holliday, T.W., 2012. Body size, body shape, and the circumscription of the genus Homo. Curr. Anthropol. 53, 330-345.

Hrdlička, A., 1898. Study of the normal tibia. Am. Anthropol. 11 (old series), 307-312. Jacobs, K., 1992. Estimating femur and tibia length from fragmentary bones: an evaluation of Steele's (1970) method using prehistoric European sample. Am. J. Phys. Anthropol. $89,333-345$.

Johanson, D.C., Lovejoy, C.O, Kimbel, W.H., White, T.D., Bush, M.E., Latimer, B.M., 
Coppens, Y., 1982. Morphology of the Pliocene partial hominid skeleton (A.L. 288-1) from the Hadar formation, Ethiopia. Am. J. Phys. Anthropol. 57, 403-451.

Johanson, D.C., Masao, F.T., Eck, G.G., White, T.D., Walter, R.C., Kimbel, W.H., Asfaw, B., Manega, P., Ndessokia, P., Suwa, G., 1987. New partial skeleton of Homo habilis from Olduvai Gorge, Tanzania. Nature 327, 205-209.

Jungers, W.L., Larson, S.G., Harcourt-Smith, W., Morwood, M.J., Sutikna, T., Awe, R.D., Djubiantono, T., 2009. Descriptions of the lower limb skeleton of Homo floresiensis. J. Hum. Evol. 57, 538-554.

Kennedy, G., 1983. Some aspects of femoral morphology in Homo erectus. J. Hum. Evol. 12, $587-616$.

Kingsley, P.C., Olmsted, K.L., 1948. A study to determine the angle of anteversion of the neck of the femur. J. Bone Joint Surg. 30-A, 745-751.

Kivell, T.L., Deane, A.S., Tocheri, M.W., Orr, C.M., Schmid, P., Hawks, J., Berger, L.R., Churchill, S.E., 2015.The hand of Homo naledi. Nat. Commun. 6, 8431.

Latimer, B., Ohman, J.C., Lovejoy, C.O., 1987. Talocrural joint in African hominoids: Implications for Australopithecus afarensis. Am. J. Phys. Anthropol. 74, 155-175. Leakey, M.G., Spoor, F., Dean., M.C., Feibel, C.S., Antón, S.C., Kiarie, C., Leakey, L.N., 2012. New fossils from Koobi Fora in northern Kenya confirm taxonomic diversity in early Homo. Nature 488, 201-204.

Leakey, R.E.F., 1973. Evidence from an advanced Plio-Pleistocene hominid from East Rudolf, Kenya. Nature 242, 447-459.

Leakey, R.E.F, Walker, A.C., 1985. Further hominids from the Plio-Pleistocene of Koobi Fora, Kenya. Am. J. Phys. Anthropol. 67, 135-163.

Lieberman, D., Raichlen, D.A., Pontzer, H., Bramble, D.M., Cutright-Smith, E., 2006. The human gluteus maximus and its role in running. J. Exp. Biol. 209, 2143-2155. 
Lordkipanidze, D., Jashashvili, T., Vekua, A., Ponce de León, M., Zollikofer, C.P.E.,

Rightmire, G.P., Pontzer, H., Ferring, R., Oms, O., Tappen, M., Bukhsianidze, M., Agusti, J., Kahlke, R., Kiladze, G., Martinez-Navarro, B., Mouskhelishvili, A.,

Nioradze, M., Rook, L., 2007. Postcranial evidence from early Homo from Dmanisi, Georgia. Nature 449, 205-310.

Lordkipanidze, D., Ponce de León, M., Margvelashvili, A., Rak, Y., Rightmire, G.P., Vejua, A., Zollikofer, C.P.E., 2013. A complete skull from Dmanisi, Georgia, and the evolutionary biology of Early Homo. Science 342, 326-331.

Lovejoy, C.O., 1975. Biomechanical perspectives on the lower limb of early hominids. In:

Tuttle, R. (Ed.), Primate Functional Morphology and Evolution. Mouton, The Hague, pp. 291-326.

Lovejoy, C.O., 2007. The natural history of human gait and posture. Part 3. The knee. Gait Posture 25, 325-341.

Lovejoy, C.O., Johanson, D.C., Coppens, Y.,1982. Hominid lower limb bones recovered from the Hadar formation: 1974-1977 collections. Am. J. Phys. Anthropol. 57, 679700.

Lovejoy, C.O., Meindl, R.S., Ohman, J.C., Heiple, K.G., White, T.D., 2002. The Maka femur and its bearing on the antiquity of human walking: Applying contemporary concepts of morphogenesis to the human fossil record. Am. J. Phys. Anthropol. 119, 97-133.

Marchi, D., 2015. Using the morphology of the hominoid distal fibula to interpret arboreality in Australopithecus afarensis. J. Hum. Evol. 85, 136-148.

Martin, R., Saller, K., 1957. Lehrbuch der Anthropologie.Vol. I. Fischer Verlag, Stuttgart. McHenry, H.M., 1994. Early hominid postcrania: phylogeny and function. In: Corruccini, R.S., Chocon , R.L. (Eds.), Integrative paths to the past: Paleoanthropological advances in honor of F. Clark Howell. Englewood Cliffs, Prentice Hall, pp. 251-268. 
McHenry, H.M., Corruccini, R.S., 1978. The femur in human evolution. Am. J. Phys. Anthropol. 49, 473-487.

Mosimann, J.E., 1970. Size allometry: size and shape variables with characterizations of the lognormal and generalized Gamma distributions. J. Am. Sta. Assoc. 65, 930-945.

Moyà-Solà, S., Köhler, M., Alba, D., Almécija, S., 2008. Taxonomic attribution of the Olduvai Hominid 7 manual remains and the functional interpretation of hand morphology in the robust australopithecines. Folia Primatol. 79, 215-250.

Myatt, J.P., Schilling, N., Thorpe, S.K.S., 2011. Distribution patterns of fibre types in the triceps surae muscle group of chimpanzees and orangutans. J. Anat. 218, 402-412.

Noyes, F.R., Sonstegard, D.A., 1973. Biomechanical function of the pes anserinus at the knee and the effect of its transplantation. J. Bone Joint Surg. Am. 55, 1225-1241.

Ohman, J.C., Krochta, T.J., Lovejoy, C.O., Mensforth, R.P., Latimer, B., 1997. Cortical bone distribution in the femoral neck of hominoids: implications for the locomotion of Australopithecus afarensis. Am. J. Phys. Anthropol. 104, 117-131.

Partridge, T.C., Granger, D.E., Caffee, M.W., Clarke, R.J., 2003. Lower Pliocene hominid remains from Sterkfontein. Science 300, 607-612.

Pickering, T.R., Heaton, J.L., Clarke, R.J., Sutton, M.B., Brain, C.K., Human, K., 2012. New hominid fossils from Member 1 of the Swartkrans formation, South Africa. J. Hum. Evol. 62, 618-628.

Pickford, M., Senut, B., Gommery, D., Treil, J., 2002. Bipedalism in Orrorin tugenensis revealed by its femora. C.R. Palevol. 1, 191-203.

Pontzer, H., 2007. Effective limb length and the scaling of locomotor cost in terrestrial animals. J. Exp. Biol. 210, 1752-1761. 
Pontzer, H., Rolian, C., Rightmire, G.P., Jashashvili, T., Ponce de León, M.S., Lordkipanidze, D., Zollikofer, C.P., 2010. Locomotor anatomy and biomechanics of the Dmanisi hominins. J. Hum. Evol. 58, 492-504.

Puymerail, L., Ruff, C.B., Bondioli, L., Widianto, H., Trinkaus, E., Macchiarelli, R., 2012. Structural analysis of the Kresna 11 Homo erectus femoral shaft (Sangiran, Java). J. Hum. Evol. 63, 741-749.

Reed, K.E., Kitching, J.W., Grine, F.E., Jungers, W.L., Sokoloff, L., 1993. Proximal femur of Australopithecus africanus from Member 4, Makapansgat, South Africa. Am. J. Phys. Anthropol. 92, 1-15.

Richmond, B.R., Jungers, W.L., 2008. Orrorin tugenensis femoral morphology and the evolution of hominin bipedalism. Science 319, 1662-1665.

Ruff, C.B., 1995. Biomechanics of the hip and birth in early Homo. Am. J. Phys. Anthropol. $98,527-574$.

Ruff, C.B., Higgins, R., 2013. Femoral neck structure and function in early hominins. Am. J. Phys. Anthropol. 150, 512-525.

Schmid, P., 1983. Eine Rekonstruktion des Skelettes von A.L. 288-1 (Hadar) und deren Konsequenzen. Folia Primatol. 40, 283-306.

Silveira, L.F., Bernardes, C., Portella, G., Araujo, F., Loss, J., 2006. Influence of patellar thickness on patellofemoral contact forces and quadriceps muscle forces. J. Biomech. 39, S492.

Sládek, V., Berner, M., Galeta, P., Friedl, L., Kudrnova, S., 2010. Technical Note: The effect of midshaft location on the error ranges of femoral and tibial cross-sectional parameters. Am. J. Phys. Anthropol. 141, 325-332. 
Spoor, F., Gunz, P., Neubauer, S., Stelzer, S., Scott, N., Kwekason, A., Dean, M.C., 2015. Reconstructed Homo habilis type $\mathrm{OH} 7$ suggests deep-rooted species diversity in early Homo. Nature 519, 83-86.

Steele, D.G., McKern, T.W., 1969. A method for assessment of maximum long bone length and living stature from fragmentary long bones. Am. J. Phys. Anthropol. 31, 215-228.

Stern, J.T., Susman, R.L., 1983. Locomotor anatomy of Australopithecus afarensis. Am. J. Phys. Anthropol. 50, 279-317.

Susman, R.L., Stern, J.T., 1982. Functional morphology of Homo habilis. Science 217, 931934.

Susman, R.L., de Ruiter, D., Brain, C.K., 2001. Recently identified postcranial remains of Paranthropus and early Homo from Swartkrans Cave, South Africa. J. Hum. Evol. 41, $607-629$.

Tardieu, C., 2010. Development of the human hind limb and its importance for the evolution of bipedalism. Evol. Anthropol. 19, 174-186.

Trinkaus, E., 1983. The Shanidar Neandertals. Academic Press, NewYork.

Trinkaus, E., Ruff, C.B., 1999. Diaphyseal cross-sectional geometry of Near Eastern Middle Paleolithic humans: the tibia. J. Archaeol. Sci. 26, 1289-1300.

Van Arsdale, A., Wolpoff, M.H., 2012. A single lineage in early Pleistocene Homo: size variation continuity in early Pleistocene Homo crania from East Africa and Georgia. Evolution 67, 841-850.

VanSickle, C., Williams, S.A., Garcia-Martinez, D., Cofran, Z.D., Churchill, S.E., Berger, L.R., Hawks, J., (in review). The pelvis of Homo naledi. J. Hum. Evol.

Walker, A.C., Leakey, R.E.F., 1993. The postcranial bones. In: Walker, A.C., Leakey, R.E.F. (Eds.), The Nariokotome Homo erectus skeleton. Harvard University Press,

Cambridge, 
pp. $95-160$.

Walker, C.S., 2015. Ontogeny of lower limb morphology and proportions in the Dinaledi hominins. Ph.D. Dissertation, Duke University.

Ward, C.V., Kimbel, W.H., Harmon, E.H., Johanson, D.C., 2012. New postcranial fossils of Australopithecus afarensis from Hadar, Ethiopia (1990-2007). J. Hum. Evol. 63, 151.

Ward, C.V., Feibel, C.S., Hammond, A.S., Leakey, L.N., Moffett, E.A., Plavcan, J.M., Skinner, M.M., Spoor, F., Leakey, M.G., 2015. Associated ilium and femur from Koobi Fora, Kenya, and postcranial diversity in early Homo. J. Hum. Evol. 81, 48-67.

Wood, B., Leakey, M., 2011. The Omo-Turkana basin fossil hominins and their contribution to our understanding of human evolution in Africa. Evol. Anthropol. 20, 264-292.

Wright, L.E., Vásquez, M.A., 2003. Estimating the length of incomplete long bones: forensic standards from Guatemala. Am. J. Phys. Anthropol. 120, 223-251.

Zipfel, B., DeSilva, J.M., Kidd, R.S., Carlson, K.J., Churchill, S.E., Berger, L.R., 2011.The foot and ankle of Australopithecus sediba. Science 333, 1417-1420.

\section{Figure legends}

Fig. 1. Method used to quantify femoral neck anteversion relative to the proximal shaft on a left human femur. (a) Anterior view, (b) medial view, (c) cranial view (anterior to the right and posterior to the left). White arrows indicate the L-square used to position the linea aspera. See text for explanation.

Fig. 2. Femoral neck sagittal outlines. (a) Black arrows indicate the neck/shaft junction where sections of the femoral neck were taken; (b) external outlines in sagittal view at the neck- 
shaft junction are shown for Homo naledi (U.W. 101-002, U.W. 101-398, and U.W. 1011391) and compared to other fossil hominins, chimpanzees, and modern humans. Note the presence of two pillars on the superior aspect of the femoral neck of $H$. naledi, one superoanterior (1) and the other inferoposterior (2). The pit between the two may signify a more medially encroaching lateral attachment for mm. obturator internus and gemelli in $H$. naledi . Sup. $=$ superior; Inf. $=$ inferior; Ant. $=$ anterior; Post $=$ posterior.

Fig. 3. The tibia and fibula from a Khoe-San skeleton is compared with the fragmentary U.W. 101-484 tibia to help estimate Homo naledi tibial length. The proximal break in the U.W. 101-484 tibia is just proximal to the tibial tubercle and it is at the same level of the tibial tubercle of the Khoe-San tibia. Also note the gracility (compared to tibial length) of the H. naledi tibia compared to the modern human.

Fig. 4. Proximal femora of Homo naledi. From left to right: (a) U.W. 101-002, (b) U.W. 101018, (c) U.W. 101-398, (d) U.W. 101-1136, (e) U.W. 101-1391, and (f) U.W. 101-1475. Note the presence of a third trochanter (1) on five of the six femora and the well-marked gluteal line for the distal insertion of $\mathrm{m}$. gluteus maximus (2). In medial view, note the anterversion of the femoral neck as indicated by the angle formed by the longitudinal axis of the neck and the longitudinal axis of the proximal diaphysis.

Fig. 5. Proximal femora U.W. 101-398 and U.W. 101-1391, posterior view. Note superiorly, along the neck, the presence of two mediolaterally oriented pillars of bone and the resulting groove between the two. One pillar is more inferior and posterior, the other is more superior and anterior.

Fig. 6. Homo naledi femoral shafts. Anterior view on the left, posterior view on the right. For U.W. 101-012, the proximal view of the break in the shaft is shown. Note the thick diaphyseal cortex. Also note the linea aspera (1) in U.W. 101-003 and U.W. 101-012. 
Fig. 7. Homo naledi proximal femur U.W. 101-018 in (a) anterior (left) and posterior (right) view. (b) Medial view of a natural break in the neck. Left is anterior, right is posterior. Note the relatively thicker cortex inferiorly compared to superiorly. (c) Distal view of the distal break in the diaphysis. Note the thick cortex.

Fig. 8. Homo naledi distal femur U.W. 101-215. Anterior view on the left, posterior view on the right. The medial condyle is attached to the specimen in posterior view, but not anterior view. Note the bicondylar angle observable in posterior view.

Fig. 9. Homo naledi proximal femoral fragments: U.W. 101-271, U.W. 101-421, and U.W. 101-1300. U.W. 101-421 is shown at the top in anterior view with a conjoining fragment of femoral head. Below, the femoral neck and trochanteric region is shown in anterior (left) and posterior (right) views. To the right are two fragmentary femoral heads. Neither fossil conjoins with a $H$. naledi femoral neck, though each is complete enough to measure a femoral head diameter.

Fig. 10. Homo naledi femoral shafts. Anterior view on the left, posterior view on the right. U.W. 101-545 is a right distal femoral shaft. Note the thick cortex at the proximal break and the presence of a weak pilaster in cross-section. Distally, U.W. 101-545 preserves evidence of a sustrochlear hollow, palpable just above the distal break. U.W. 101-1482 is a left femoral shaft fragment preserved from a break in the shaft inferior to the lesser trochanter to a break in the midshaft region.

Fig. 11. Immature femora of Homo naledi. Top left: U.W. 101-1000 and epiphyseal head U.W. 101-1098 in anterior (left) and posterior (right) view. The capital epiphysis is attached in just the posterior view. Top right: Completely preserved proximal portion and shaft of U.W. 101-938 in (left) anterior and (right) posterior view. At the center is just the proximal portion in posterior view with the attached capital epiphysis. Bottom left: the distal femoral 
epiphysis U.W. 101-1120 in anterior (left) and inferior (right) views. Note the rising lateral lip in inferior view.

Fig. 12. Homo naledi patellae. From left to right: anterior, posterior, and superoinferior (transverse plane section) view. Note the anteroposterior thickness in the SI view.

Fig. 13. Homo naledi tibial shafts. Left anterior view, right medial view. Note the platycnemic shape in all tibiae.

Fig. 14. Distal tibia of Homo naledi. (a) Left distal tibia. Left anterior view, center lateral view, right distal view. Anteriorly, the rim of the tibiotalar surface possesses a small squatting facet (1). (b) Left distal tibia. Left anterior view, center lateral view, right distal view. Note the squatting facet visible in anterior view (2) and the strong interosseous crest in lateral view (3). (c) Right distal tibia. From left to right: anterior view, lateral view, distal view, and lateral view articulated with talus U.W. 101-1417, which belongs to foot 1 (Harcourt-Smith et al., 2015). Note the large laterally positioned anterior tubercle for the anterior tibiofibular ligament (4). Laterally, there is a strong interosseous crest (5) descending anterodistally. Note in lateral view (6) the posterior rim of the tibial plafond that is more distally projecting than the anterior rim.

Fig. 15. Anterior and medial view of the tibia of (a) Homo naledi (U.W. 101-484) and (b) OH 35. Note the straight diaphysis of $H$. naledi as compared to $\mathrm{OH} 35$ in anterior view. $H$. naledi is also characterized by a relatively less robust tibia due to its longer diaphysis compared to OH 35 (see text). Note the rounded anterior border (1) of U.W. 101-484, similar to OH 35, and proximally the presence of a tubercle for the pes anserinus (2).

Fig. 16. Immature tibiae of Homo naledi: U.W. 101-996 and U.W. 101-1070 shown in anterior (left) and medial (right) views. U.W. 101-1070 is the most complete bone from the 
thigh and leg in the Dinaledi collection. The two fossils are also the only clear antimeres in the thigh and leg assemblage.

Fig. 17. Fibular epiphyses of Homo naledi. (a) Medial view (top) and anterior view (bottom) of the immature U.W. 101-817 left proximal fibula; (b) anterior view (left) and medial view (right) of the mature U.W. 101-1437 right distal fibula; (c) anterior view (left) and medial view (right) of the mature U.W. 101-1701 left distal fibula.

Fig. 18. (a) Modern human fibula compared to (b) Homo naledi (U.W. 101-1037), (c) OH 35, and (d) Pan troglodytes. Note the proximal portion of the subcutaneous triangular surface (STS; 1) and of the interosseous ligament insertion (ILI; 2). In U.W. 101-1037, the proximal portion of the two structures is more or less at the same level in the diaphysis, similar to $\mathrm{OH}$ 35 fibula. In humans, the STS is more cranial than the ILI. Note the grooves for $\mathrm{m}$. tibialis posterior (3) and m. peroneus longus (4) in U.W. 101-1037, also present in the OH 35 fibula. Fig. 19. (a) Discriminant function analysis (DFA) of proximal femoral shape among hominins. The Dinaledi femora (shaded in red) span the gap between fossils attributed to Australopithecus (shaded in yellow) and early Homo, including H. erectus (shaded in green). To the right (shaded in blue) are fossils generally attributed to A. boisei (OH 20 and KNMER 1503) clustering with many fossils only identified as "hominin indet.," suggesting that these too may belong to A. boisei. (b) DFA structure matrix based on shape variables, along with Wilks' lambda and significance values. (c) DFA of proximal femoral shape among hominins as presented in (a) except that the uncertain "Hominin indet." specimens were not included. Again, the Dinaledi femora (shaded in red) plot in the space between fossil Homo (shaded in green) and Australopithecus (shaded in yellow). (d) DFA structure matrix based on shape variables, along with Wilks' lambda and significance values. Measurements are defined in the text. 
Fig. 20. Relative length of the femoral neck in Homo naledi compared to fossil hominins and extant humans and apes. The femoral neck length is divided by the squareroot of the product of the mediolateral and anteroposterior dimensions of the subtrochanteric region of the shaft. The box-and-whisker plots show the median (dark horizontal line), upper and lower quartiles (boxes), range (whiskers), and outliers (circles). The 95\% confidence interval of the slope of the RMA regression line characterizing the scaling relationship between neck length and subtrochanteric dimensions includes $1.0(0.994-1.275)$, justifying the treatment of these data as a ratio. The lone H. erectus fossil is the KNM-WT 15000 juvenile, which may have such a long relative neck because it is an immature individual. Note the position of relative neck length in the Dinaledi femora within the range of Australopithecus and early fossil Homo.

Fig. 21. Relative shape of the femoral neck in Homo naledi compared to fossil hominins and extant humans and apes. The box-and-whiskers plots show the median (dark horizontal line), upper and lower quartiles (boxes), range (whiskers), and outliers (circles). Individual values are listed in DeSilva et al. (2013) and Ward et al. (2015). The 95\% confidence interval of the slope of the RMA regression line characterizing the scaling relationship between neck SI and ML diameters includes $1.0(0.911-1.022)$, justifying the treatment of these data as a ratio. Fossil Homo has a more circular femoral neck, whereas the femoral neck of earlier hominins is anteroposteriorly compressed. The Dinaledi femora are australopith-like in having a more compressed neck than fossil Homo, though one individual (U.W. 101-1391) is in the range of early Homo.

Fig. 22. Platymeric index in Homo naledi compared to fossil hominins and extant humans and apes. The box-and-whiskers plot shows the median (dark horizontal line), upper and lower quartiles (boxes), range (whiskers), and outliers (circles). Individual values are listed in DeSilva et al. (2013). The 95\% confidence interval of the slope of the RMA regression line characterizing the scaling relationship between subtrochanteric mediolateral diameter and 
anteroposterior diameter includes $1.0(0.83-1.04)$, justifying the treatment of these data as a ratio. The Dinaledi femora are more platymeric than early Homo, but less so than that found in $H$. erectus (though this is not significant with the current sample sizes: $p=0.13$ ).

Fig. 23. Head/neck anteversion of Homo naledi compared to fossil hominins and extant humans and chimpanzees. The box-and-whiskers plot shows the median (dark horizontal line), upper and lower quartiles (boxes), range (whiskers), and outliers (circles). Australopithecus: A.L. 288-1AP, A.L. 333-95, StW 99, MH1; hominin indet.: KNM-ER 3728; early Homo: KNM-ER 1472, KNM-ER 1481; H. naledi: U.W. 101-002, U.W. 101398, U.W. 101-1391, U.W. 101-1475

Fig. 24. Bivariate plot of mediolateral (ML) diameter by anteroposterior (AP) diameter of the patella of Homo naledi (red star) compared to extant humans (black circles), African apes (gorillas open circles, chimpanzees open diamonds), and other hominins. For the fossil taxa, each symbol represents a single fossil or an average if multiple specimens are known (e.g., Neanderthals). This figure is derived from data in Table 4. A reduced major axis (RMA) regression line is drawn through the extant data: $\mathrm{y}=0.528 * \mathrm{x}-2.11\left(\mathrm{R}^{2}=0.81\right)$. Notice that for a given ML diameter of the patella, humans tend to have AP thicker patellae, while gorillas have AP thinner patellae. The H. naledi patella is human-like in its relative thickness.

Fig. 25. Results of the bootstrap analysis calculating distributions of tibia length: femoral head diameter ratios in orangutans (purple), gorillas (green), chimpanzees (red), and humans (blue). Fossils are the black vertical lines. Note that extant data and $H$. naledi are derived from bootstrapping analysis of mixed tibial lengths and femoral head diameters, whereas data for the other fossils are based on femoral head diameters and tibial length estimates taken from the same individual (Dmanisi, MH2, KNM-WT 15000, KSD-VP 1/1). The Dinaledi 
tibia are relatively long compared with the size of the femoral heads currently in the collection.

Fig. 26. Relative thickness of the medial malleolus of Homo naledi compared to fossil hominins and extant humans and apes. The box-and-whiskers plot shows the median (dark horizontal line), upper and lower quartiles (boxes), range (whiskers), and outliers (circles). Individual values are listed in Zipfel et al. (2011). 


\section{Tables}

Table 1. List of Homo naledi thigh and leg remains.

\begin{tabular}{|c|c|c|}
\hline Catalogue number & Element & SI Preserved Length $(\mathrm{mm})$ \\
\hline \multicolumn{3}{|l|}{ Femur } \\
\hline U.W. 101-002 & Right proximal femur & 136.3 \\
\hline U.W. 101-003 & Right femoral shaft & 219.2 \\
\hline U.W. 101-012 & Right femoral shaft & 210.7 \\
\hline U.W. $101-014^{\mathrm{a}}$ & Femoral shaft & 65.3 \\
\hline U.W. 101-018 & Right proximal femur & 97.5 \\
\hline U.W. 101-143 & Right proximal femoral shaft & 66.0 \\
\hline U.W. 101-215 & Left distal femur & 101.0 \\
\hline U.W. 101-268 & Left femoral shaft & 227.2 \\
\hline U.W. 101-271 & Femoral head & 35.8 \\
\hline U.W. 101-341 & Femoral fragment & 86.7 \\
\hline U.W. 101-398 & Left proximal femur & 144.1 \\
\hline U.W. 101-421 & Left proximal femur & 55.3 \\
\hline U.W. 101-545 & Right distal femoral shaft & 106.0 \\
\hline U.W. 101-857 & Left distal femoral shaft & 78.5 \\
\hline U.W. 101-898 & Femoral condyle fragment & 21.5 \\
\hline U.W. 101-938 & Right proximal femur & 272.9 \\
\hline U.W. 101-1000a & Right proximal femur & 95.2 \\
\hline U.W. 101-1098 & Right epiphyseal head & 25.7 \\
\hline U.W. 101-1120a & Left distal femur & 21.7 \\
\hline U.W. 101-1136 & Right proximal femur & 115.3 \\
\hline U.W. 101-1284 & Right distal femoral shaft & 158.4 \\
\hline U.W. 101-1300 & Femoral head & 35.2 \\
\hline U.W. 101-1391 & Right proximal femur & 137.2 \\
\hline U.W. 101-1434 & Left proximal femur & 83.0 \\
\hline U.W. 101-1475 & Left proximal femur & 99.3 \\
\hline U.W. 101-1482 & Left femoral shaft fragment & 121.9 \\
\hline U.W. 101-1523 ${ }^{\mathrm{a}}$ & Right distal femoral shaft & 84.3 \\
\hline U.W. $101-1555^{\mathrm{a}}$ & $\begin{array}{l}\text { Femoral neck fragment with } \\
\text { attached partial head }\end{array}$ & 24.5 \\
\hline U.W. 101-1694 ${ }^{\mathrm{a}}$ & Right distal femoral condyle & 18.3 \\
\hline \multicolumn{3}{|l|}{ Patella } \\
\hline U.W. 101-852 & Right patella & 24.9 \\
\hline U.W. 101-1404 & Right patella & 26.0 \\
\hline U.W. 101-1512 & Partial patella & 23.7 \\
\hline U.W. 101-1639 & Right patella & 23.0 \\
\hline \multicolumn{3}{|l|}{ Tibia } \\
\hline U.W. 101-013 & Distal tibial shaft & 85.5 \\
\hline U.W. 101-017 & Right proximal tibial shaft & 57.0 \\
\hline U.W. 101-042 ${ }^{\mathrm{a}}$ & Tibial shaft fragment & 51.2 \\
\hline U.W. 101-072 & Left distal tibial shaft & 119.9 \\
\hline U.W. 101-085 & Tibia shaft fragment & 53.5 \\
\hline U.W. 101-136 & Right proximal tibial shaft & 92.5 \\
\hline U.W. 101-213 & Right proximal tibial shaft & 159.0 \\
\hline U.W. 101-237 & Left proximal tibial shaft & 59.6 \\
\hline U.W. 101-239 & Proximal tibial shaft & 109.8 \\
\hline U.W. 101-313 & Left proximal tibial shaft & 59.0 \\
\hline U.W. 101-402 & Right distal tibial shaft & 67.0 \\
\hline U.W. 101-420 & Left distal tibia & 82.7 \\
\hline U.W. 101-484 & Right tibia & 293.0 \\
\hline U.W. $101-498^{\mathrm{a}}$ & Left proximal tibial shaft & 138.8 \\
\hline U.W. 101-500 & Left proximal tibial shaft & 144.4 \\
\hline U.W. 101-567 & Tibia shaft fragment & 58.7 \\
\hline
\end{tabular}


U.W. 101-571

U.W. 101-586

U.W. 101-711

U.W. $101-848$

U.W. 101-973

U.W. 101-996

U.W. 101-1070

U.W. 101-1210

U.W. 101-1214

U.W. 101-1241

U.W. 101-1262

U.W. 101-1288

U.W. 101-1295

U.W. 101-1416

U.W. 101-1518
Right proximal tibial shaft

Tibial shaft fragment

Left distal tibia

Right tibial shaft

Left proximal tibial shaft

Left tibia $\quad 278.0$

Right distal tibial shaft $\quad 56.9$

Right tibial midshaft $\quad 35.6$

Left distal tibial shaft $\quad 63.5$

Right distal tibia $\quad 36.5$

Right distal tibial shaft $\quad 142.4$

Tibial shaft fragment $\quad 42.1$

Right distal tibia $\quad 42.2$

Left distal tibia $\quad 29.8$

\section{Fibula}

U.W. 101-181

U.W. 101-416

U.W. 101-449

U.W. 101-508

U.W. $101-580$

U.W. 101-675

U.W. 101-702

U.W. 101-719

U.W. 101-722

U.W. 101-737

U.W. 101-778

U.W. 101-782

U.W. 101-806

U.W. 101-813

U.W. $101-817^{\mathrm{a}}$

U.W. 101-876

U.W. 101-892

U.W. 101-902

U.W. 101-925

U.W. 101-968

U.W. 101-987

U.W. 101-1037

U.W. 101-1045

U.W. 101-1046

U.W. 101-1066

U.W. 101-1071

U.W. 101-1094

U.W. 101-1113

U.W. 101-1114

U.W. 101-1115

U.W. 101-1122

U.W. 101-1138

U.W. 101-1143

U.W. 101-1231

U.W. 101-1254

U.W. 101-1259

U.W. 101-1260

U.W. 101-1313

U.W. 101-1436

U.W. 101-1437

U.W. 101-1451

U.W. 101-1520

U.W. 101-1679

\begin{tabular}{|c|c|}
\hline Distal fibular shaft & 26.9 \\
\hline Left proximal fibular shaft & 28.7 \\
\hline Proximal fibular shaft & 25.9 \\
\hline Right fibular midshaft & 47.9 \\
\hline Left distal fibular shaft & 59.1 \\
\hline Proximal fibular shaft & 21.8 \\
\hline Left proximal fibular shaft & 65.5 \\
\hline Left proximal fibular shaft & 57.5 \\
\hline Proximal fibular shaft & 23.3 \\
\hline Right distal fibular shaft & 38.0 \\
\hline Distal fibular shaft & 17.9 \\
\hline Distal fibular shaft & 38.6 \\
\hline Fibula shaft fragment & 25.5 \\
\hline Fibula shaft fragment & 26.7 \\
\hline Proximal left fibula & 34.3 \\
\hline Proximal fibular shaft & 20.4 \\
\hline Distal fibular shaft & 45.9 \\
\hline Left proximal fibular shaft & 61.9 \\
\hline Right proximal fibular shaft & 89.4 \\
\hline Right distal fibular shaft & 115.6 \\
\hline Proximal fibular shaft & 22.6 \\
\hline Proximal left fibular shaft & 238.0 \\
\hline Left fibula & 207.5 \\
\hline Left distal fibular shaft & 31.0 \\
\hline Fibular midshaft & 84.9 \\
\hline Distal fibular shaft & 30.2 \\
\hline Fibula shaft fragment & 24.4 \\
\hline Right proximal fibular shaft & 34.7 \\
\hline Distal fibular shaft & 32.9 \\
\hline Fibular midshaft & 35.3 \\
\hline Fibula shaft fragment & 32.5 \\
\hline Proximal fibular shaft & 21.5 \\
\hline Right fibular shaft & 54.7 \\
\hline Distal fibular shaft & 22.0 \\
\hline Right proximal fibular shaft & 112.5 \\
\hline Fibula shaft fragment & 21.0 \\
\hline Left proximal fibular shaft & 59.0 \\
\hline Proximal fibular shaft & 48.3 \\
\hline Fibular midshaft & 38.7 \\
\hline Right distal fibula & 21.4 \\
\hline Left proximal fibular shaft & 36.1 \\
\hline Fibula shaft fragment & 26.0 \\
\hline Right proximal fibular shaft & 27.6 \\
\hline
\end{tabular}


U.W. 101-1701

Left distal fibula

23.6

${ }^{a}$ Immature status based on the presence of unfused epiphysis or size (see methods) 
Table 2. Summary of the Dinaledi Chamber thigh and leg remains. Minimum number of elements (MNE) and minimum number of individuals (MNI) by each element.

\begin{tabular}{lccc|ccc}
\hline Element & \multicolumn{2}{c|}{ MNE } & \multicolumn{3}{c}{ MNI } \\
\cline { 2 - 7 } & Mature & Immature & Total & Mature & Immature & Total \\
\hline Femora & 21 & 8 & 29 & 8 & 3 & 11 \\
Patellae & 4 & & 4 & 3 & & 3 \\
Tibiae & 27 & 4 & 31 & 7 & 2 & 9 \\
Fibulae & 42 & 2 & 44 & 9 & 2 & 11 \\
\hline \multicolumn{2}{c}{ Total MNE } & 108 & \multicolumn{2}{c}{ Total MNI } & 11 \\
\hline
\end{tabular}


1573 Table 3. Comparative femur dimensions. ${ }^{\text {a }}$

\begin{tabular}{|c|c|c|c|c|c|c|c|c|c|c|c|}
\hline Specimen/Species & $\begin{array}{l}\text { Head } \\
\text { diameter } \\
(\mathrm{mm})\end{array}$ & $\begin{array}{l}\text { Neck SI } \\
(\mathrm{mm})\end{array}$ & $\begin{array}{l}\text { Neck AP } \\
(\mathrm{mm})\end{array}$ & $\begin{array}{l}\text { Neck shape } \\
(\mathrm{AP} / \mathrm{SI}) \times 100\end{array}$ & $\begin{array}{l}\text { Neck-shaft angle } \\
\text { (degrees) }\end{array}$ & $\begin{array}{l}\text { Neck } \\
\text { length } \\
(\mathrm{mm})\end{array}$ & $\begin{array}{l}\text { Neck } \\
\text { length/subtrochanteric } \\
\text { dimensions }^{\circ}\end{array}$ & $\begin{array}{l}\text { Subtroch. AP } \\
(\mathrm{mm})\end{array}$ & $\begin{array}{l}\text { Subtroch. ML } \\
(\mathrm{mm})\end{array}$ & Platymeric index & $\begin{array}{l}\text { Femoral } \\
\text { anteversion } \\
\text { (degrees) }\end{array}$ \\
\hline U.W. 101-002 & - & 22.6 & 15.0 & 66.4 & 115.7 & 30.0 & 1.44 & 18.5 & 23.6 & 78.4 & 118.9 \\
\hline U.W. 101-003 & - & - & - & - & & - & - & 21.6 & 31.4 & 68.8 & - \\
\hline U.W. 101-018 & - & - & - & - & - & - & - & 18.1 & 23.8 & 76.1 & - \\
\hline U.W. 101-143 & - & - & - & - & - & - & - & 17.6 & 20.2 & 87.1 & - \\
\hline U.W. 101-268 & & - & - & - & - & - & - & 21.1 & 26.3 & 80.2 & - \\
\hline U.W. 101-271 & 35.8 & & - & - & - & - & - & - & - & & - \\
\hline U.W. 101-398 & & 22.9 & 16.1 & 70.3 & 118.2 & 34.3 & 1.60 & 19.1 & 24.0 & 79.6 & 114.5 \\
\hline U.W. 101-421 & $33.5^{\mathrm{e}}$ & 25.8 & 16.9 & 65.5 & & 32.8 & - & - & & & - \\
\hline U.W. 101-1136 & - & - & - & - & - & - & - & 16.9 & 25.5 & 66.3 & - \\
\hline U.W. $101-938^{\mathrm{d}}$ & 25.9 & 22.0 & 16.0 & 72.7 & 112.0 & 28.1 & 1.59 & 15.9 & 19.6 & 81.1 & - \\
\hline U.W. $101-1000^{d}$ & 25.7 & 20.9 & 16.7 & 79.9 & 117.6 & - & - & 16.7 & 19.9 & - & - \\
\hline U.W. 101-1300 & 35.2 & - & - & - & - & - & - & - & - & - & - \\
\hline U.W. 101-1391 & & 21.7 & 17.5 & 80.7 & 118.0 & 27.4 & 1.29 & 18.8 & 23.9 & 78.7 & 108.6 \\
\hline U.W. 101-1434 & - & - & - & - & - & - & - & 15.4 & 19.1 & 80.6 & \\
\hline U.W. 101-1475 & - & - & - & - & - & - & - & 18.8 & 29.0 & 64.8 & 118.9 \\
\hline U.W. 101-1482 & & - & 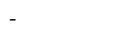 & - & - & - & - & 20.7 & 28.9 & 71.6 & H. \\
\hline U.W. $101-1555^{\mathrm{d}}$ & $24.3^{\mathrm{e}}$ & - & 14.3 & - & & - & - & - & 然 & - & - \\
\hline \multirow[t]{3}{*}{ Homo naled $t^{\circ}$} & $35.5 \pm 0.4$ & $23.3 \pm 1.8$ & $16.4 \pm 1.1$ & $70.7 \pm 7.0$ & $117.3 \pm 1.4$ & $31.1 \pm 3.1$ & $1.44 \pm 0.16$ & $18.8 \pm 1.8$ & $25.0 \pm 3.7$ & $75.7 \pm 6.8$ & $115.2 \pm 4.9$ \\
\hline & $35.2-35.8$ & $21.7-25.8$ & $15.0-17.5$ & $65.5-80.6$ & $115.7-118.2$ & $27.4-34.3$ & $1.29-1.60$ & $15.4-21.6$ & $19.1-31.4$ & $64.8-87.1$ & $108.6-118.9$ \\
\hline & $\begin{array}{l}(n=2) \\
45.5 \pm 5.6\end{array}$ & $\begin{array}{l}(n=4) \\
31.3 \pm 4.0\end{array}$ & $\begin{array}{l}(n=4) \\
25.5 \pm 3.7\end{array}$ & $\begin{array}{l}(n=4) \\
81.3 \pm 4.7\end{array}$ & $\begin{array}{l}(n=3) \\
119.0 \pm 4.3\end{array}$ & $\begin{array}{l}(n=4) \\
32 \pm 6.2\end{array}$ & $\begin{array}{l}(n=3) \\
0.92 \pm 0.18\end{array}$ & $\begin{array}{l}(n=11) \\
31.9 \pm 4.0\end{array}$ & $\begin{array}{l}(n=11) \\
383+48\end{array}$ & $\begin{array}{l}(n=11) \\
832+40\end{array}$ & $(n=4)$ \\
\hline \multirow{2}{*}{ Gorilla gorilla } & $\begin{array}{l}45.5 \pm 5.6 \\
36.5-54.7\end{array}$ & $\begin{array}{l}11.3 \pm 4.0 \\
24.2-39.1\end{array}$ & $\begin{array}{l}25.5 \pm 3.1 \\
17.1-33.0\end{array}$ & $\begin{array}{l}81.3 \pm 4.7 \\
70.6-92.6\end{array}$ & $\begin{array}{l}119.0 \pm 4.3 \\
111.6-127.3\end{array}$ & $\begin{array}{l}32 \pm 6.2 \\
21.6-48.9\end{array}$ & $\begin{array}{l}0.92 \pm 0.18 \\
0.54-1.44\end{array}$ & $\begin{array}{l}31.9 \pm 4.0 \\
24.7-39.3\end{array}$ & $\begin{array}{l}38.3 \pm 4.8 \\
29.3-45.9\end{array}$ & $\begin{array}{l}83.2 \pm 4.0 \\
76.5-93.8\end{array}$ & \\
\hline & $(n=47)$ & $(n=47)$ & $(n=47)$ & $(n=47)$ & $(n=20)$ & $(n=47)$ & $(n=47)$ & $(n=47)$ & $(n=47)$ & $(n=47)$ & \\
\hline & $33.5 \pm 2.1$ & $23.4 \pm 1.9$ & $20.0 \pm 1.3$ & $85.9 \pm 5.1$ & $124.1 \pm 4.6$ & $27.3 \pm 4.3$ & $1.08 \pm 0.20$ & $23.4 \pm 1.4$ & $27.7 \pm 1.9$ & $85.0 \pm 5.5$ & $77.5 \pm 11.9$ \\
\hline troglodytes & $\begin{array}{l}23.7-37.4 \\
(n=42)\end{array}$ & $\begin{array}{l}19.7-27.6 \\
(n=42)\end{array}$ & $\begin{array}{l}17.9-22.8 \\
(n=42)\end{array}$ & $\begin{array}{l}76.7-95.7 \\
(n=42)\end{array}$ & $\begin{array}{l}115-130.9 \\
(n=20)\end{array}$ & $\begin{array}{l}20.2-40 \\
(n=42)\end{array}$ & $\begin{array}{l}0.75-1.8 \\
(n=42)\end{array}$ & $\begin{array}{l}20.6-26.2 \\
(n=42)\end{array}$ & $\begin{array}{l}23.7-32.4 \\
(n=42)\end{array}$ & $\begin{array}{l}71.1-95.5 \\
(n=42)\end{array}$ & $\begin{array}{l}39.0-100.0 \\
(n=56)\end{array}$ \\
\hline \multirow{2}{*}{ Homo sapiens } & $43.0 \pm 4.3$ & $31.5 \pm 3.6$ & $25.9 \pm 3.4$ & $82.4 \pm 5.9$ & $124.4 \pm 3.8$ & $33.4 \pm 4.0$ & $1.17 \pm 0.14$ & $25.7 \pm 2.6$ & $31.9 \pm 3$ & $80.8 \pm 6.8$ & $83.2 \pm 16.6$ \\
\hline & $\begin{array}{l}32.1-52.4 \\
(n=195)\end{array}$ & $\begin{array}{l}23.7-40.8 \\
(n=170)\end{array}$ & $\begin{array}{l}17.2-34.0 \\
(n=170)\end{array}$ & $\begin{array}{l}63.9-104.3 \\
(n=170)\end{array}$ & $\begin{array}{l}114.0-132.0 \\
(n=100)\end{array}$ & $\begin{array}{l}23.5-42.8 \\
(n=83)\end{array}$ & $\begin{array}{l}0.85-1.51 \\
(n=83)\end{array}$ & $\begin{array}{l}19.7-32.8 \\
(n=195)\end{array}$ & $\begin{array}{l}23.4-39.3 \\
(n=195)\end{array}$ & $\begin{array}{l}56.1-96.6 \\
(n=195)\end{array}$ & $\begin{array}{l}34.0-129.5 \\
(n=105)\end{array}$ \\
\hline \multirow{3}{*}{ Australopithecus sp. ${ }^{\mathrm{f}}$} & $33.2 \pm 3.2$ & $25.5 \pm 3.2$ & $17.8 \pm 2.5$ & $69.6 \pm 6.9$ & $120.3 \pm 5.6$ & $34.3 \pm 7.6$ & $1.29 \pm 0.17$ & $22.4 \pm 3.8$ & $29.9 \pm 4.8$ & $74.8 \pm 3.5$ & $108.7 \pm 5.4$ \\
\hline & $28.6-40.2$ & $21.1-32.4$ & $13.8-24.9$ & $55.5-81.2$ & $112.5-134.0$ & $22.2-43.1$ & $1.12-1.59$ & $16.9-29.6$ & $21.8-38.9$ & $66.4-81.7$ & $104.0-116.3$ \\
\hline & $(n=25)$ & $(n=25)$ & $(n=25)$ & $(n=25)$ & $(n=14)$ & $(n=10)$ & $(n=8)$ & $(n=18)$ & $(n=19)$ & $(n=18)$ & \\
\hline \multirow[t]{2}{*}{ Hominin indet. ${ }^{g}$} & $34.4 \pm 1.9$ & $26.4 \pm 3.4$ & $17.0 \pm 2.3$ & $65.0 \pm 8.0$ & $117.7 \pm 4.6$ & $35.4 \pm 3.8$ & $1.43 \pm 0.15$ & $22.2 \pm 2.7$ & $28.9 \pm 1.95$ & $77.1 \pm 7.9$ & 122.8 \\
\hline & $\begin{array}{l}33-35.7 \\
(n=2)\end{array}$ & $\begin{array}{l}21.9-30 \\
(n=6)\end{array}$ & $\begin{array}{l}\begin{array}{l}15-20.5 \\
(n=6)\end{array} \\
\text { (n) }\end{array}$ & $\begin{array}{l}54.6-71.9 \\
(n=6)\end{array}$ & $\begin{array}{l}115-123 \\
(n=3)\end{array}$ & $\begin{array}{l}30.1-39.7 \\
(n=6)\end{array}$ & $\begin{array}{l}1.30-1.66 \\
(n=5)\end{array}$ & $\begin{array}{l}18.8-27.1 \\
(n=7)\end{array}$ & $\begin{array}{l}26.8-31.3 \\
(n=7)\end{array}$ & $\begin{array}{l}\begin{array}{l}61.4-86.6 \\
(n=7)\end{array} \\
\text { a }\end{array}$ & $(n=1)$ \\
\hline \multirow{2}{*}{ Early $\mathrm{Homo}^{\mathrm{h}}$} & $40.1 \pm 3.1$ & $26.4 \pm 2.8$ & $20.2 \pm 4.2$ & $83.4 \pm 2.7$ & $124 \pm 1.4$ & $36.4 \pm 1.8$ & $1.36 \pm 0.08$ & $22.5 \pm 1.6$ & $28.2 \pm 5.0$ & $81.6 \pm 12.3$ & $106.7 \pm 19.7$ \\
\hline & $\begin{array}{l}37-43.1 \\
(n=3)\end{array}$ & $\begin{array}{l}24-30.3 \\
(n=4)\end{array}$ & $\begin{array}{l}13.2-24.2 \\
(n=5)\end{array}$ & $\begin{array}{l}80.0-85.9 \\
(n=4)\end{array}$ & $\begin{array}{l}123-125 \\
(n=2)\end{array}$ & $\begin{array}{l}35.1-37.6 \\
(n=2)\end{array}$ & $\begin{array}{l}1.30-1.41 \\
(n=2)\end{array}$ & $\begin{array}{l}20.4-24.2 \\
(n=4)\end{array}$ & $\begin{array}{l}20.9-31.9 \\
(n=4)\end{array}$ & $\begin{array}{l}69.6-97.6 \\
(n=4)\end{array}$ & $\begin{array}{l}92.7-120.6 \\
(n=2)\end{array}$ \\
\hline \multirow[t]{3}{*}{ Homo erectusi } & $43.5 \pm 3.5$ & $30.6 \pm 2.2$ & $24.5 \pm 11.0$ & $78.5 \pm 1.3$ & 110 & 46.3 & 1.61 & $25.6 \pm 2.2$ & $35.7 \pm 2.7$ & $71.8 \pm 5.0$ & - \\
\hline & $41-46$ & $29-32.1$ & $13.4-39.3$ & $77.6-79.4$ & $(n-1)$ & $\mathrm{x}_{\mathrm{s}}$ & $(n-1)$ & $22.7-30.8$ & $32.2-39.9$ & $66.1-80.1$ & \\
\hline & $(n=2)$ & $(n=2)$ & $(n=2)$ & $(n=2)$ & $(n=1)$ & $(n=1)$ & $(n=1)$ & $(n=13)$ & $(n=13)$ & $(n=13)$ & \\
\hline \multirow[t]{2}{*}{ Middle Pleistocene Africa ${ }^{j}$} & $50.4 \pm 7.9$ & 41.4 & 39.3 & $84.6 \pm 8.9$ & 135 & $38.8 \pm 2.3$ & $1.07 \pm 0.12$ & $32.4 \pm 3.4$ & $40.8 \pm 0.07$ & $79.5 \pm 8.5$ & - \\
\hline & $\begin{array}{l}44.8-56.0 \\
(n=2)\end{array}$ & $(n=1)$ & $(n=1)$ & $\begin{array}{l}79.0-94.9 \\
(n=3)\end{array}$ & $(n=1)$ & $\begin{array}{l}37.2-40.4 \\
(n=2)\end{array}$ & $\begin{array}{l}0.99-1.15 \\
(n=2)\end{array}$ & $\begin{array}{l}30-34.8 \\
(n=2)\end{array}$ & $\begin{array}{l}40.7-40.8 \\
(n=2)\end{array}$ & $\begin{array}{l}73.5-85.5 \\
(n=2)\end{array}$ & \\
\hline
\end{tabular}

${ }^{a}$ Fossil measurements taken on high quality casts and original specimens. Linear measurements are in $\mathrm{mm}$, angular measurements are in degrees. Measurements are represented by mean \pm std.dev., range, and sample size 
$1576 \quad{ }^{\mathrm{b}}$ Neck length from intertrochanteric crest to the lateral edge of the head

'Minimum head diame

'Mature specimens: U.W. 101-002, U.W. 101-018, U.W. 101-271, U.W. 101-398, U.W. 101-421, U.W. 101-938, U.W. 101-1136, U.W. 101-1300, U.W. 101-1391, U.W. 101-1434, U.W. 101-1475, U.W. 101-1482

'Includes specimens commonly classified as Paranthropus: U.W.88-51 (MH2), U.W. 88-4,5,39 (MH1), A.L. 128-1, A.L.152-2, A.L.211-1, A.L. 288-1, A.L. 333-3, A.L.333-95, A.L.333-131, A.L.827-1, MAK-VP 1/1, BOU-VP-12/1, KNM-WT 16002, MLD 46, Sts 14, StW 25, StW 99, StW 361, StW 392, StW 403, StW 479, StW 501, StW 522, StW 527, StW 598, SK 82, SK 97, SK 14024, SKX 3121, SKX 19, SWT1/LB-2, OH 20, OH 80, KNM-ER 1500, KNM-ER 1503, KNM-ER 1505

KNM-ER 738, KNM-ER 815, KNM-ER 1463, KNM-ER 1465, KNM-ER 1809, KNM-ER 3728, KNM-ER 5880, StW 311

KNM-ER 1472, KNM-ER 147, KNM-ER 1481, KNM-ER 5881, OH 62

28, BOU-VP 1775, BOU-VP 19/63, Peking 1, Peking 4, Trinil 2, Trinil 3, Trinil 4, KNM-WT 15000

Berg Aukas, KNM-ER 999, Kabwe 
Table 5. Comparative tibia dimensions. ${ }^{\text {a }}$

\begin{tabular}{|c|c|c|c|c|c|c|c|c|c|c|c|c|c|c|}
\hline \multirow[t]{2}{*}{ Specimen/Species } & \multicolumn{6}{|c|}{ Diaphysis } & \multicolumn{2}{|c|}{ Distal Metaphysis } & \multicolumn{6}{|c|}{ Talar Articular Surface } \\
\hline & $\begin{array}{l}\text { ML at } \\
\text { nutrient } \\
\text { foramen }\end{array}$ & $\begin{array}{l}\text { AP at } \\
\text { nutrient } \\
\text { foramen }\end{array}$ & $\begin{array}{l}\text { Platycnemic } \\
\text { index at } \\
\text { nutrient } \\
\text { foramen } \\
\text { (ML/AP) } \times 100 \\
\end{array}$ & $\begin{array}{l}\text { Midshaft } \\
\text { ML }\end{array}$ & $\begin{array}{l}\text { Midshaft } \\
\text { AP }\end{array}$ & $\begin{array}{l}\text { Midshaft } \\
\text { index } \\
\text { (ML/AP) }) \\
100\end{array}$ & $\mathrm{AP}$ & $\mathrm{ML}$ & AP lateral & $\begin{array}{l}\text { AP } \\
\text { midpoint }\end{array}$ & AP medial & $\begin{array}{l}\mathrm{ML} \\
\text { anterior }\end{array}$ & $\begin{array}{l}\text { ML } \\
\text { midpoint }\end{array}$ & $\begin{array}{l}\text { ML } \\
\text { posterior }\end{array}$ \\
\hline U.W. $101-420$ & & & & & & & 30.3 & & 20.0 & 19.5 & 17.2 & & 19.4 & - \\
\hline U.W. 101-484 & 18.0 & 27.1 & 66.4 & 17.6 & 25.0 & 70.4 & - & - & - & - & - & - & - & - \\
\hline U.W. 101-711 & & & & - & - & - & 29.5 & - & - & - & - & - & - & - \\
\hline U.W. 101-973 & 18.0 & 27.1 & 66.4 & - & - & - & & & - & - & - & - & - & - \\
\hline U.W. 101-996 & 14.7 & 21.3 & 69.0 & - & - & - & 19.8 & 21.2 & - & - & - & - & - & - \\
\hline U.W. $101-1070^{b}$ & 14.3 & 21.3 & 67.1 & 14.1 & 20.0 & 70.5 & - & 21.7 & - & 15.4 & 14.1 & - & - & - \\
\hline U.W. 101-1262 & & & - & & & & & & & & 14.1 & & & \\
\hline U.W. 101-1416 & - & - & - & - & - & - & 25.4 & - & 15.4 & - & & 18.7 (est.) & 17.1 & 15.0 \\
\hline Homo naledi ${ }^{c}$ & $\begin{array}{l}18.0 \\
18.0-18.0 \\
(n=2)\end{array}$ & $\begin{array}{l}27.1 \\
27.1-27.1 \\
(n=2)\end{array}$ & $\begin{array}{l}66.4 \\
66.4-66.4 \\
(n=2)\end{array}$ & $\begin{array}{l}17.6 \\
(n=1)\end{array}$ & $\begin{array}{l}25.0 \\
(n=1)\end{array}$ & $\begin{array}{l}70.4 \\
(n=1)\end{array}$ & $\begin{array}{l}28.4 \pm 2.6 \\
25.4-30.3 \\
(n=3)\end{array}$ & - & $\begin{array}{l}17.7 \\
15.4-20.0 \\
(n=2)\end{array}$ & $\begin{array}{l}19.5 \\
(n=1)\end{array}$ & $\begin{array}{l}15.7 \\
14.1-17.2 \\
(n=2)\end{array}$ & $\begin{array}{l}18.7 \\
(n=1)\end{array}$ & $\begin{array}{l}18.3 \\
17.1-19.4 \\
(n=2)\end{array}$ & $\begin{array}{l}15.0 \\
(n=1)\end{array}$ \\
\hline Gorilla gorilla & $\begin{array}{l}24.1 \pm 1.1 \\
23-25.5\end{array}$ & $\begin{array}{l}35.8 \pm 4.0 \\
28.4-40\end{array}$ & $\begin{array}{l}67.9 \pm 7.5 \\
58.1-81.1\end{array}$ & $\begin{array}{l}23.7 \pm 2.2 \\
20.6-25.8\end{array}$ & $\begin{array}{l}31.7 \pm 4.0 \\
25.1-37.1\end{array}$ & $\begin{array}{l}75.2 \pm 6.1 \\
68.3-82.9\end{array}$ & $\begin{array}{l}28 \pm 4.6 \\
20.1-38.1\end{array}$ & $\begin{array}{l}44.1 \pm 7 \\
31.3-56.8\end{array}$ & $\begin{array}{l}24.7 \pm 3.1 \\
18.5-30.5\end{array}$ & $\begin{array}{l}27.7 \pm 3.7 \\
22.0-36.0\end{array}$ & $\begin{array}{l}26.4 \pm 3.3 \\
18-32.5\end{array}$ & $\begin{array}{l}38.7 \pm 4.5 \\
30.3-45.7\end{array}$ & $\begin{array}{l}29 \pm 3.8 \\
23.8-37.2\end{array}$ & $\begin{array}{l}21.6 \pm 3.3 \\
15.5-30.1\end{array}$ \\
\hline & $\begin{array}{l}25-25.5 \\
(n=6)\end{array}$ & $\begin{array}{l}28.4-40 \\
(n=6)\end{array}$ & 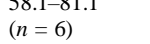 & $\begin{array}{l}l 0.6-25.8 \\
(n=6\end{array}$ & $\begin{array}{l}25.1-3 / .1 \\
(n=6)\end{array}$ & 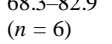 & $\begin{array}{l}l 0.1-38.1 \\
(n=44)\end{array}$ & $\begin{array}{l}(n=44)-56.8 \\
(n=44)\end{array}$ & $\begin{array}{l}\text { (8.5-30.5 } \\
(n=44)\end{array}$ & $\begin{array}{l}(n=44) \\
(n=40.0\end{array}$ & $\begin{array}{l}(n=44) \\
(n=43.5\end{array}$ & $\begin{array}{l}50.3-4 ., \\
(n=44)\end{array}$ & $\begin{array}{l}23.0-3,2 \\
(n=44)\end{array}$ & $\begin{array}{l}(n=44) \\
(n=30.1\end{array}$ \\
\hline Pan troglodytes & $18.0 \pm 2.0$ & $28.1 \pm 3.5$ & $64.3 \pm 5.5$ & $16.6 \pm 1.5$ & $24.4 \pm 2.9$ & $68.3 \pm 6.4$ & $21.1 \pm 1.8$ & $30.6 \pm 3.1$ & $19.2 \pm 1.6$ & $20.8 \pm 1.9$ & $18.7 \pm 1.7$ & $27.3 \pm 2.1$ & $21.4 \pm 1.5$ & $17.6 \pm 1.7$ \\
\hline & $\begin{array}{l}14.7-20.3 \\
(n=10)\end{array}$ & $\begin{array}{l}23.8-33.2 \\
(n=10)\end{array}$ & $\begin{array}{l}55.7-73.0 \\
(n=10)\end{array}$ & $\begin{array}{l}14.8-19.3 \\
(n=10)\end{array}$ & $\begin{array}{l}20.3-29.3 \\
(n=1)\end{array}$ & $57.6-77.2$ & $\begin{array}{l}17.6-25.9 \\
(n-49)\end{array}$ & $\begin{array}{l}25.1-40 \\
(n-49)\end{array}$ & $16.3-21.6$ & $16.7-24.5$ & $\begin{array}{l}15.2-22 \\
(n=49)\end{array}$ & $24.3-35.9$ & $18.5-27$ & $14.3-21$ \\
\hline Homo sapiens & $\begin{array}{l}(n=10) \\
23.1 \pm 3.1\end{array}$ & $\begin{array}{l}(n=10) \\
30.7 \pm 4.4\end{array}$ & $\begin{array}{l}(n=10) \\
75.2 \pm 5.2\end{array}$ & $\begin{array}{l}(n=10) \\
22 / 4 \pm 2.4\end{array}$ & $\begin{array}{l}(n=10) \\
30.6 \pm 2.4\end{array}$ & $\begin{array}{l}(n=10) \\
73.4 \pm 6.1\end{array}$ & $\begin{array}{l}(n=49) \\
30.9 \pm 3.6\end{array}$ & $\begin{array}{l}(n=49) \\
37.6 \pm 3.9\end{array}$ & $\begin{array}{l}(n=49) \\
28.4 \pm 2.6\end{array}$ & $\begin{array}{l}(n=49) \\
27.0 \pm \pm 2.6\end{array}$ & $\begin{array}{l}(n=49) \\
23.7 \pm 2.2\end{array}$ & $\begin{array}{l}(n=49) \\
31.9+2.8\end{array}$ & $\begin{array}{l}(n=49) \\
28.4 \pm 2.4\end{array}$ & $\begin{array}{l}(n=49) \\
25+22\end{array}$ \\
\hline & $19.2-29.5$ & $25.2-39.4$ & $64.8-84.7$ & $18-26.7$ & $23.2-34.6$ & $64.3-86.9$ & $23.2-40$ & $29.3-46.8$ & $22.9-24.9$ & $21.8-35$ & $18.7-30.1$ & $25.5-38.8$ & $23.2-34.7$ & $20.3-31.4$ \\
\hline & $(n=23)$ & $\begin{array}{l}(n=23) \\
(n)\end{array}$ & $(n=23)$ & $(n=23)$ & $(n=23)$ & $(n=23)$ & $(n=79)$ & $(n=79)$ & $(n=145)$ & $(n=145)$ & $(n=145)$ & $(n=145)$ & $(n=145)$ & $(n=145)$ \\
\hline Australopithecus & $15.0 \pm 0.5$ & $22.5 \pm 0.1$ & 66.7 & - & (2) & - & $26.7 \pm 3.6$ & $30.1 \pm 3.5$ & $21 \pm 2.5$ & $20.1 \pm 2.3$ & $17.4 \pm 1.7$ & $22.7 \pm 2.9$ & $20.1 \pm 2.9$ & $18.8 \pm 2.6$ \\
\hline sp. ${ }^{d}$ & $14.7-15.3$ & $\begin{array}{l}22.4-22.5 \\
(n=2)\end{array}$ & $\begin{array}{l}64.7-68.4 \\
(n=2)\end{array}$ & & & & $\begin{array}{l}21.3-33.4 \\
(n=10)\end{array}$ & $\begin{array}{l}24.5-35.6 \\
(n=10)\end{array}$ & $\begin{array}{l}18.6-25 \\
(n=11)\end{array}$ & $\begin{array}{l}17.2-23.9 \\
(n=10)\end{array}$ & $\begin{array}{l}14.6-20.4 \\
(n=11)\end{array}$ & $\begin{array}{l}19.2-28.3 \\
(n=12)\end{array}$ & $\begin{array}{l}17.2-25.4 \\
(n=13)\end{array}$ & $\begin{array}{l}14.4-23.2 \\
(n=12)\end{array}$ \\
\hline Early Homo $^{\circ}$ & $\begin{array}{l}(n=2) \\
15.6\end{array}$ & $\begin{array}{l}(n=2) \\
25.5\end{array}$ & $\begin{array}{l}(n=2) \\
61.2\end{array}$ & 14.5 & 22.2 & 65.3 & $\begin{array}{l}n=10) \\
29.6 \pm 5.3\end{array}$ & $\begin{array}{l}(n=10) \\
32.7 \pm 8.1\end{array}$ & $\begin{array}{l}n=11) \\
22.7 \pm 2.4\end{array}$ & $\begin{array}{l}(n=10) \\
20.5 \pm 3.9\end{array}$ & $\begin{array}{l}(n=11) \\
19.3 \pm 2.6\end{array}$ & $\begin{array}{l}(n=12) \\
24.8 \pm 3.0\end{array}$ & $\begin{array}{l}(n=13) \\
23.0 \pm 3.0\end{array}$ & $\begin{array}{l}(n=12) \\
18.8 \pm 3.0\end{array}$ \\
\hline Earry пото & $(n=1)$ & $(n=1)$ & $\begin{array}{l}01.2 \\
(n=1)\end{array}$ & $(n=1)$ & $(n=1)$ & $(n=1)$ & $\begin{array}{l}27-38.4 \\
(n=3)\end{array}$ & $\begin{array}{l}27.0-38.4 \\
(n=2)\end{array}$ & $\begin{array}{l}20.1-24.9 \\
(n=3)\end{array}$ & $\begin{array}{l}16.3-24.0 \\
(n=3)\end{array}$ & $\begin{array}{l}16.4-21.3 \\
(n=3)\end{array}$ & $\begin{array}{l}21.6-27.4 \\
(n=3)\end{array}$ & $\begin{array}{l}19.8-25.7 \\
(n=3)\end{array}$ & $\begin{array}{l}16.5-22.2 \\
(n=3)\end{array}$ \\
\hline Homo erectus ${ }^{f}$ & $\begin{array}{l}23.0 \\
(n=1)\end{array}$ & $\begin{array}{l}32.0 \\
(n=1)\end{array}$ & $\begin{array}{l}71.2 \\
(n=1)\end{array}$ & $\begin{array}{l}19.7 \pm 1.2 \\
18.0-20.4 \\
(n=4)\end{array}$ & $\begin{array}{l}26.0 \pm 2.2 \\
24.0-28.6 \\
(n=4)\end{array}$ & $\begin{array}{l}76.2 \pm 9.3 \\
66.7-85.0 \\
(n=4)\end{array}$ & $\begin{array}{l}35.7 \\
(n=1)\end{array}$ & $\begin{array}{l}35.3 \pm 0.8 \\
34.7-35.8 \\
(n=2)\end{array}$ & $\begin{array}{l}31.5 \pm 0.4 \\
31.2-31.7 \\
(n=2)\end{array}$ & $\begin{array}{l}28.9 \pm 1.1 \\
28.1-29.7 \\
(n=2)\end{array}$ & $\begin{array}{l}25.3 \pm 2.2 \\
23.7-26.8 \\
(n=2)\end{array}$ & $\begin{array}{l}30.7 \pm 1.9 \\
29.3-32.0 \\
(n=2)\end{array}$ & $\begin{array}{l}27.4 \pm 0.9 \\
26.8-28.0 \\
(n=2)\end{array}$ & $\begin{array}{l}25.9 \pm 0.5 \\
25.5-26.2 \\
(n=2)\end{array}$ \\
\hline
\end{tabular}

${ }^{\mathrm{a}}$ Measurements taken on high quality casts and original specimens. Linear measurements are in $\mathrm{mm}$. Measurements are represented by mean \pm std.dev., range, and sample size.

"Mature specimens: U.W. 101-420, U.W. 101-484, U.W. 101-711, U.W. 101-973, U.W. 101-1262, U.W. 101-1416

${ }^{d}$ Includes specimens commonly classified as Paranthropus: A.L 288-1 AQ, A.L 129-1b, A.L 333-6, A.L. 333-7, A.L. 545-3 from Ward et al., 2012, KNM-KP 29285, StW 181, StW 358, StW 389, StW 515, U.W. 88-21 (MH4), U.W. 88-97 (MH2), KNM-ER 1500, KNM-ER 2596 OH35a, KNM-ER 1481; StW 567

'D3901 from Lordkipanidze et al., 2007, KNM-ER 741, KNM-ER 803b, KNM-WT 15000 
1601 Table 6. Comparative fibula dimensions.

\begin{tabular}{|c|c|c|c|c|c|c|c|c|c|}
\hline Specimen/Species & Neck ML & Neck AP & $\begin{array}{l}\text { Neck robusticity } \\
\text { (ML/AP) } \times 100^{b, c}\end{array}$ & Midshaft ML & Midshaft AP & $\begin{array}{l}\text { Midshaft } \\
\text { robusticity } \\
(\text { ML/AP) } \times 100\end{array}$ & $\begin{array}{l}\text { Angle between } \\
\text { STS and } \\
\text { fibulotalar } \\
\text { surface }^{d}\end{array}$ & $\begin{array}{l}\text { Area of } \\
\text { proximal } \\
\text { portion } \\
\text { fibulotalar } \\
\text { articulation } \\
\end{array}$ & $\begin{array}{l}\text { Area of distal } \\
\text { portion } \\
\text { fibulotalar } \\
\text { articulation }\end{array}$ \\
\hline U.W. 101-702 & 7.5 & 7.7 & 97.4 & - & - & - & - & - & - \\
\hline U.W. 101-925 & 5.3 & 7.3 & 72.6 & - & - & - & - & - & - \\
\hline U.W. 101-1037 & 7.0 & 7.2 & 97.4 & 8.1 & 9.8 & 82.2 & - & - & - \\
\hline U.W. 101-1113 & 6.9 & 7.1 & 97.2 & - & - & - & - & - & - \\
\hline U.W. 101-1143 & 7.8 & 8.2 & 95.1 & - & - & - & - & - & - \\
\hline U.W. 101-1254 & 8.0 & 10.2 & 78.4 & - & - & - & - & - & - \\
\hline U.W. 101-1437 & - & - & - & - & - & - & 36 & 113.6 & 43.6 \\
\hline U.W. 101-1451 & 6.9 & 7.0 & 98.6 & - & - & - & - & - & - \\
\hline U.W. 101-1679 & 7.6 & 8.4 & 86.0 & - & - & - & - & - & - \\
\hline U.W. 101-1701 & - & - & - & - & - & - & - & - & 41.3 \\
\hline Homo naledi $i^{e}$ & $\begin{array}{l}7.1 \pm 0.9 \\
5.3-8.0 \\
(n=8)\end{array}$ & $\begin{array}{l}7.9 \pm 1.1 \\
7.0-10.2 \\
(n=8)\end{array}$ & $\begin{array}{l}89.9 \pm 10.3 \\
72.6-98.6 \\
(n=8)\end{array}$ & $\begin{array}{l}8.1 \\
(n=1)\end{array}$ & $\begin{array}{l}9.8 \\
(n=1)\end{array}$ & $\begin{array}{l}82.2 \\
(n=1)\end{array}$ & $\begin{array}{l}36.0 \\
(n=1)\end{array}$ & $\begin{array}{l}113.6 \\
(n=1)\end{array}$ & $\begin{array}{l}42.5 \\
41.3-43.6 \\
(n=2)\end{array}$ \\
\hline Gorilla gorilla & $\begin{array}{l}12.9 \pm 2.5 \\
9.3-16.0 \\
(n=7)\end{array}$ & $\begin{array}{l}17.0 \pm 2.4 \\
12.5-19.6 \\
(n=7)\end{array}$ & $\begin{array}{l}75.8 \pm 8.2 \\
65.6-88.1 \\
(n=7)\end{array}$ & $\begin{array}{l}12.4 \pm 1.3 \\
9.9-13.6 \\
(n=7)\end{array}$ & $\begin{array}{l}15.5 \pm 2.3 \\
12.1-17.9 \\
(n=7)\end{array}$ & $\begin{array}{l}80.8 \pm 8.6 \\
68.9-94.5 \\
(n=7)\end{array}$ & $\begin{array}{l}57.1 \pm 7.7 \\
42.6-70.2 \\
(n=11)\end{array}$ & $\begin{array}{l}279.6 \pm 76.3 \\
169.7-451.6 \\
(n=27)\end{array}$ & $\begin{array}{l}97.2 \pm 35.9 \\
46.1-177.7 \\
(n=27)\end{array}$ \\
\hline Pan troglodytes & $\begin{array}{l}8.6 \pm 2.5 \\
4.6-12.5 \\
(n=10)\end{array}$ & $\begin{array}{l}12.2 \pm 2.4 \\
6.8-15.2 \\
(n=10)\end{array}$ & $\begin{array}{l}71.8 \pm 22.3 \\
37.9-108.7 \\
(n=10)\end{array}$ & $\begin{array}{l}9.6 \pm 1.5 \\
6.8-11.9 \\
(n=10)\end{array}$ & $\begin{array}{l}13.0 \pm 2.3 \\
7.4-15.3 \\
(n=10)\end{array}$ & $\begin{array}{l}74.9 \pm 10.0 \\
58.1-92.6 \\
(n=10)\end{array}$ & $\begin{array}{l}49.3 \pm 9.1 \\
29.4-65.6 \\
(n=17)\end{array}$ & $\begin{array}{l}154.0 \pm 34.1 \\
88.4-236.0 \\
(n=29)\end{array}$ & $\begin{array}{l}45.5 \pm 16.5 \\
12.6-88.2 \\
(n=29)\end{array}$ \\
\hline Australopithecus sp. ${ }^{\mathrm{f}}$ & $\begin{array}{l}9.2 \pm 1.6 \\
8.4-10.0 \\
(n=2)\end{array}$ & $\begin{array}{l}9.8 \pm 2.6 \\
8.0-11.6 \\
(n=2)\end{array}$ & $\begin{array}{l}95.7 \\
86.3-105.0 \\
(n=2)\end{array}$ & $\begin{array}{l}11.9 \\
(n=1)\end{array}$ & $\begin{array}{l}11.1 \\
(n=1)\end{array}$ & $\begin{array}{l}106.9 \\
(n=1)\end{array}$ & $\begin{array}{l}37.6 \pm 3.4 \\
34.0-42.0 \\
(n=5)\end{array}$ & $\begin{array}{l}141.5 \pm 18.4 \\
111.0-159.6 \\
(n=5)\end{array}$ & $\begin{array}{l}21.0 \pm 11.2 \\
3.7-33.7 \\
(n=5)\end{array}$ \\
\hline Early Homo ${ }^{\mathrm{g}}$ & $\begin{array}{l}9.1 \\
(n=1)\end{array}$ & $\begin{array}{l}8.2 \\
(n=1)\end{array}$ & $\begin{array}{l}111.1 \\
(n=1)\end{array}$ & $\begin{array}{l}11.0 \\
(n=1)\end{array}$ & $\begin{array}{l}11.8 \\
(n=1)\end{array}$ & $\begin{array}{l}93.4 \\
(n=1)\end{array}$ & - & - & - \\
\hline Homo erectus ${ }^{\mathrm{h}}$ & $\begin{array}{l}5.9 \pm 0.4 \\
5.6-6.1 \\
(n=2)\end{array}$ & $\begin{array}{l}10.0 \pm 0.1 \\
9.9-10.1 \\
(n=2)\end{array}$ & $\begin{array}{l}58.5 \pm 2.7 \\
56.6-60.4 \\
(n=2)\end{array}$ & $\begin{array}{l}9.0 \pm 0.1 \\
8.9-9.1 \\
(n=2)\end{array}$ & $\begin{array}{l}11.5 \pm 1.4 \\
10.5-12.5 \\
(n=2)\end{array}$ & $\begin{array}{l}78.9 \pm 10.9 \\
71.2-86.7 \\
(n=2)\end{array}$ & - & - & - \\
\hline
\end{tabular}

beasurements taken on high quality casts or original specimens unless noted otherwise.

1605 Linear measurements are in $\mathrm{mm}$, areas in $\mathrm{mm}^{2}$, angular measurements are in degrees. Measurements are represented by mean \pm std.dev., range, and sample size.

STS: subcutaneous triangular surface. Angle measured following indications in Marchi (2015).

Mature specimens: U.W. 101-702, U.W. 101-925, U.W. 101-1037, U.W. 101-1113, U.W. 101-1143, U.W. 101-1254, U.W. 101-1437, U.W. 101-1451, U.W. 101-1679, U.W. 101-1701

${ }^{\mathrm{I}}$ Includes

$1609{ }^{\mathrm{h}}$ KNM-WT 15000 (juvenile) 
1611 Table 4. Comparative patella dimensions. ${ }^{a}$

\begin{tabular}{|c|c|c|c|c|}
\hline Specimen/Species & ML width & SI height & AP thickness & $\mathrm{AP} / \mathrm{ML} \times 100$ \\
\hline U.W. 101-852 & - & - & 18.3 & - \\
\hline U.W. 101-1404 & 30.0 & - & 16.2 & 54.0 \\
\hline U.W. 101-1639 & - & - & 14.9 (min) & - \\
\hline \multirow[t]{3}{*}{ Gorilla gorilla } & $38.1 \pm 5.0$ & $35.6 \pm 4.4$ & $16.8 \pm 2.4$ & $44.1 \pm 2.4$ \\
\hline & $32.3-46.4$ & $30.3-42.1$ & $13.5-20$ & $41.4-47.9$ \\
\hline & $(n=10)$ & $(n=10)$ & $(n=10)$ & $(n=10)$ \\
\hline \multirow[t]{3}{*}{ Pan troglodytes } & $24.4 \pm 1.6$ & $26.2 \pm 2.4$ & $10.2 \pm 1.5$ & $42.0 \pm 5.8$ \\
\hline & $21.5-26.3$ & $24.2-30.8$ & $8.4-12.2$ & $35.3-49.4$ \\
\hline & $(n=9)$ & $(n=9)$ & $(n=9)$ & $(n=9)$ \\
\hline \multirow[t]{3}{*}{ Homo sapiens } & $37.7 \pm 4.1$ & $36.8 \pm 4.3$ & $18.1 \pm 1.8$ & $48.0 \pm 3.3$ \\
\hline & $32.0-52.2$ & $31.7-54.5$ & $14.3-22$ & $41.6-55.7$ \\
\hline & $(n=53)$ & $(n=37)$ & $(n=53)$ & $(n=53)$ \\
\hline Australopithecus sediba ${ }^{\mathrm{b}}$ & 26.8 & 24.7 & 13.1 & 48.9 \\
\hline Australopithecus robustus ${ }^{\mathrm{c}}$ & 30.1 & - & 13.3 & 44.2 \\
\hline Homo floresiensis ${ }^{\mathrm{d}}$ & 30.7 & 32.3 & 12.2 & 39.7 \\
\hline \multirow[t]{3}{*}{ Homo antecessor } & $36.2 \pm 0.35$ & $37.0 \pm 0.14$ & $19.2 \pm 0.28$ & $53.0 \pm 0.99$ \\
\hline & $36.1-36.3$ & $36.7-37.2$ & $19.0-19.4$ & $52.3-53.7$ \\
\hline & $(n=2)$ & $(n=2)$ & $(n=2)$ & $(n=2)$ \\
\hline \multirow[t]{3}{*}{ Homo heidelbergensis ${ }^{\mathrm{e}}$} & $47.9 \pm 3.0$ & $43.7 \pm 2.0$ & $23.1 \pm 1.7$ & $48.2 \pm 1.2$ \\
\hline & $42.6-51.3$ & $40.6-46.6$ & $20.0-25.0$ & $46.9-50.0$ \\
\hline & $(n=5)$ & $(n=5)$ & $(n=5)$ & $(n=5)$ \\
\hline \multirow[t]{3}{*}{ Homo neanderthalensis ${ }^{\mathrm{e}}$} & $47.2 \pm 4.2$ & $43.5 \pm 3.9$ & $22.7 \pm 3.2$ & $48.3 \pm 2.6$ \\
\hline & $39.0-56.5$ & $36.0-51.0$ & $17.0-28.5$ & $43.6-53.5$ \\
\hline & $(n=14)$ & $(n=15)$ & $(n=13)$ & $(n=12)$ \\
\hline
\end{tabular}

$1612{ }^{a}$ Measurements taken on original specimens unless noted otherwise.

$1613 \quad{ }^{\mathrm{b}}$ U.W. 88-79,100

$1614 \quad{ }^{\mathrm{c}} \mathrm{SKX} 1084$

$1615{ }^{\mathrm{d}} \mathrm{LB} 1 / 10, \mathrm{LB} 1 / 11$.

1616 e Data from Carretero et al. (1999) 
Table 7. Phenetic comparisons of postcranial morphology in Australopithecus and early Homo. ${ }^{\text {a }}$

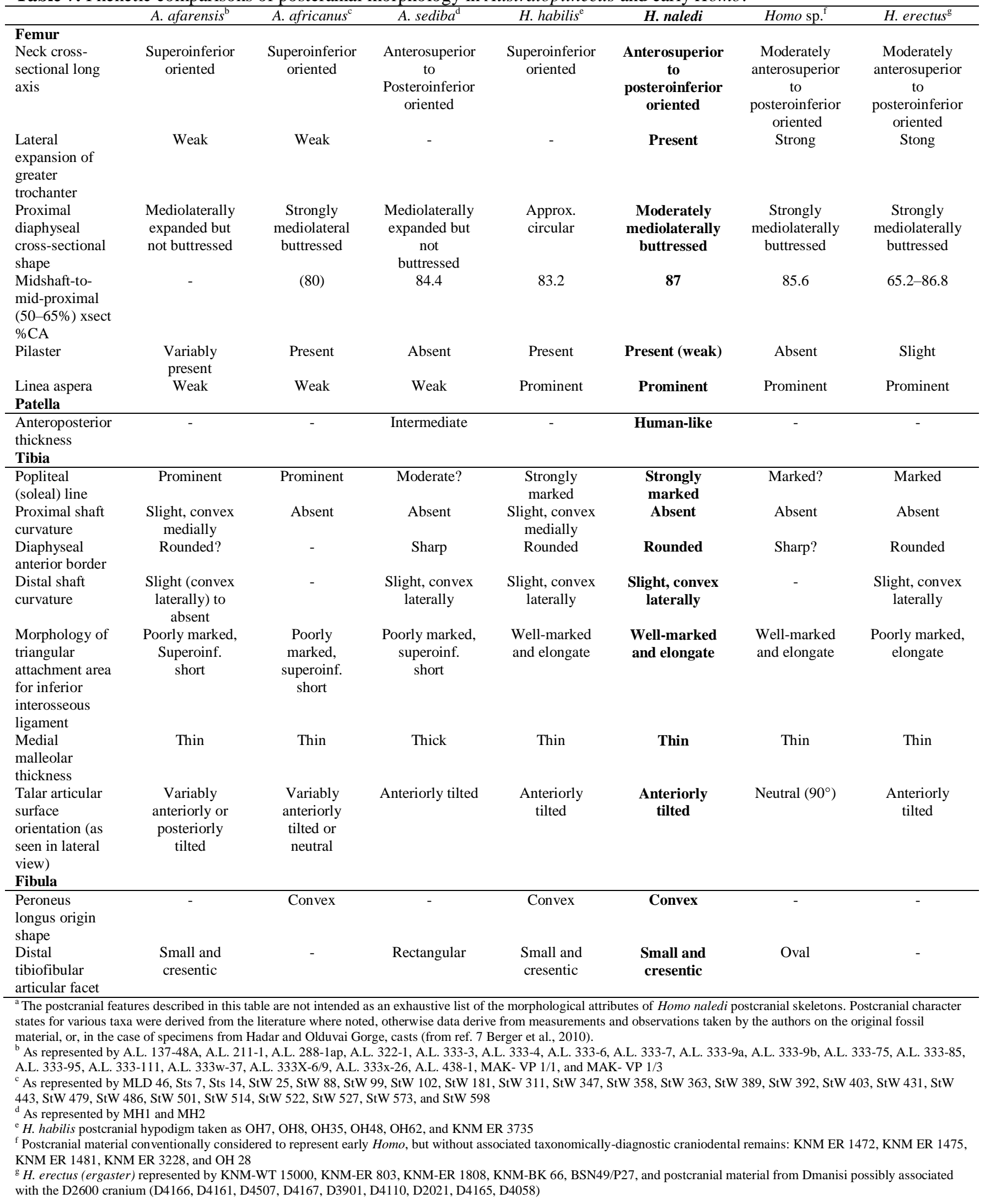


Table 8. Summary thigh and leg morphology of Homo naledi. ${ }^{\text {a }}$

\begin{tabular}{|c|c|c|c|}
\hline Traits & Femur and Patella & Tibia & Fibula \\
\hline Homo-like & $\begin{array}{l}\text { - Long neck } \\
\text { - Strong insertion of m. } \\
\text { gluteus maximus } \\
\text { - Well-marked linea aspera } \\
\text { - Distal shaft waisting } \\
\text { - AP thick patella }\end{array}$ & $\begin{array}{l}\text { - Relatively (to femoral } \\
\text { head size) long }\end{array}$ & $\begin{array}{l}\text { - Gracile fibula } \\
\text { - Laterally oriented lateral } \\
\text { malleoli }\end{array}$ \\
\hline Australopith-like & $\begin{array}{l}\text { - AP compressed, SI tall } \\
\text { and anteverted neck }\end{array}$ & $\begin{array}{l}\text { - ML compressed } \\
\text { - Large proximal } \\
\text { attachment for m. tibialis } \\
\text { posterior }\end{array}$ & $\begin{array}{l}\text { - Circular neck } \\
\text { - Convex surface for } \\
\text { attachment of mperoneus } \\
\text { brevis }\end{array}$ \\
\hline Unique & $\begin{array}{l}\text { - Two bony pillars on the } \\
\text { superior aspect of the } \\
\text { neck }\end{array}$ & $\begin{array}{l}\text { - Strong pes anserinus } \\
\text { attachment }\end{array}$ & \\
\hline
\end{tabular}

${ }^{\mathrm{a}} \mathrm{AP}=$ anteroposterior, $\mathrm{SI}=$ superoinferior, $\mathrm{ML}=$ mediolateral 
Figure 1
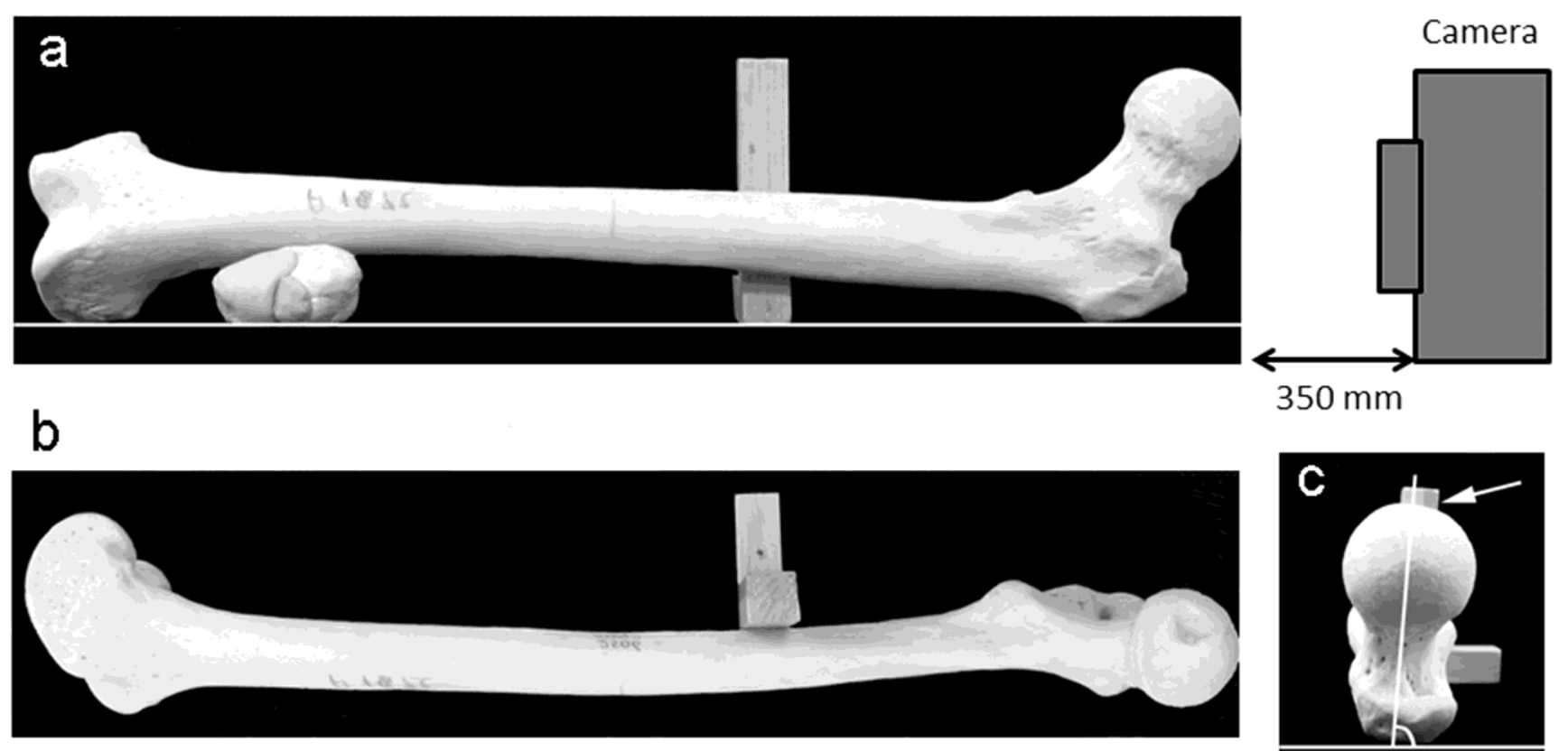

$350 \mathrm{~mm}$

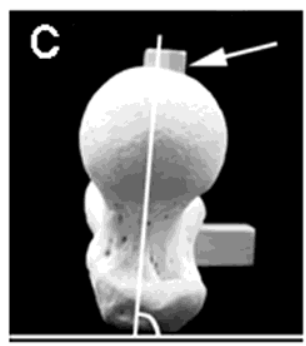


Figure 2

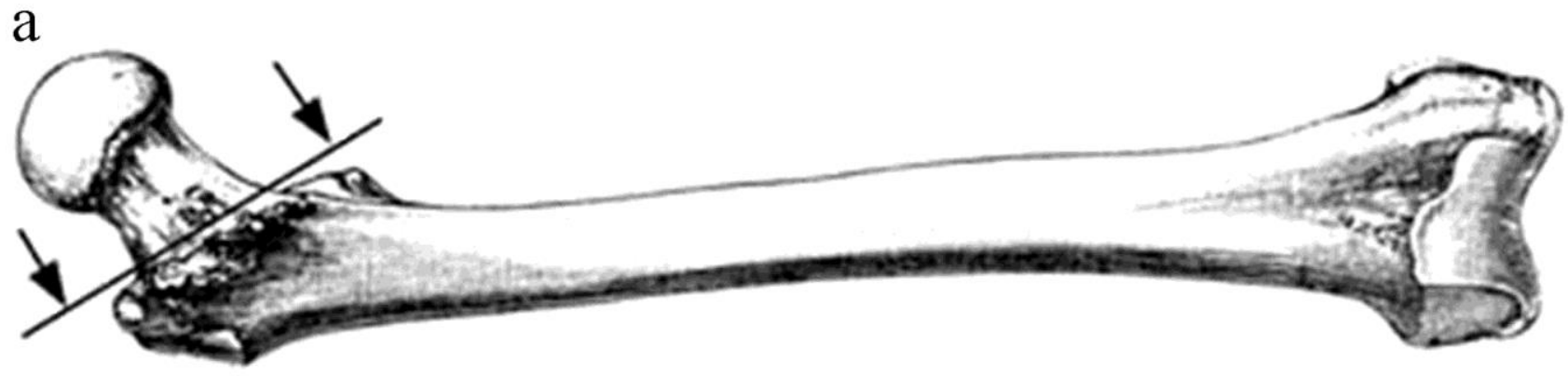

b

Sup.

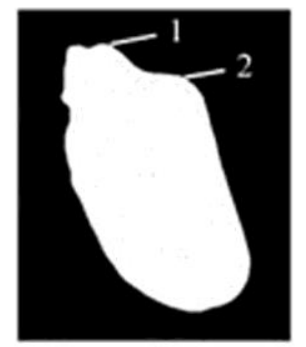

U.W. 101-002

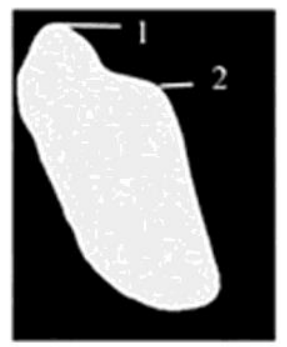

U.W. 101-398*

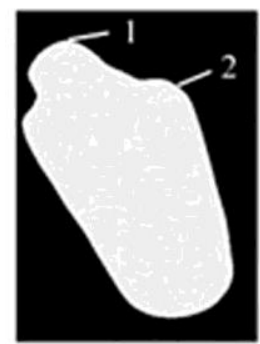

U.W. 101-1391

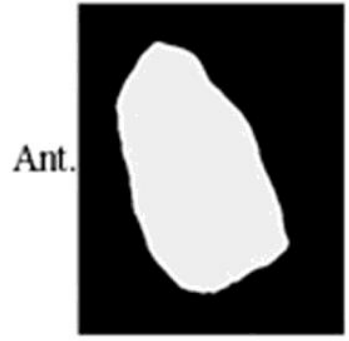

A.L. $333-3$

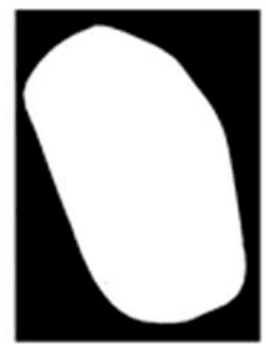

KNM-ER 1481* KNM-ER 3728*

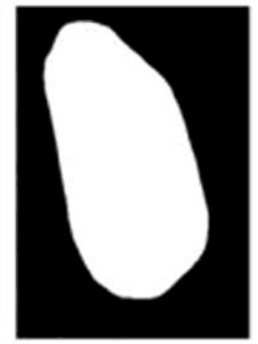

A.L. $333-95$

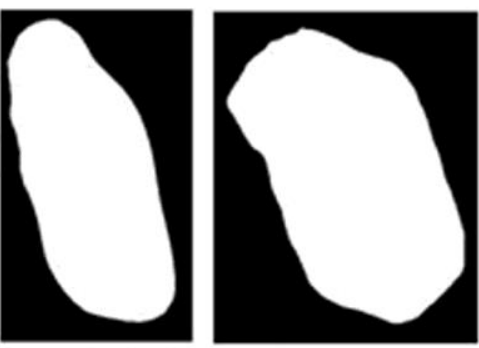

KNM-ER 738*

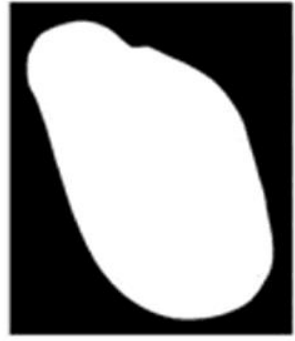

U.W. 88-4 (MH1)

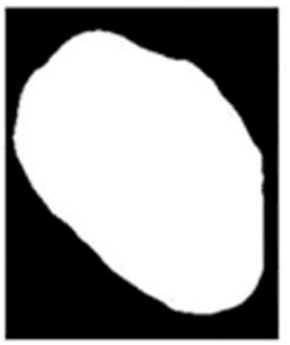

KNM-ER 1472 Inf.

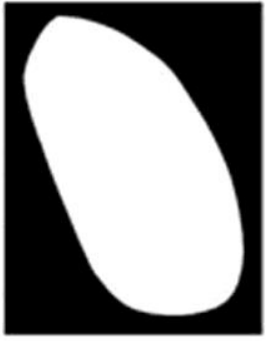

SK82

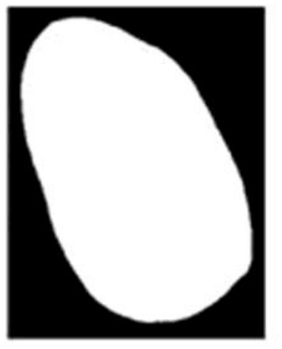

Pan troglodytes

Homo sapiens

${ }^{*}$ Mirrored images 
Figure 3

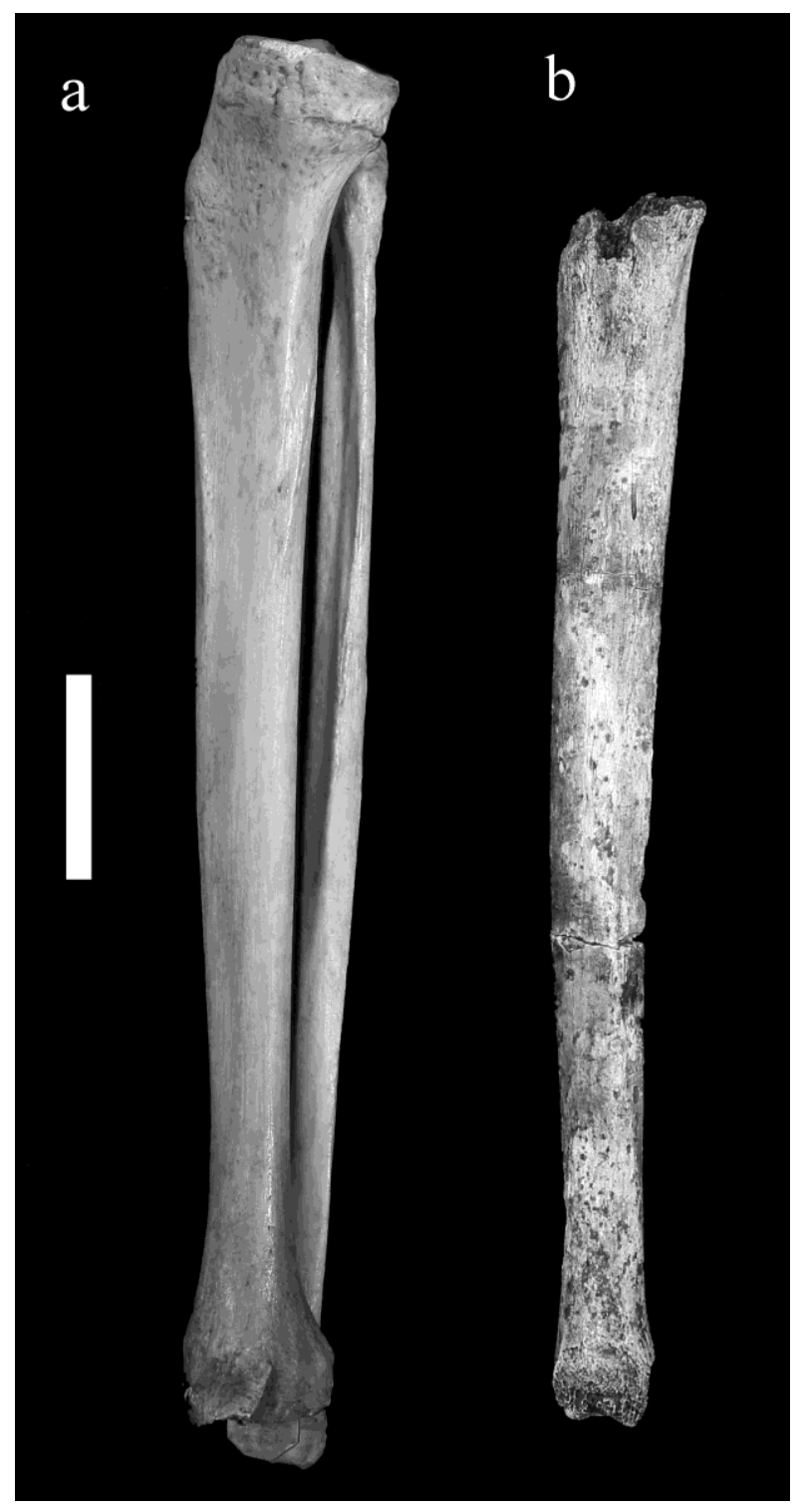


Figure 4

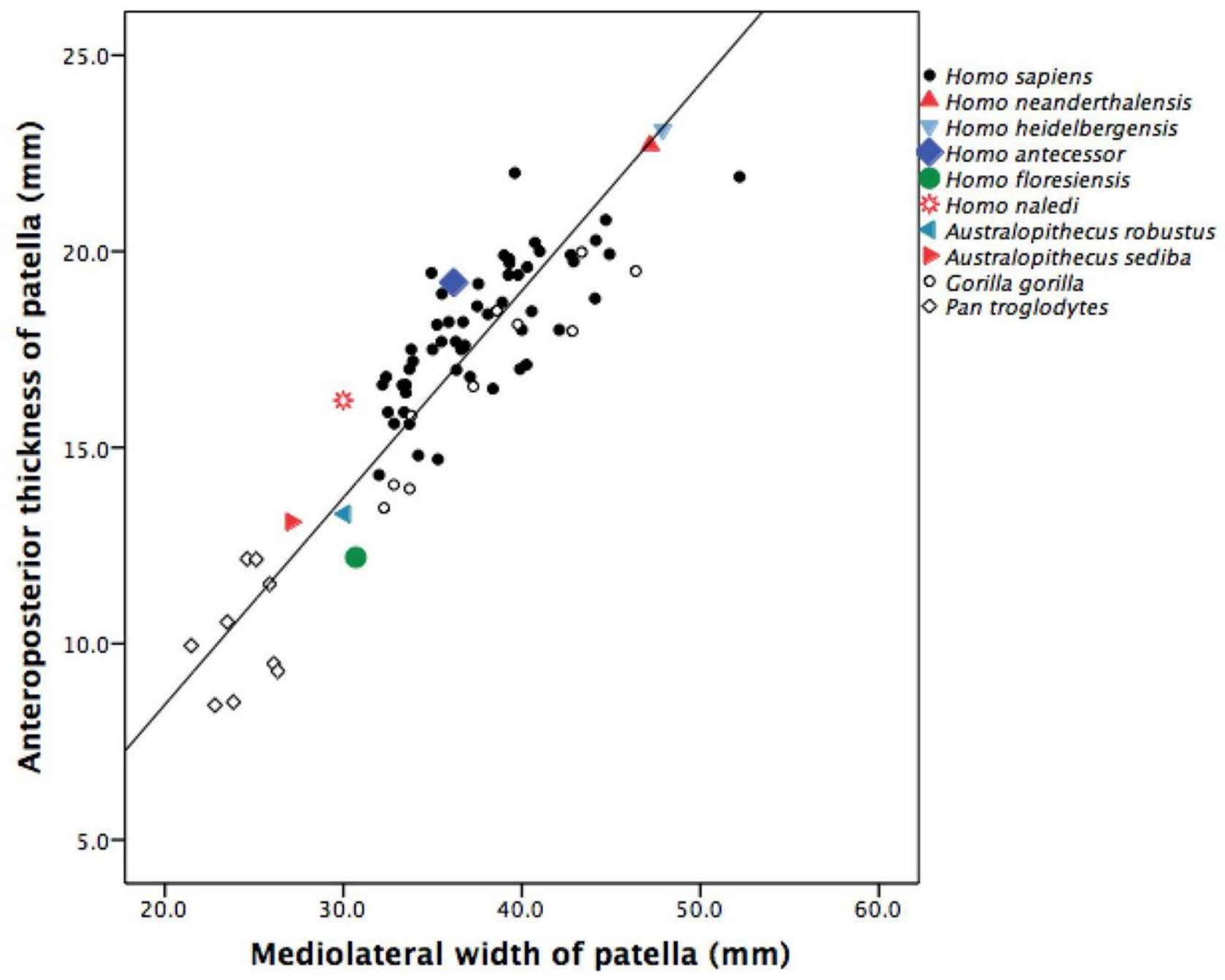




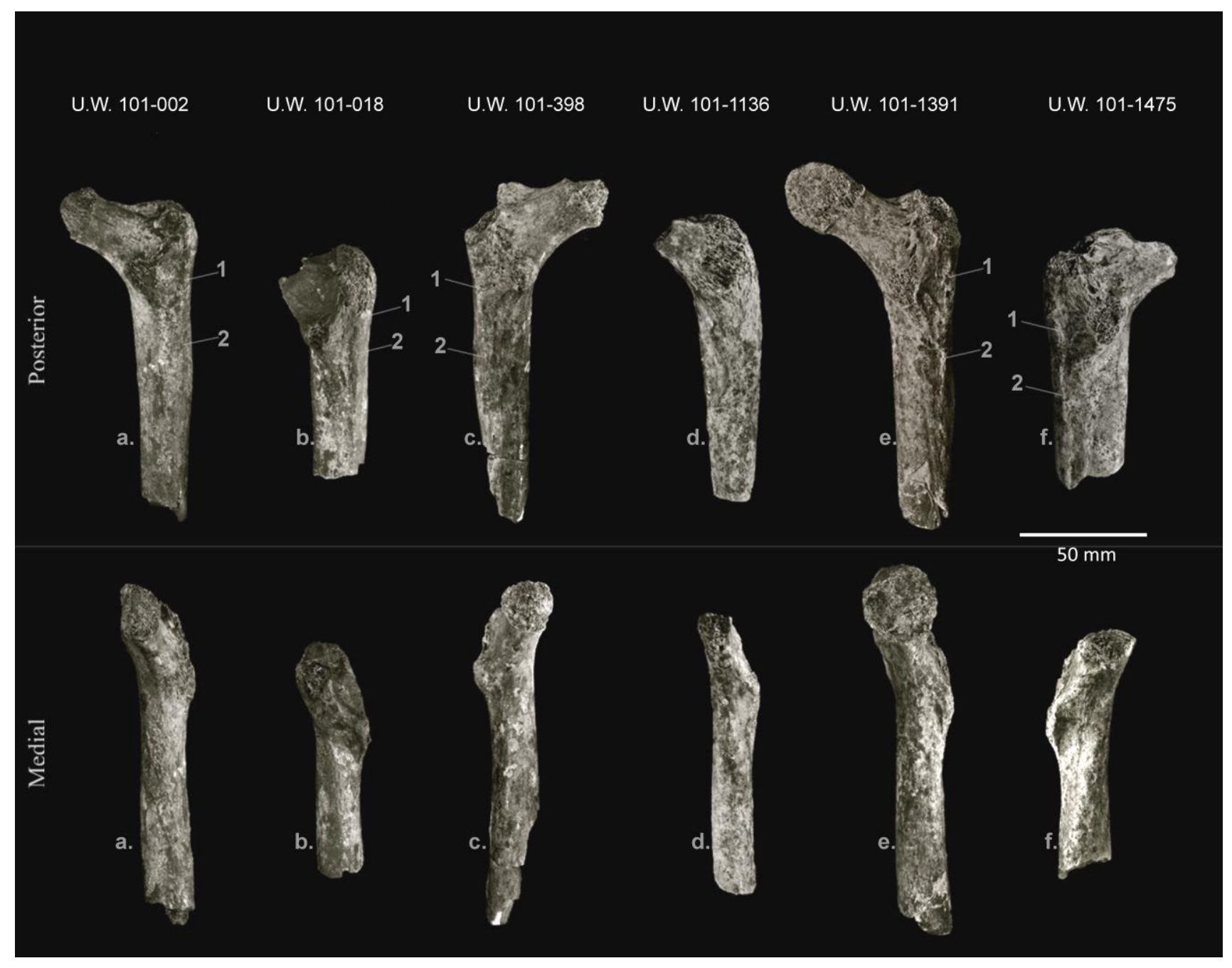


Figure 5

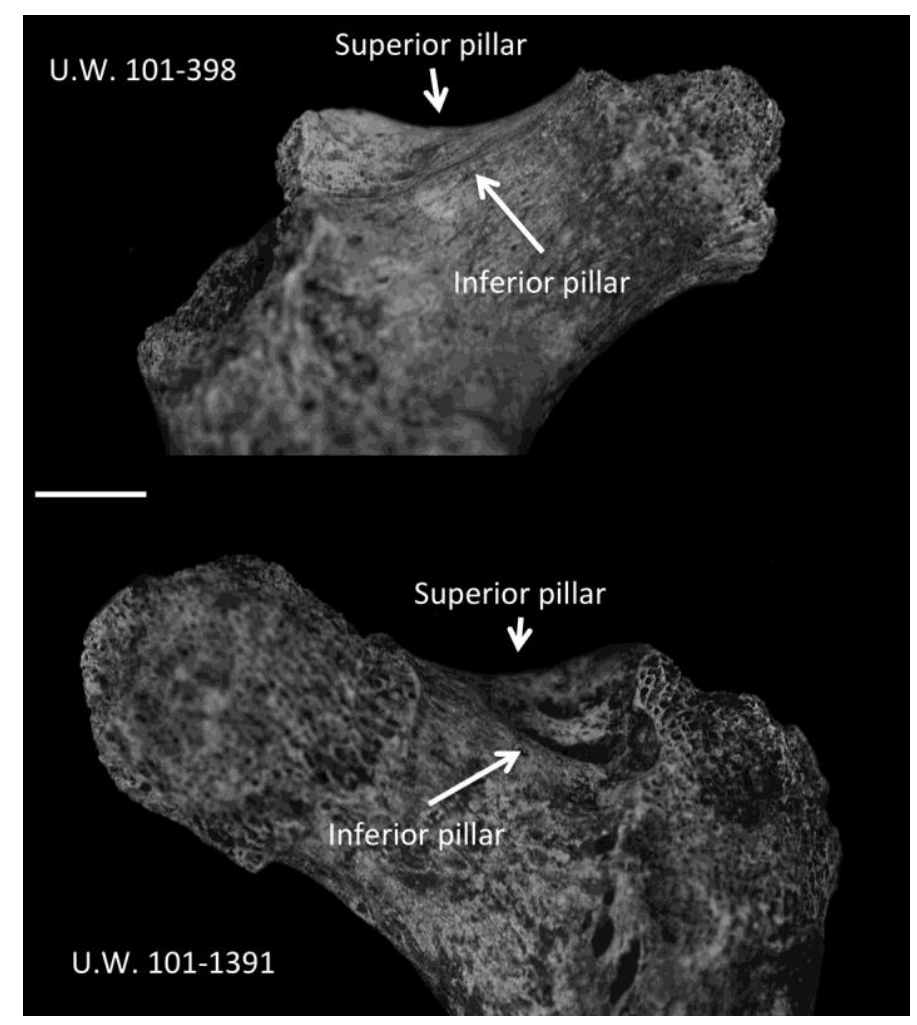


Figure 6

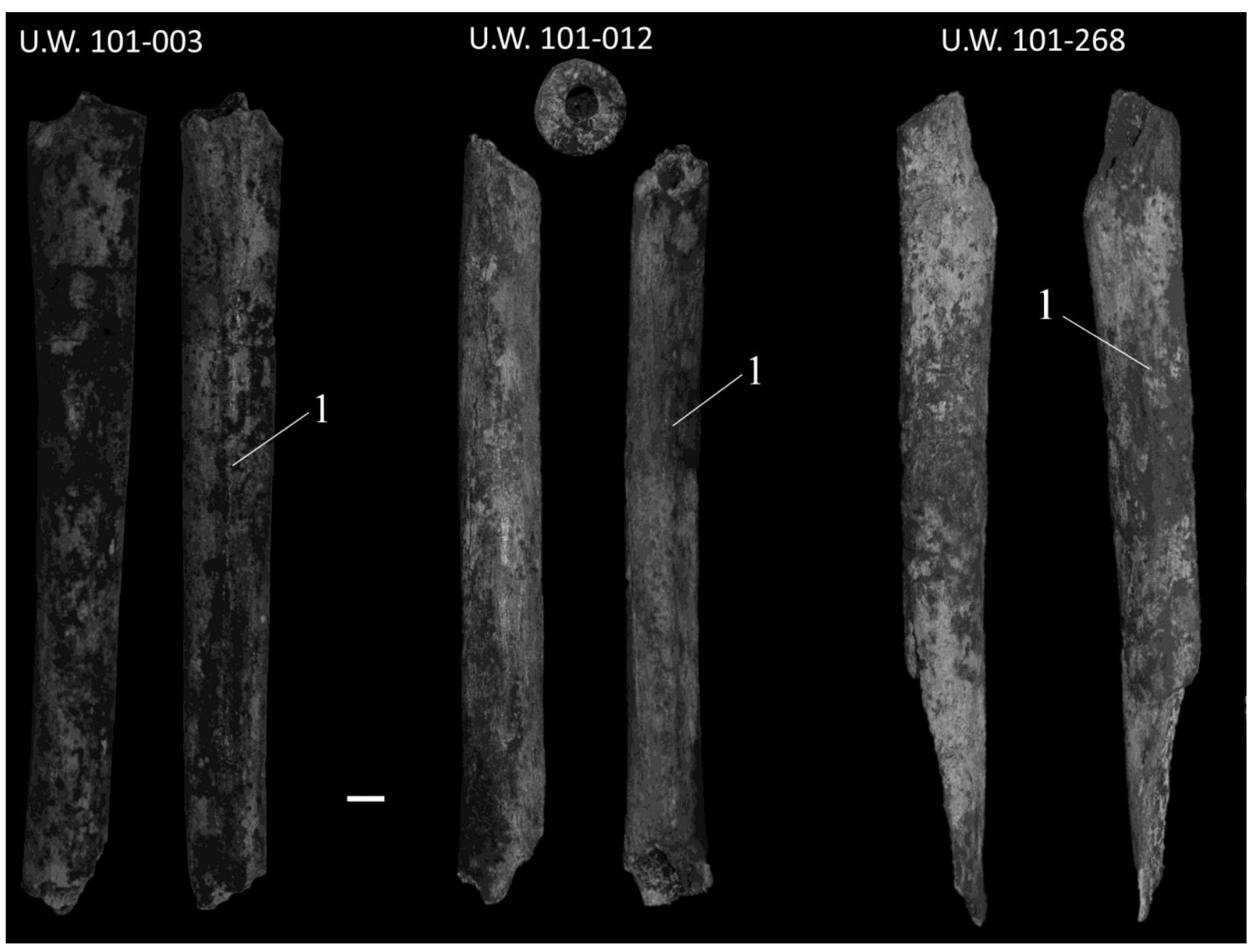


Figure 7

U.W. 101-018

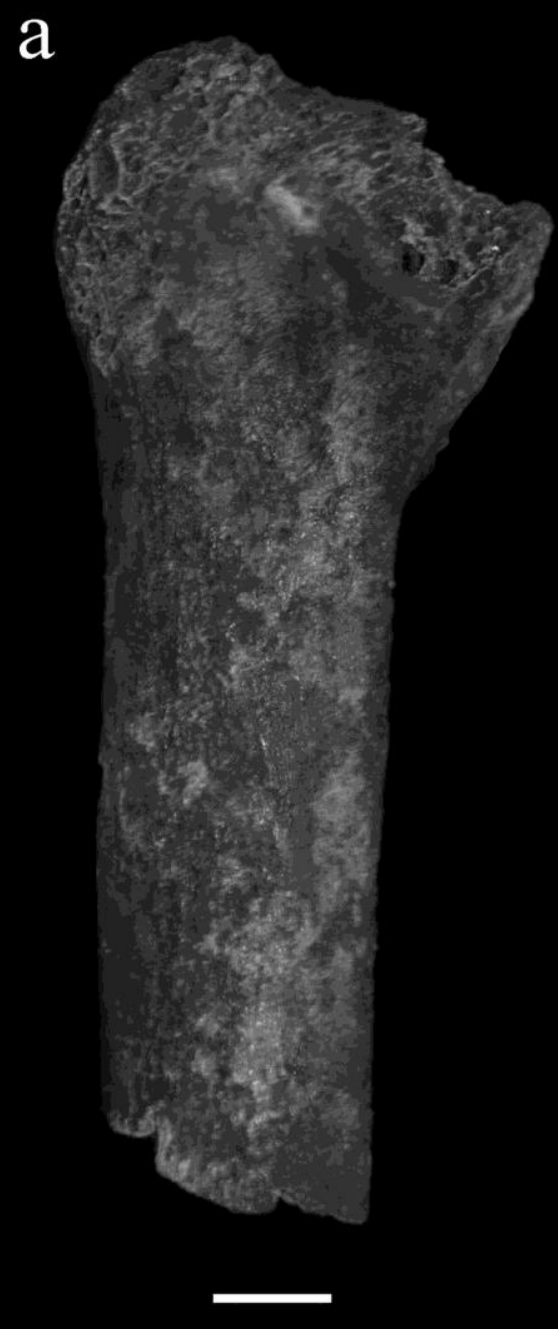

b

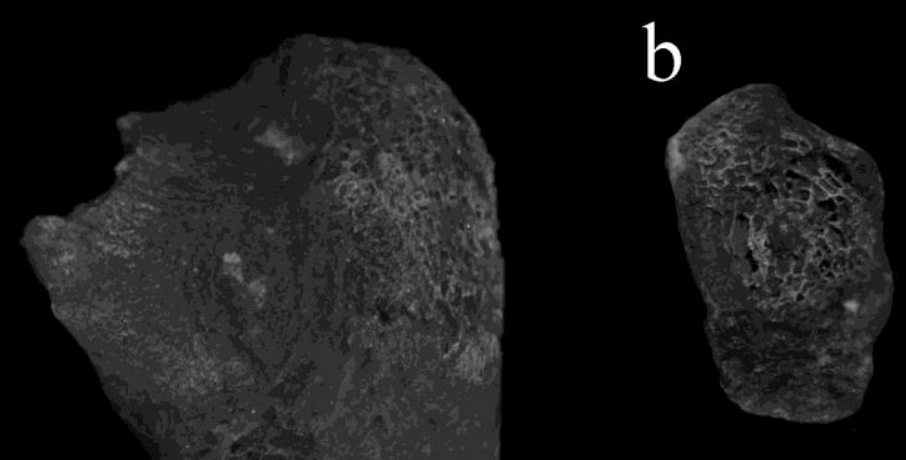

c

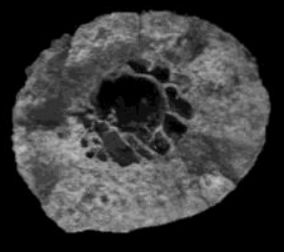


Figure 8

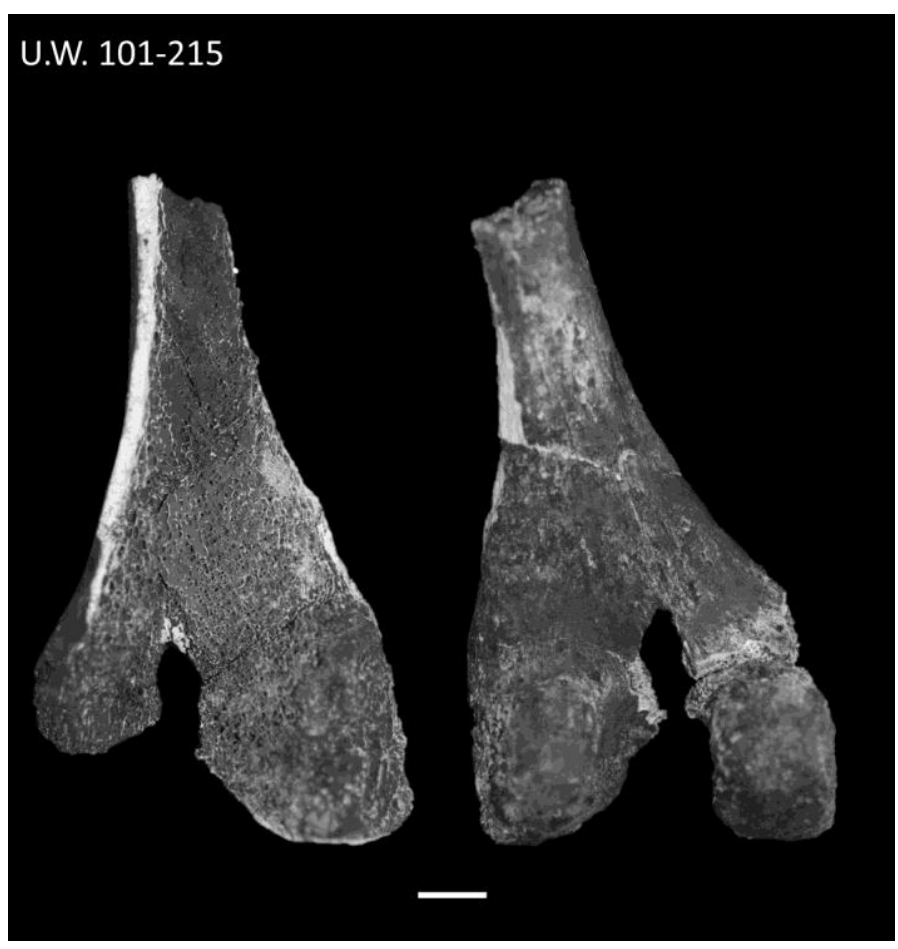


Figure 9

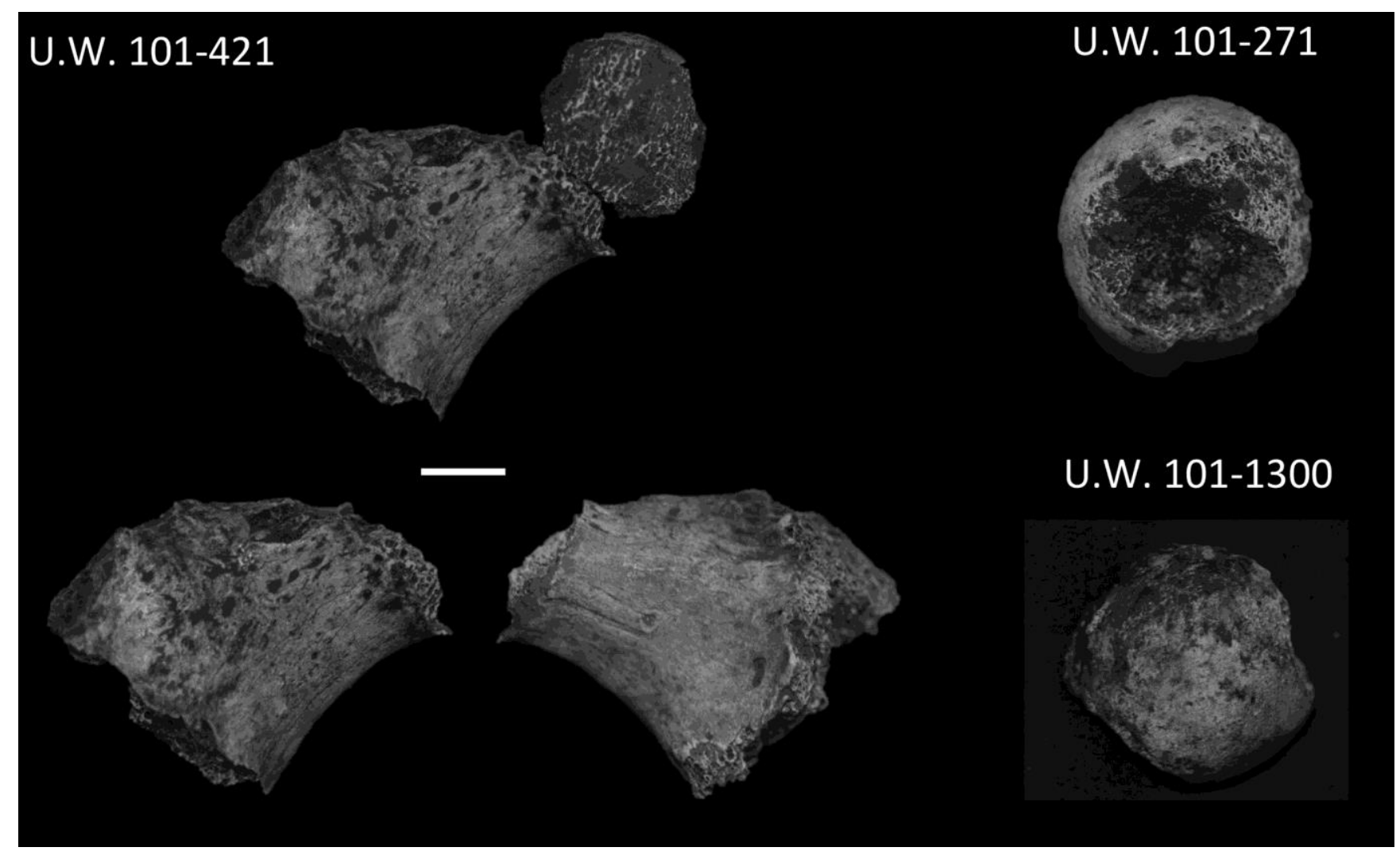


Figure 10

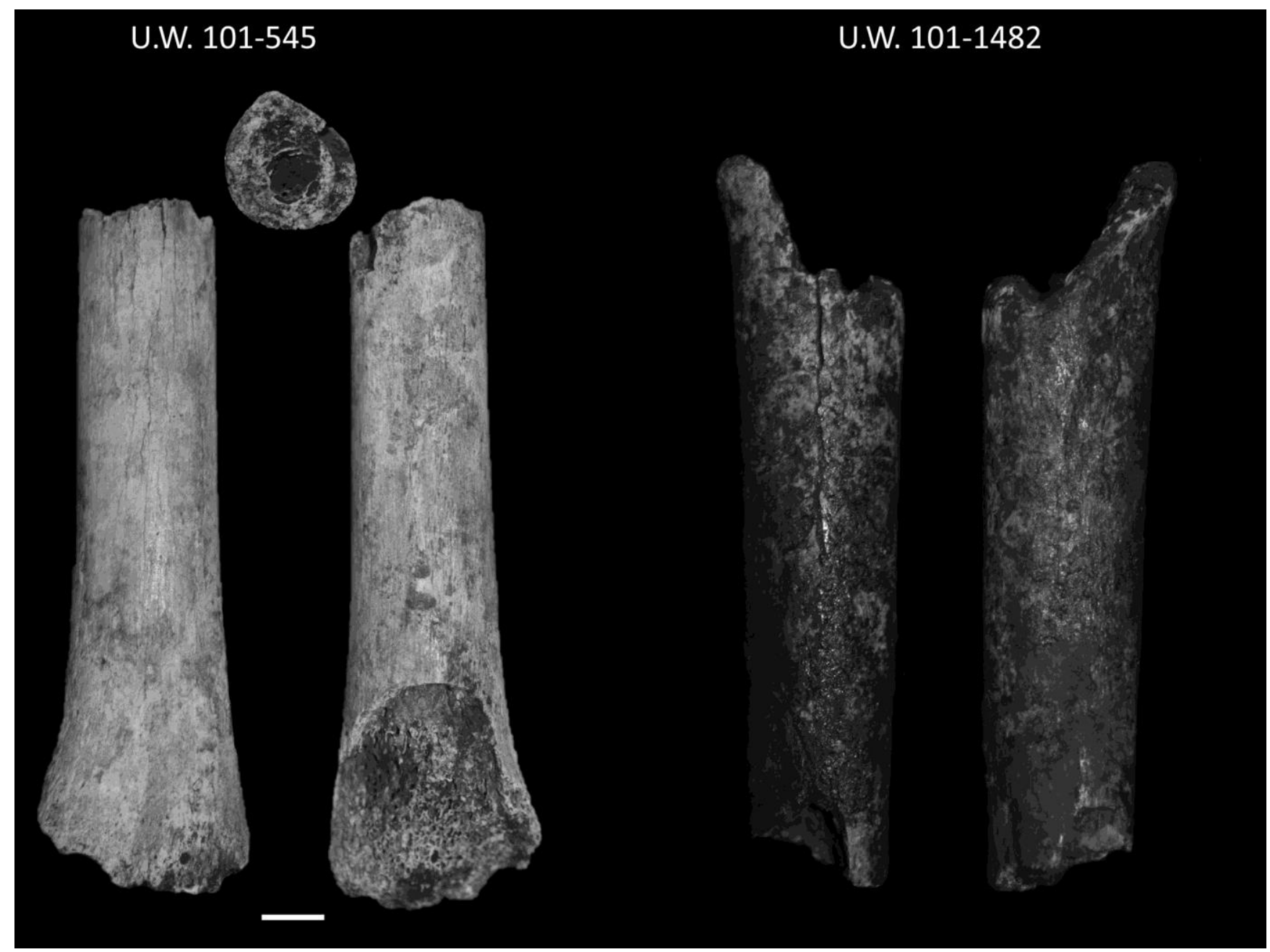


Figure 11

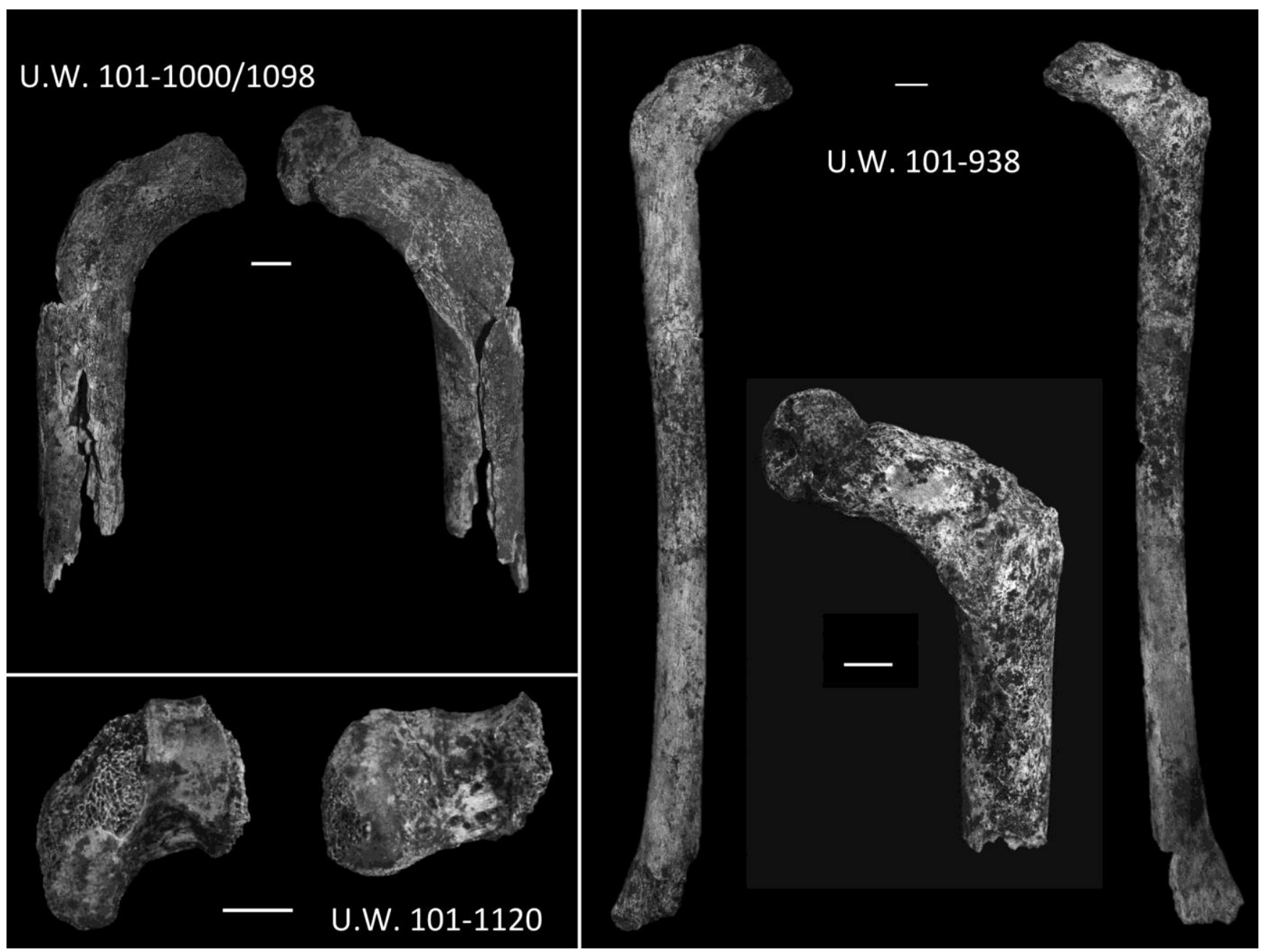


Figure 12

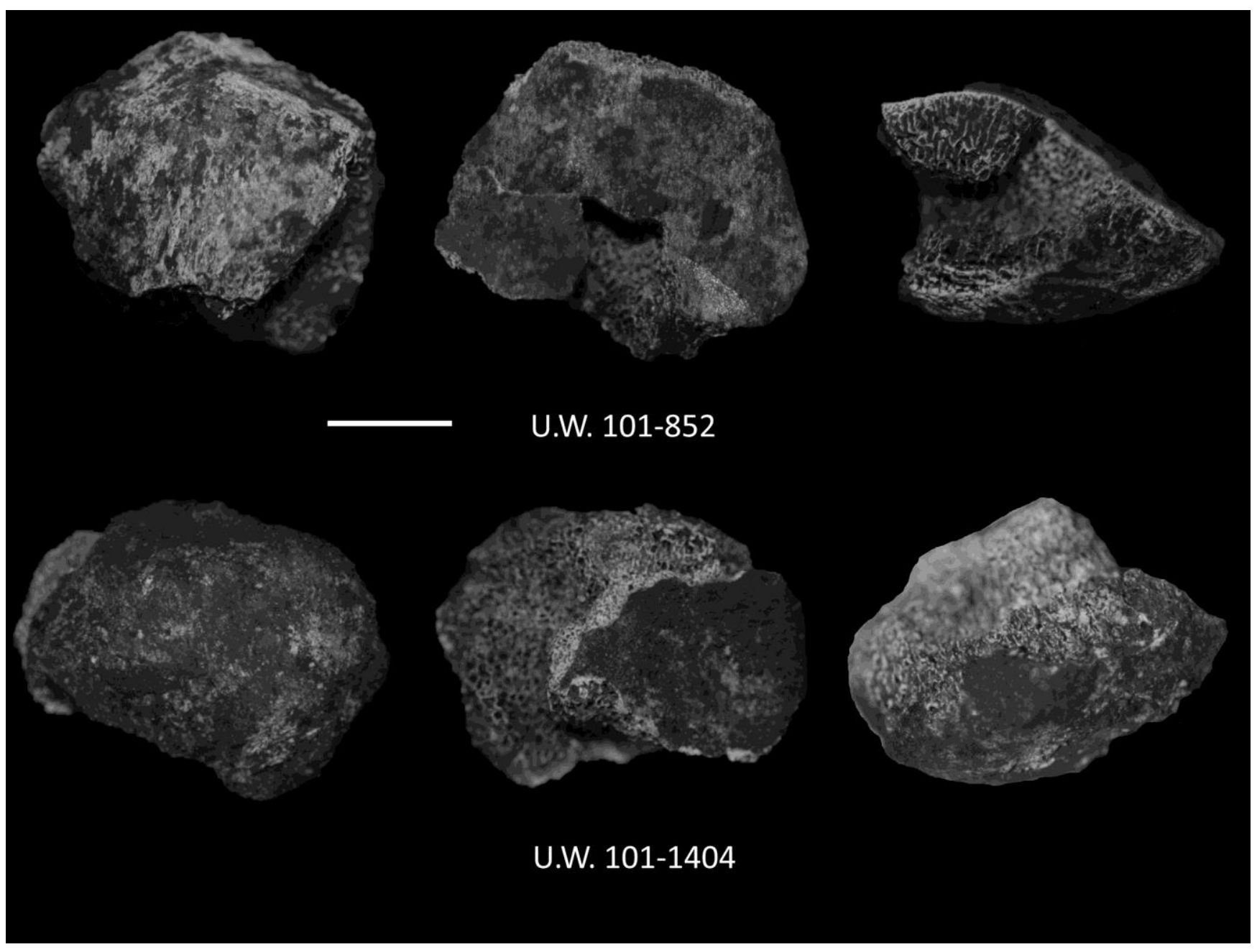


Figure 13

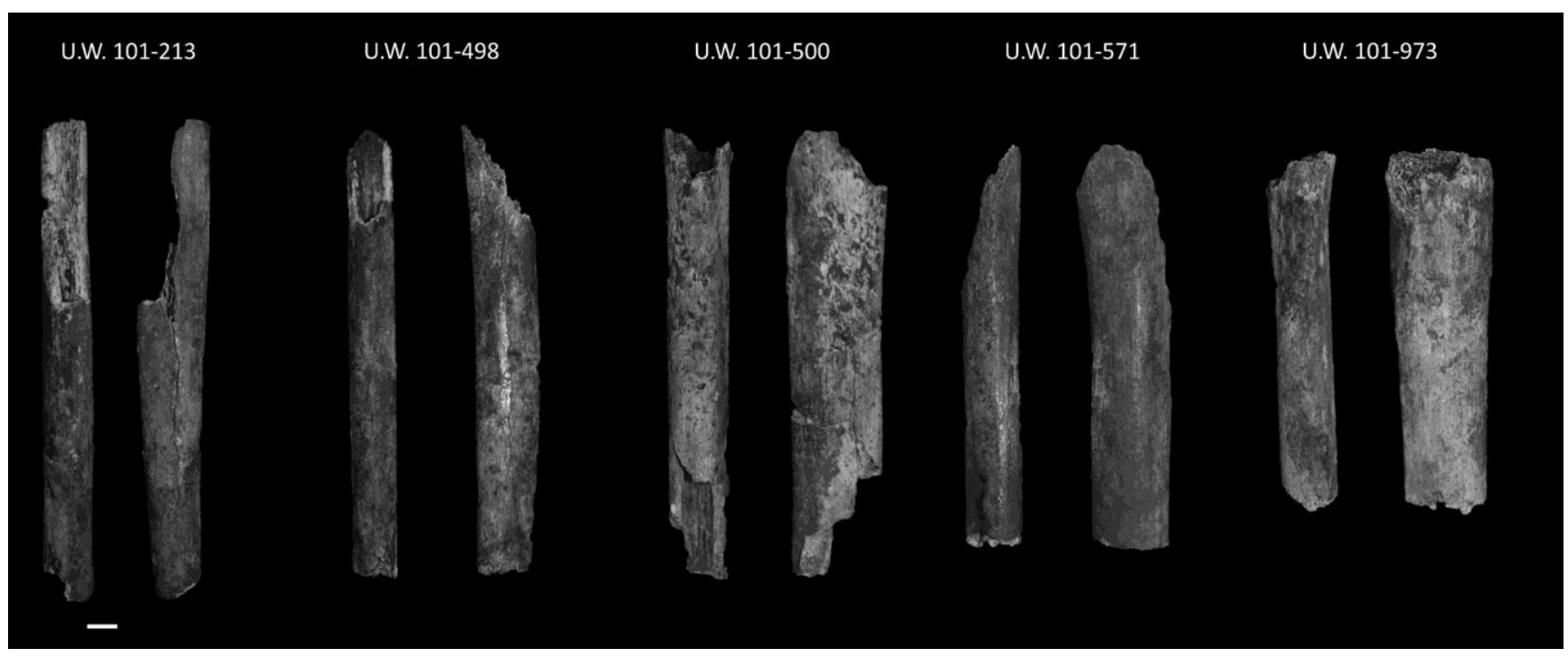


Figure 14
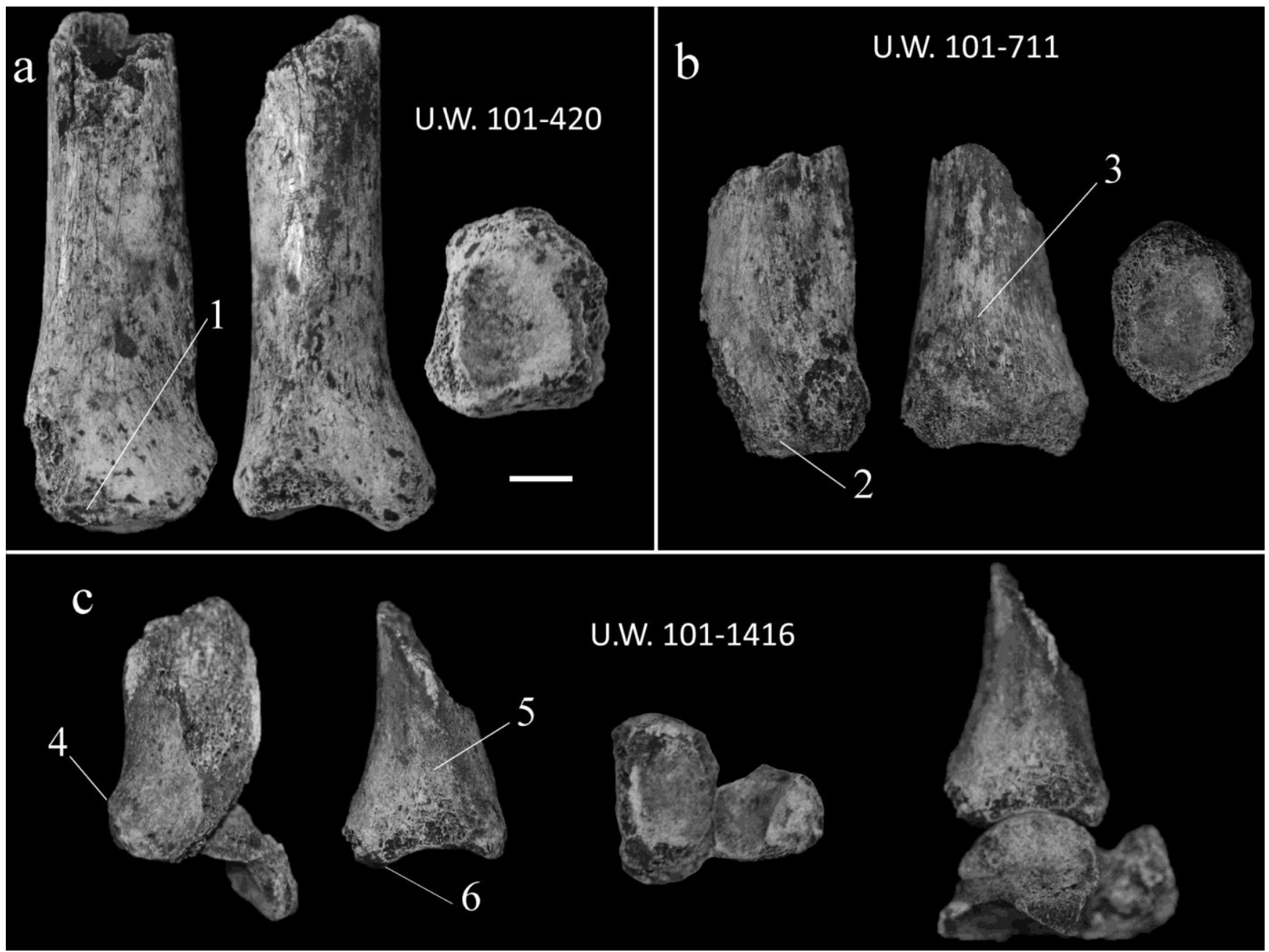
Figure 15

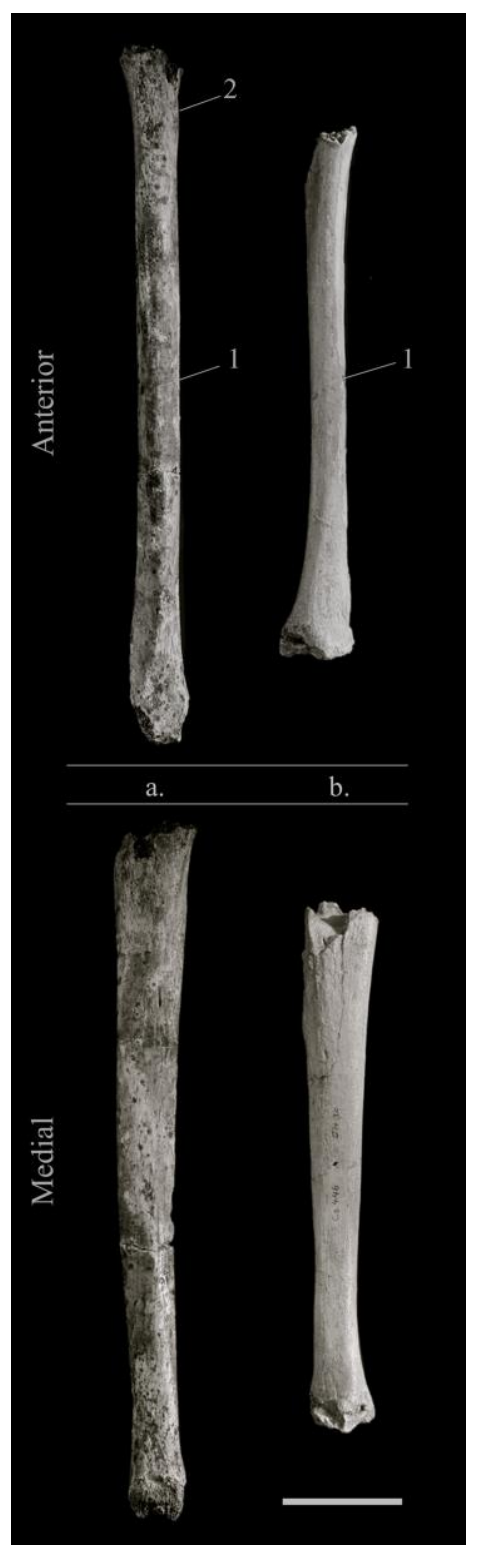


Figure 16

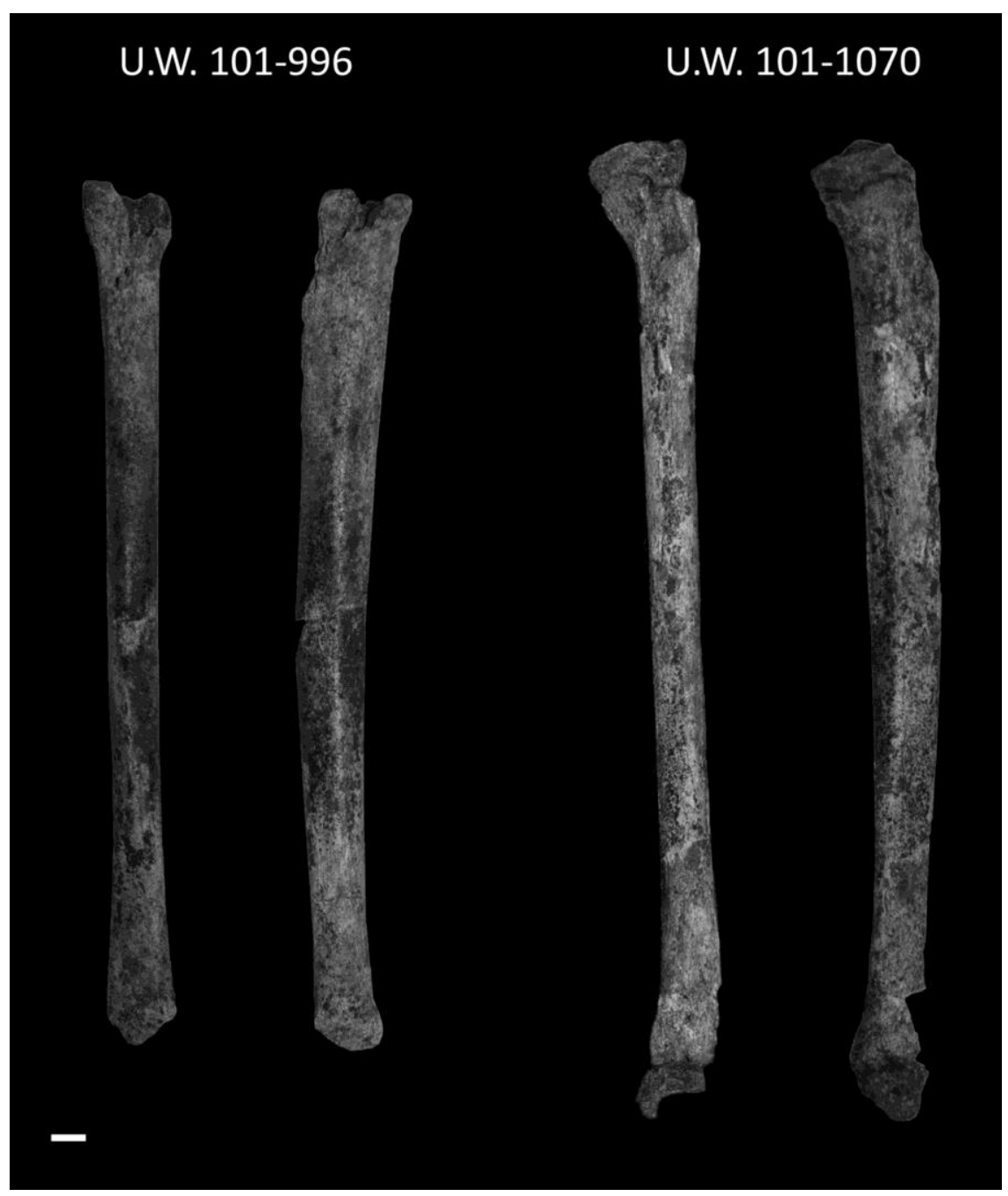


Figure 17

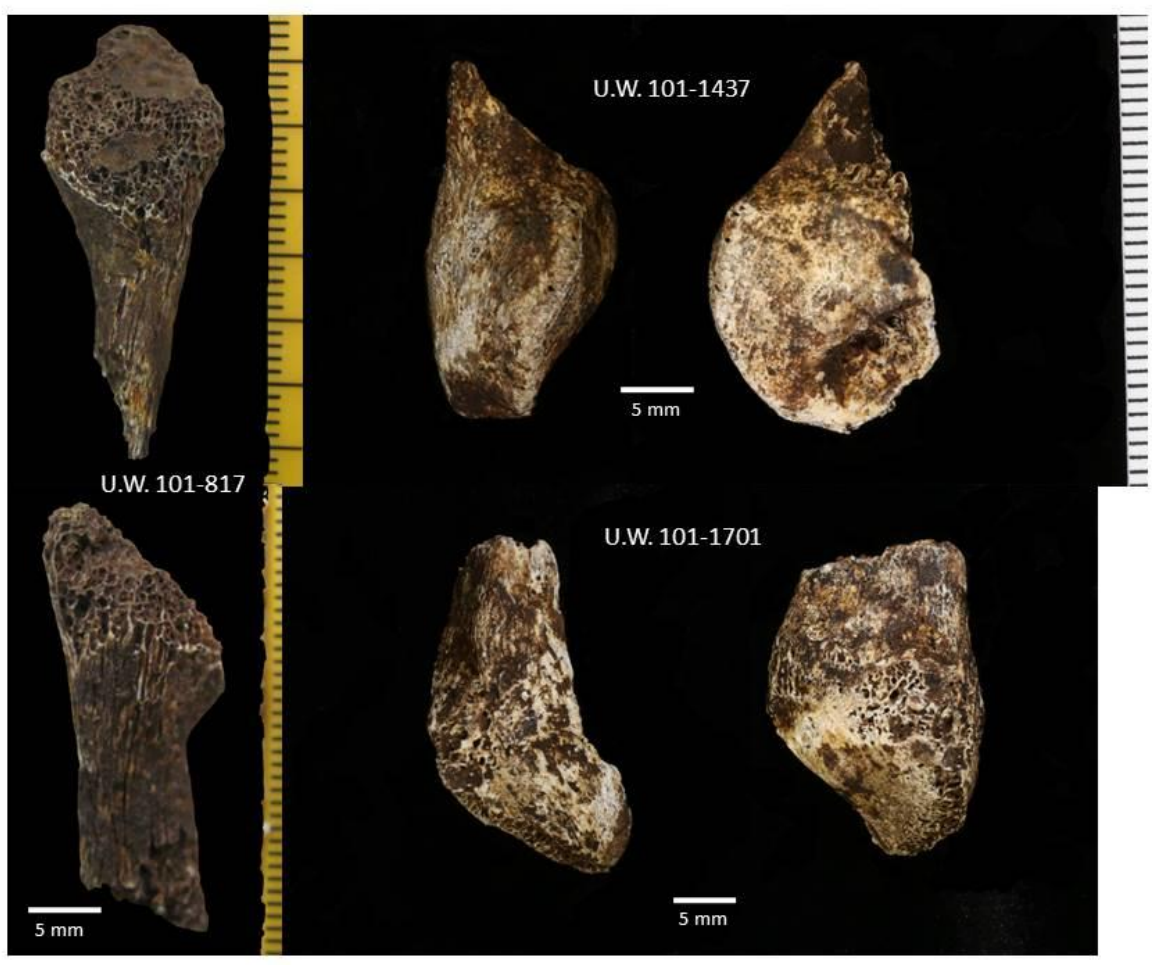


Figure 18

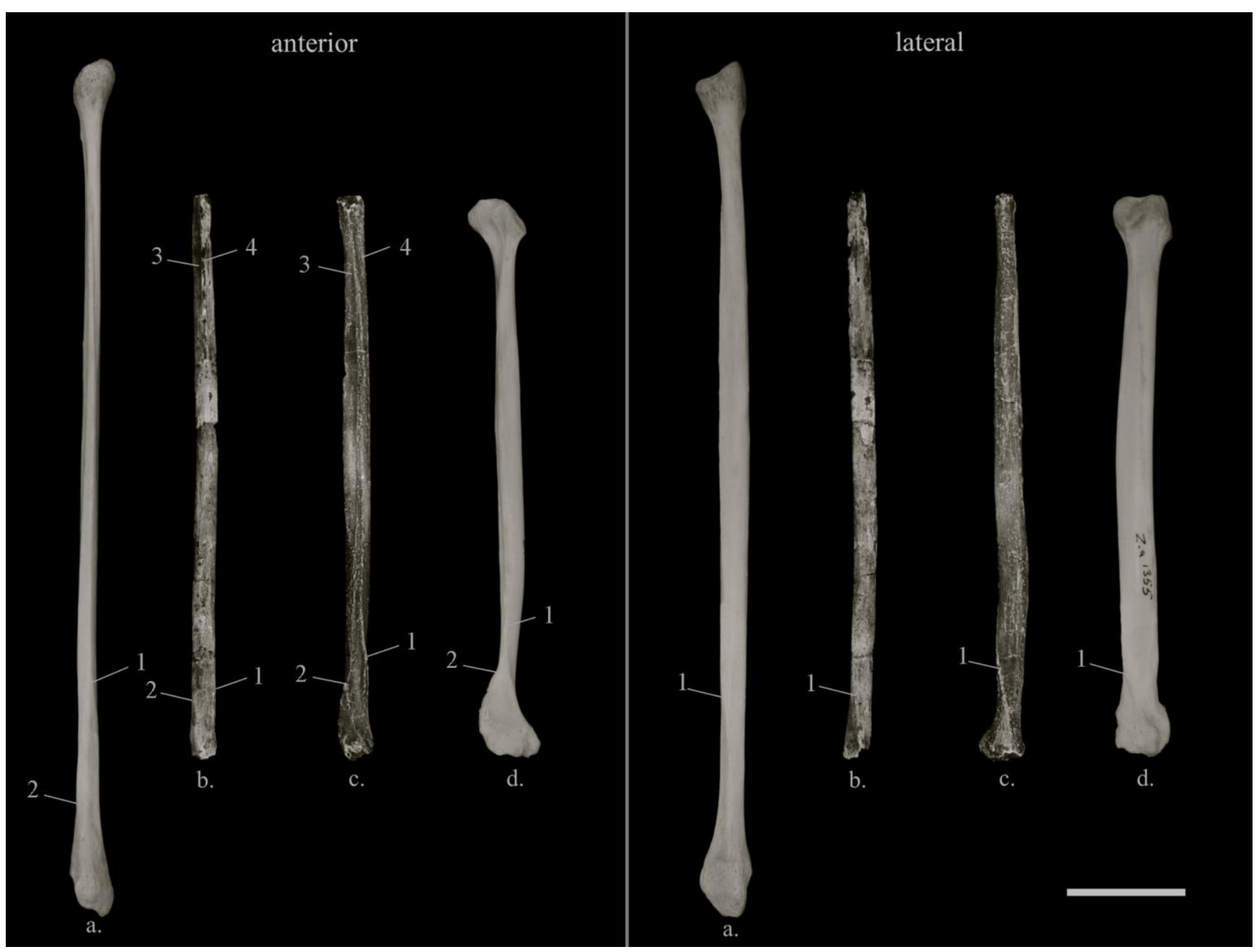


Figure 19

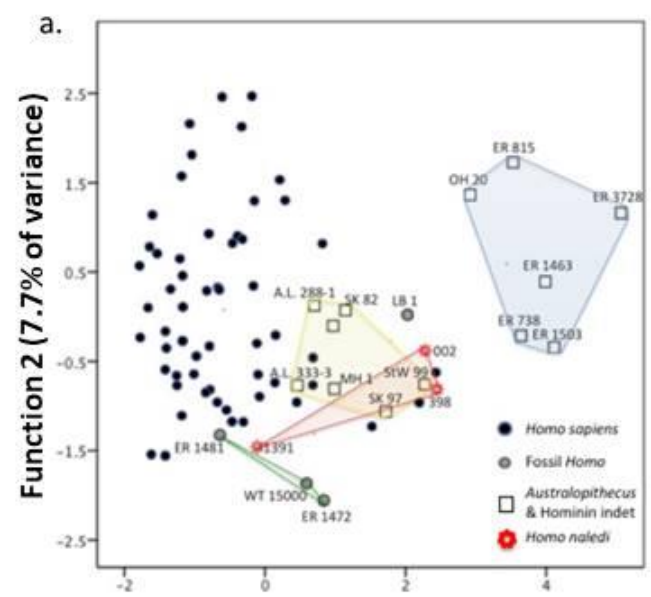

\begin{tabular}{|l|l|l|l|l|l|}
\hline & \multicolumn{3}{|c|}{ Structure Matrix } & & \\
\hline Variable & $\begin{array}{l}\text { Function } \\
1\end{array}$ & $\begin{array}{l}\text { Function } \\
2\end{array}$ & $\begin{array}{l}\text { Function } \\
3\end{array}$ & $\begin{array}{l}\text { Wilks' } \\
\text { lambda }\end{array}$ & $\begin{array}{l}\text { Significance } \\
\text { (P) }\end{array}$ \\
\hline $\begin{array}{l}\text { Neck breadth } \\
\text { (AP) }\end{array}$ & -0.896 & 0.336 & 0.260 & 0.893 & 0.045 \\
\hline Neck length & 0.622 & -0.679 & 0.341 & 0.448 & 0.000 \\
\hline $\begin{array}{l}\text { Neck height (SI) } \\
\text { bubtrochanteric }\end{array}$ & -0.211 & 0.609 & 0.183 & 0.604 & 0.000 \\
\hline $\begin{array}{l}\text { AP } \\
\text { ML }\end{array}$ & 0.00 & 0.377 & -0.460 & 0.964 & 0.450 \\
\hline
\end{tabular}

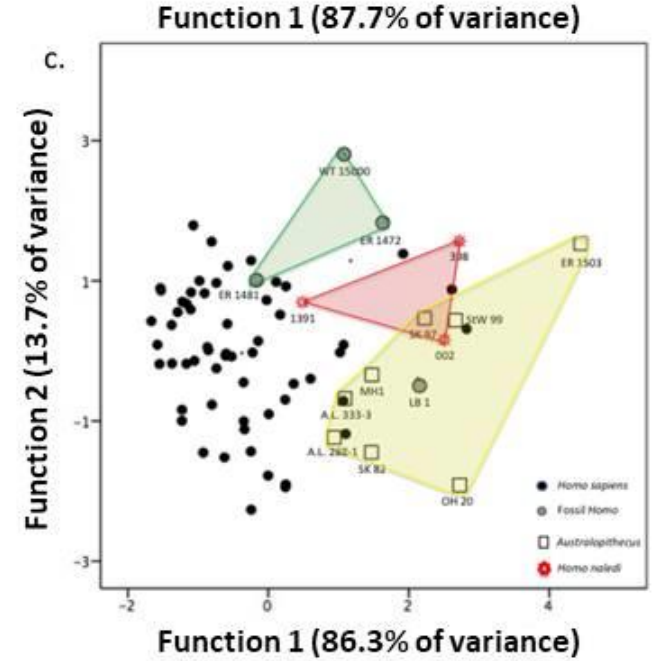

\begin{tabular}{|l|l|l|l|l|}
\hline & \multicolumn{2}{|c|}{ Structure Matrix } & & \\
\hline Variable & Function 1 & Function 2 & Wilks' lambda & Significance (P) \\
\hline Neck breadth (AP) & -0.958 & 0.015 & 0.871 & 0.010 \\
\hline Neck length & 0.698 & 0.669 & 0.594 & 0.000 \\
\hline Neck height (SI) & -0.423 & -0.353 & 0.706 & 0.000 \\
\hline Subtrochanteric AP & 0.415 & -0.246 & 0.959 & 0.242 \\
\hline Subtrochanteric ML & -0.010 & -0.603 & 0.881 & 0.014 \\
\hline
\end{tabular}


Figure 20

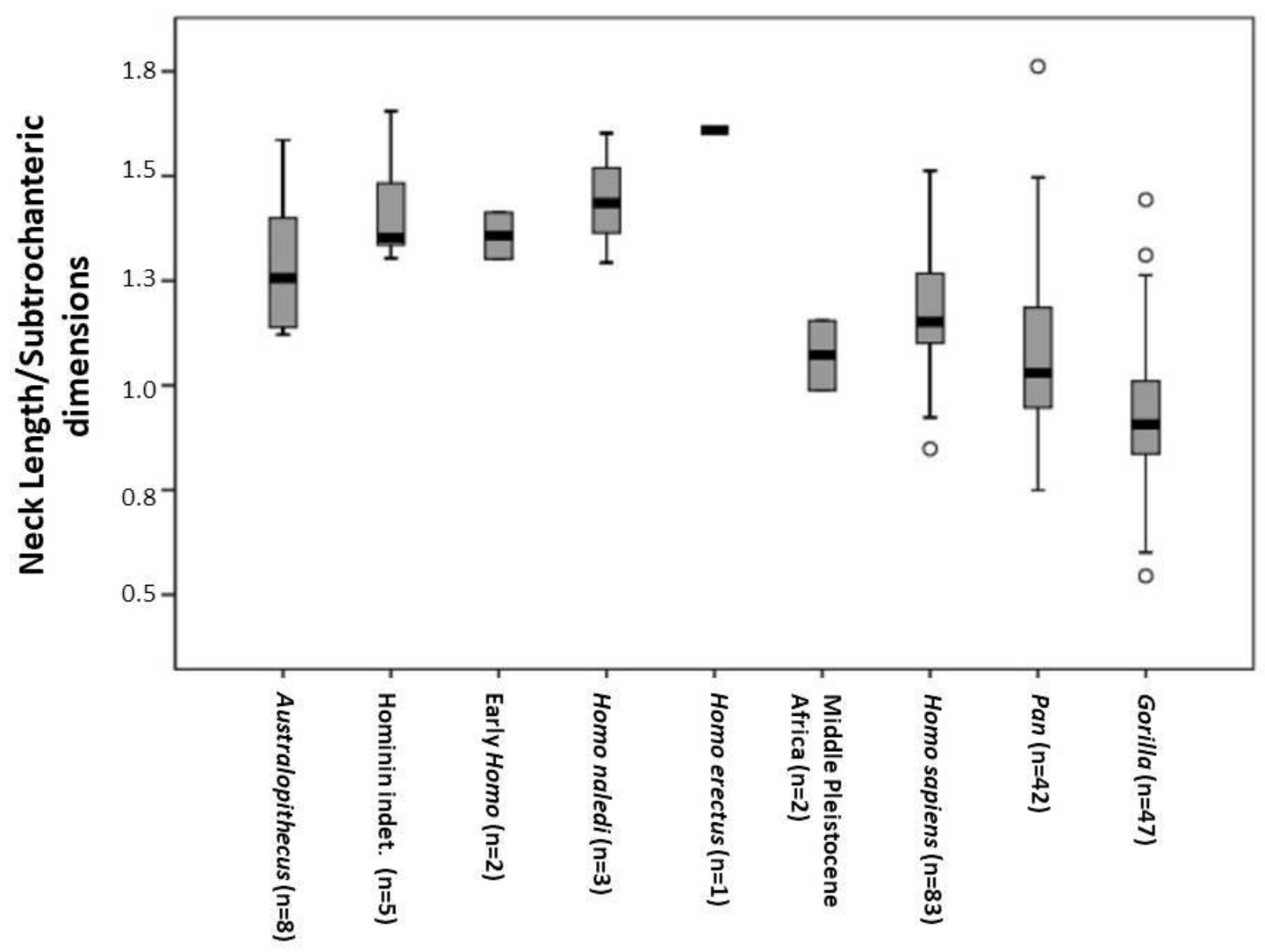


Figure 21

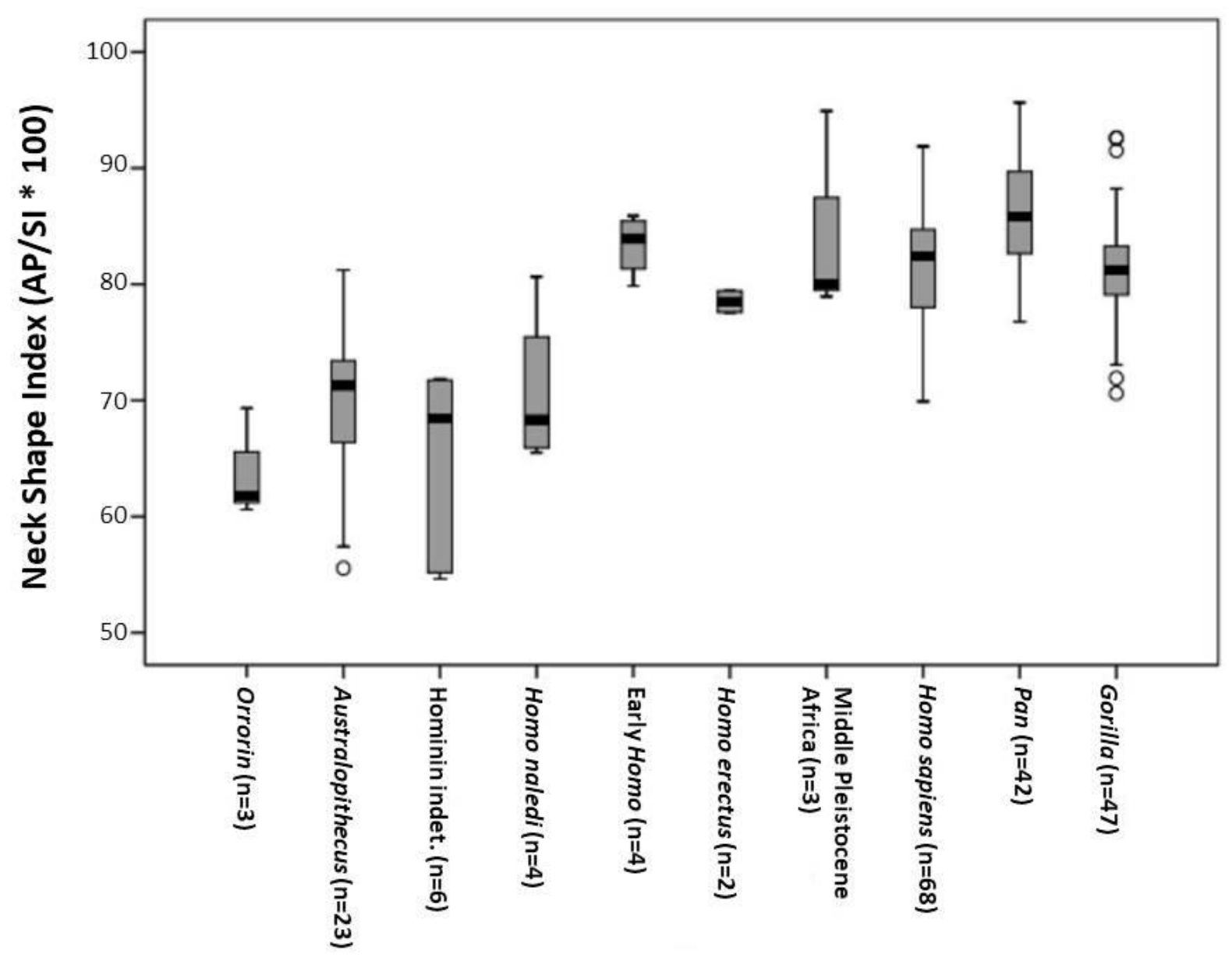


Figure 22

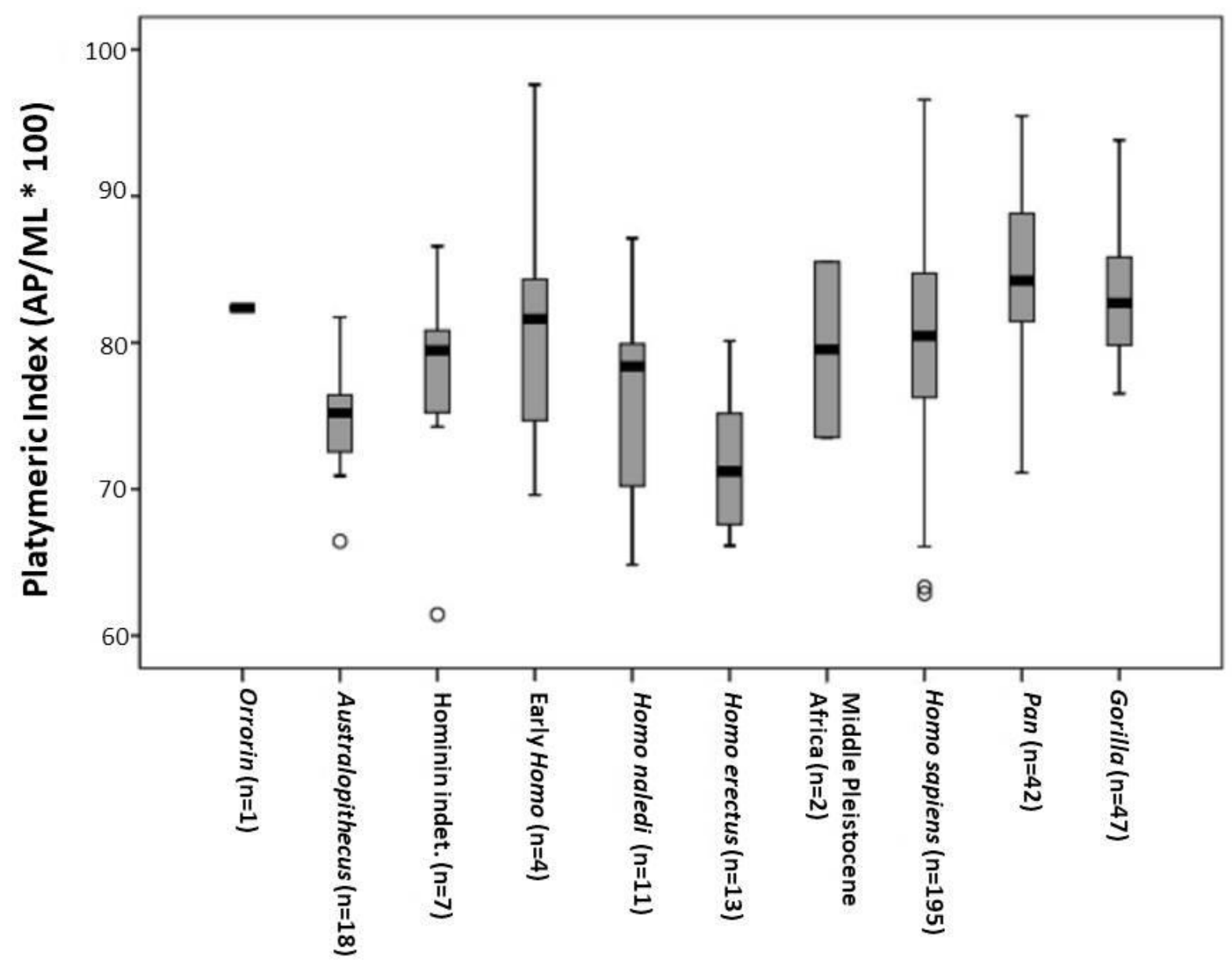


Figure 23

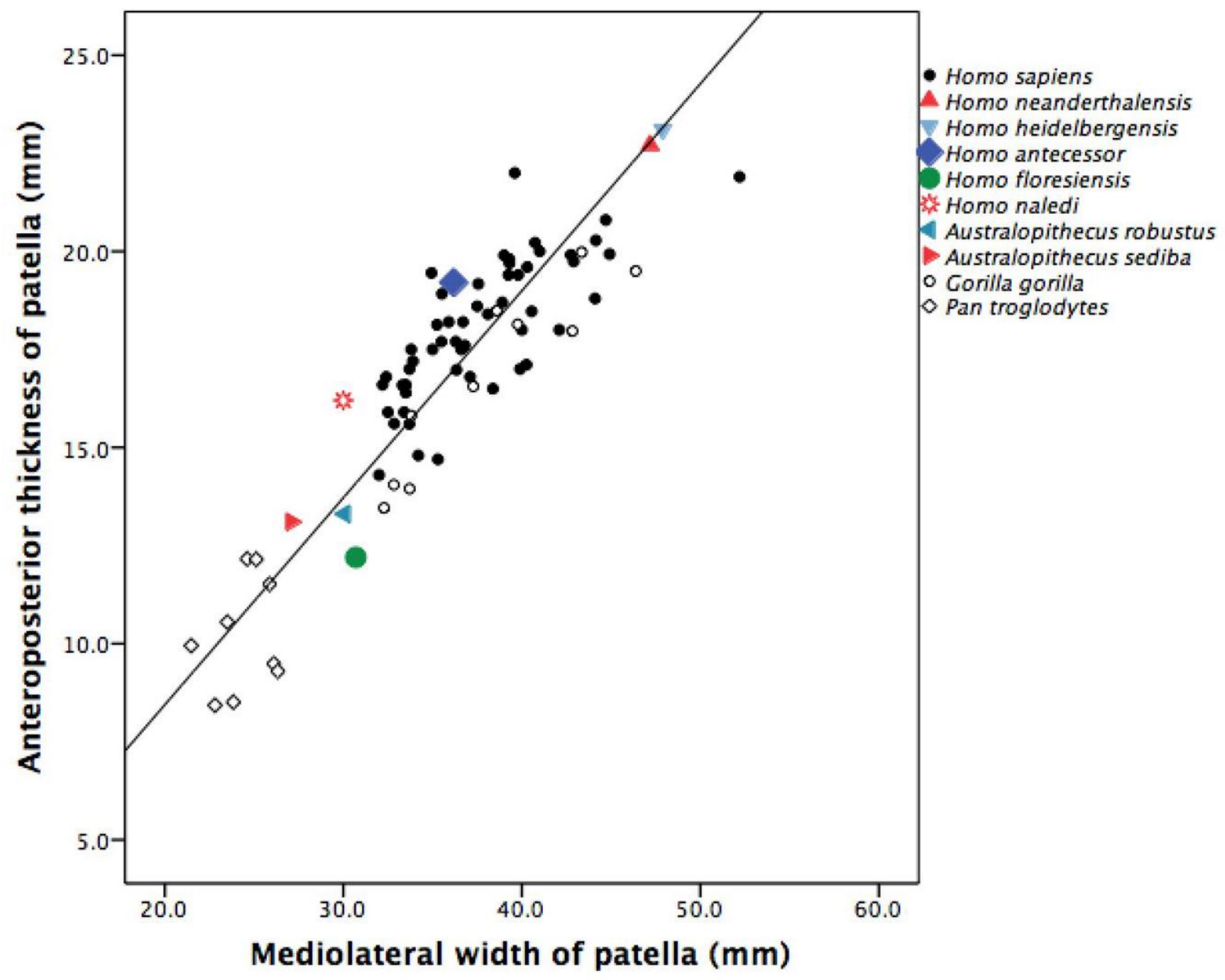


Figure 25

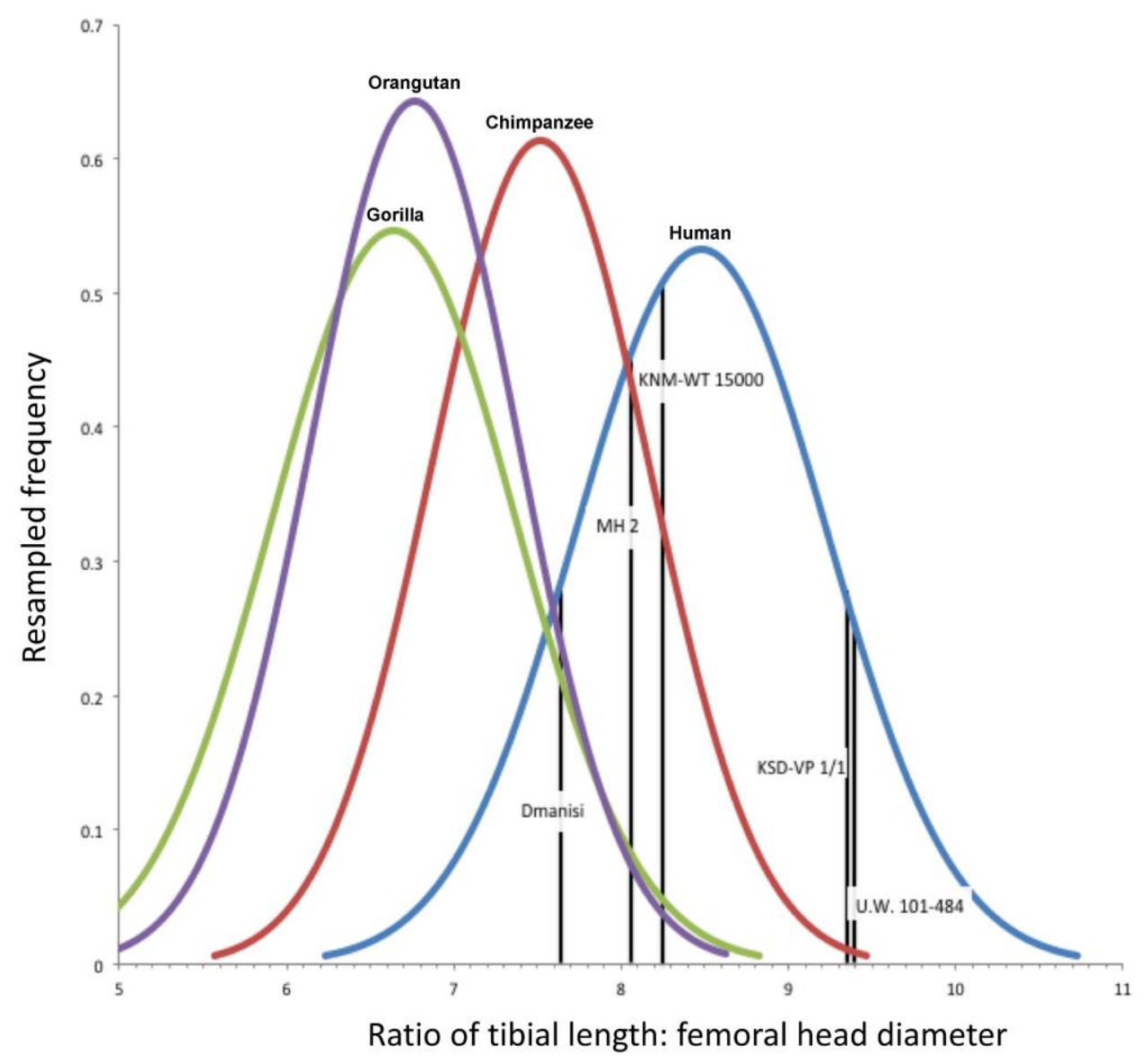


Figure 26

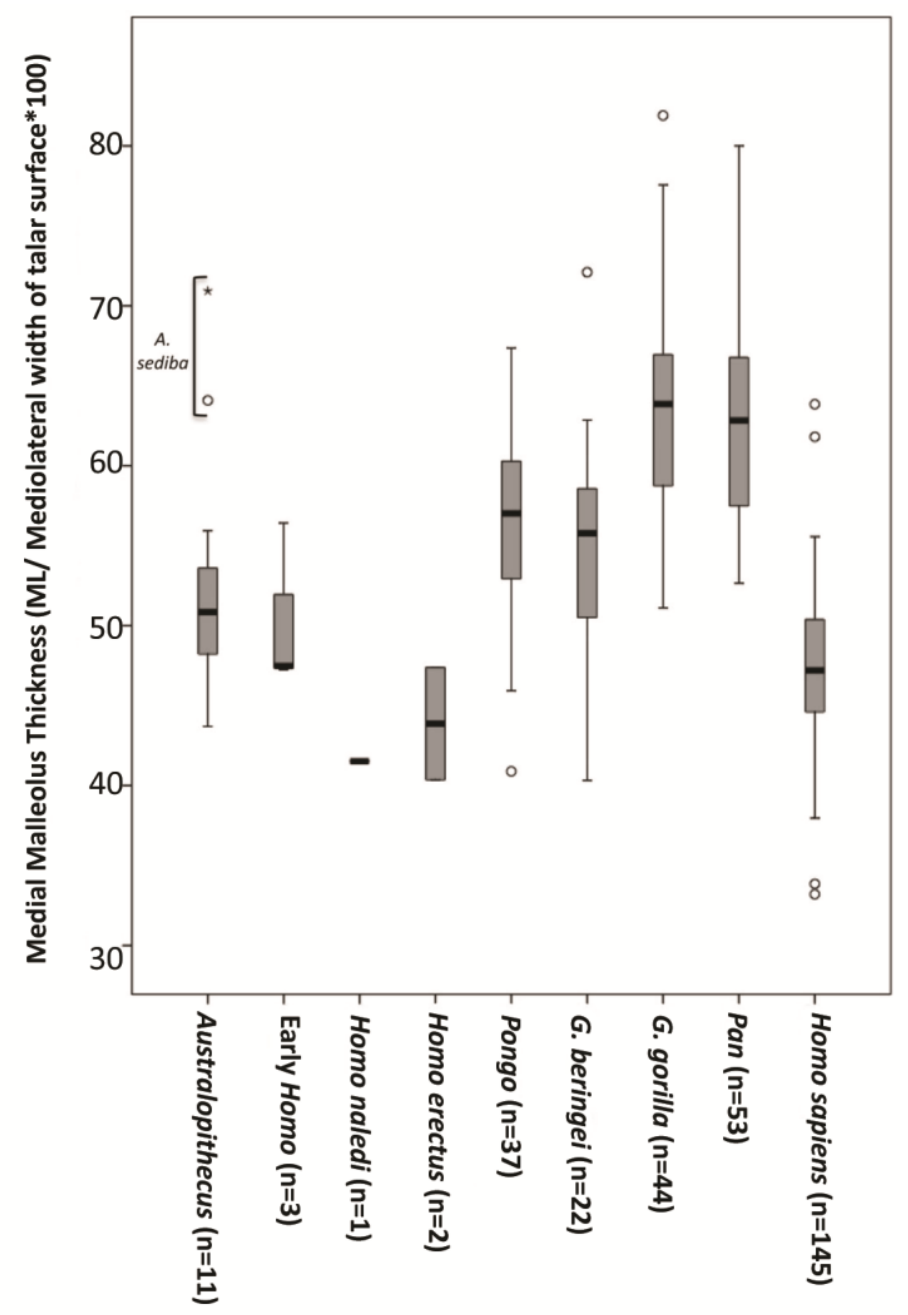




\section{Supplementary Online Material}

\section{The thigh and leg of Homo naledi}

Damiano Marchi, Christopher S. Walker, Pianpian Wei, Trenton W. Holliday, Steven E. Churchill, Lee R. Berger, Jeremy M. DeSilva.

\section{Table of Contents}

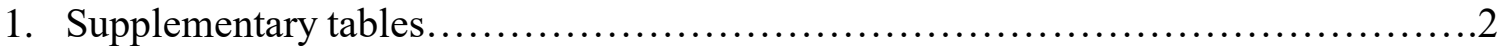

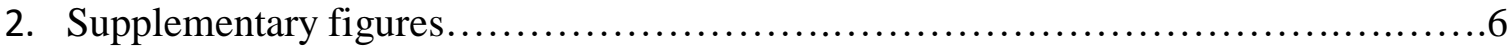

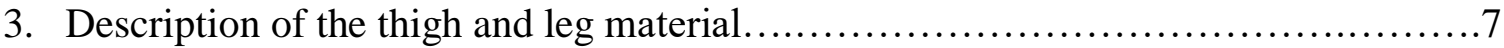

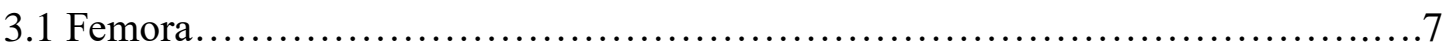

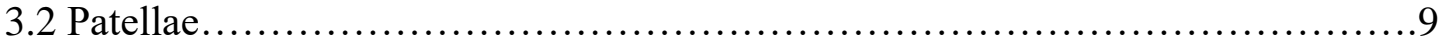

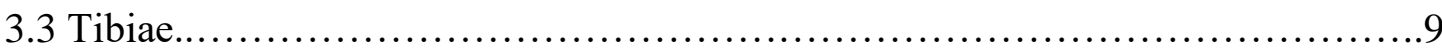

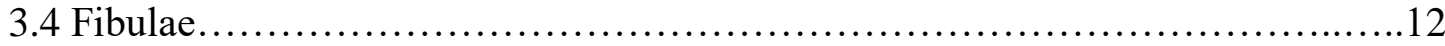

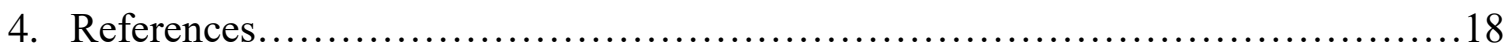




\section{Supplementary tables}

Table S1. Comparative femur and patella samples.

\begin{tabular}{|c|c|c|}
\hline & Institution $^{b}$ & $N$ or ID for fossils \\
\hline \multicolumn{3}{|l|}{ Femur } \\
\hline Homo sapiens & $\begin{array}{l}\text { PMAE, KSU, DC, } \\
\text { NMNH, UI, TU }\end{array}$ & 195 \\
\hline Chimpanzee & $\begin{array}{l}\text { MCZ, NMNH, } \\
\text { CMNH, TU }\end{array}$ & 42 \\
\hline Gorilla & $\begin{array}{l}\text { MCZ, NMNH, } \\
\text { CMNH, TU }\end{array}$ & 47 \\
\hline Orrorin & & BAR $1002^{\prime} 00^{\mathrm{c}}, \mathrm{BAR} 1003^{\prime} 00^{\mathrm{c}}, \mathrm{BAR} 1215^{\prime} 00^{\mathrm{c}}$ \\
\hline Australopithecus $^{a}$ & $\begin{array}{l}\text { SAS, ESI, DM, } \\
\text { KNM, CMNH, } \\
\text { PMAE }\end{array}$ & 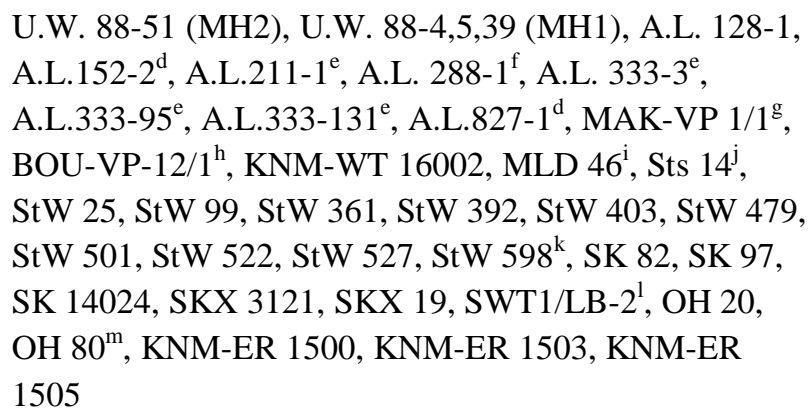 \\
\hline Hominin indet. & ESI, KNM & $\begin{array}{l}\text { KNM-ER 738, KNM-ER 815, KNM-ER 1463, KNM- } \\
\text { ER 1465, KNM-ER 1809, KNM-ER 3728, KNM-ER } \\
\text { 5880, StW } 311\end{array}$ \\
\hline Early Homo & $\begin{array}{l}\text { SAS, ESI, DM, } \\
\text { KNM, CMNH, } \\
\text { PMAE }\end{array}$ & $\begin{array}{l}\text { KNM-ER 1472, KNM-ER 1475, KNM-ER 1481, KNM- } \\
\text { ER 5881, OH } 62\end{array}$ \\
\hline Homo erectus s.l. & $\begin{array}{l}\text { SAS, ESI, DM, } \\
\text { KNM, CMNH, } \\
\text { PMAE }\end{array}$ & 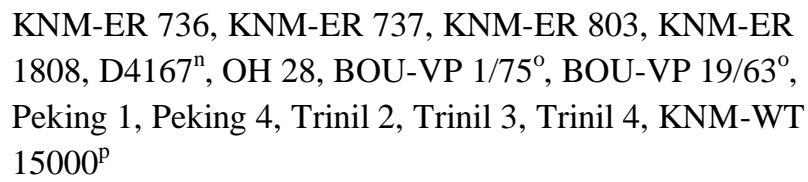 \\
\hline
\end{tabular}

MP Africa $\quad$ KNM, ESI $\quad$ Berg Aukas, KNM-ER 999, Kabwe

Patella

\begin{tabular}{lll}
\hline Homo sapiens & PMAE & 53 \\
Chimpanzee & CMNH, MCZ & 9 \\
Gorilla & CMNH, MCZ & 10 \\
Australopithecus & SAS, ESI & U.W. 88-79,100, SKX 1084 \\
Homo & & LB1/10, LB $1 / 11^{\mathrm{r}}$ \\
floresiensis & &
\end{tabular}

${ }^{\text {a }}$ Includes specimens commonly classified as Paranthropus

${ }^{\mathrm{b}}$ PMAE = Merida and Mistihalj populations, Harvard Peabody Museum of Archaeology and Ethnology; KSU = Kent State University Libben Paleoindian collection, DC: Dart Collection, University of the Witwatersrand ;

$\mathrm{NMNH}=$ the National Museum of Natural History (Smithsonian Institution) Terry Collection; UI = Department of Anthropology, University of Iowa; TU = Department of Anthropology, Tulane University; SAS = School of Anatomical 
Sciences, University of the Witwatersrand; DM = Ditsong Museum in Pretoria, South Africa; KNM = Kenya National Museum, Nairobi; MCZ = Harvard Museum of Comparative Zoology; CMNH = Cleveland Museum of Natural History; $\mathrm{ESI}=$ Evolutionary Studies Institute, University of the Witwatersrand.

${ }^{\mathrm{c}}$ Data from Pickford et al., 2002

${ }^{\mathrm{d}}$ Data from Ward et al., 2012

${ }^{\mathrm{e}}$ Data from Lovejoy et al., 1982

${ }^{\mathrm{f}}$ Data from Johanson et al., 1982

${ }^{g}$ Data from Lovejoy et al., 2002

${ }^{\mathrm{h}}$ Data from DeGusta, 2004

${ }^{\mathrm{i}}$ Data from Reed et al., 1993

${ }^{\mathrm{j}}$ Data from Lovejoy, 1975

${ }^{\mathrm{k}}$ Data from Partridge et al., 2003

${ }^{1}$ Data from Pickering et al., 2012

${ }^{\mathrm{m}}$ Data from Domínguez-Rodrigo et al., 2013

${ }^{\mathrm{n}}$ Data from Lordkipanidze et al., 2007

${ }^{\circ}$ Data from Gilbert, 2008

${ }^{\mathrm{p}}$ Data from Walker and Leakey, 1993

${ }^{\mathrm{q}}$ Data from Grine et al., 1995

${ }^{\mathrm{r}}$ Data from Jungers et al., 2009 
Table S2. Comparative tibia and fibula samples.

\begin{tabular}{|c|c|c|}
\hline & Institution $^{\mathrm{a}}$ & $N$ or ID for fossils \\
\hline \multicolumn{3}{|l|}{ Tibia } \\
\hline Homo sapiens & $\begin{array}{l}\text { KSU, CMNH, } \\
\text { UM }\end{array}$ & 145 \\
\hline Chimpanzee & $\begin{array}{l}\text { NMZ, PCSC, } \\
\text { CMNH, AMNH, } \\
\text { NMNH, CFM, } \\
\text { MCZ }\end{array}$ & 49 \\
\hline Gorilla & $\begin{array}{l}\text { NMZ, PCSC, } \\
\text { CMNH, AMNH, } \\
\text { NMNH, CFM, } \\
\text { MCZ }\end{array}$ & 44 \\
\hline Australopithecus ${ }^{\mathrm{b}}$ & $\begin{array}{l}\text { KNM, PMAE, } \\
\text { CMNH, ESI }\end{array}$ & $\begin{array}{l}\text { KNM-KP 29285, A.L 288-1AQ, } \\
\text { A.L 129-1b, A.L 333-6, A.L. } \\
\text { 333-7, A.L. 545-3 }{ }^{\text {c }, ~ S t W ~ 181, ~} \\
\text { StW 358, StW 389, StW 515, } \\
\text { U.W. 88-21, U.W. 88-97, KNM- } \\
\text { ER 1500, KNM-ER } 2596\end{array}$ \\
\hline Early Ното & $\begin{array}{l}\text { SAS, ESI, DM, } \\
\text { KNM, CMNH, } \\
\text { PMAE }\end{array}$ & $\begin{array}{l}\text { OH 35a, StW 567, KNM-ER } \\
1481\end{array}$ \\
\hline Homo erectus & KNM & $\begin{array}{l}\text { KNM-ER 803b, KNM-ER 741, } \\
\text { D3901 }{ }^{\text {d }}, \text { KNM-WT } 15000\end{array}$ \\
\hline \multicolumn{3}{|l|}{ Fibula } \\
\hline Homo sapiens & NMZ & 34 \\
\hline Chimpanzee & NMZ, PCSC & 29 \\
\hline Gorilla & NMZ, PCSC & 27 \\
\hline Australopithecus & ESI & $\begin{array}{l}\text { A.L. } 288-1 a^{*} \text {, A.L. } 333-9 a^{*}, \\
\text { A.L. } 333-9 b^{*} \text {, A.L. } 333-85^{*} \text {, A.L. } \\
\text { 333-w37*, StW 356, U.W. } 88-23\end{array}$ \\
\hline Early Homo & ESI & $\mathrm{OH} 35^{*}$ \\
\hline Homo erectus & KNM & KNM-WT 15000 \\
\hline
\end{tabular}

* High resolution cast.

${ }^{\mathrm{a}} \mathrm{PMAE}=$ Merida and Mistihalj populations, Harvard Peabody Museum of Archaeology and Ethnology; KSU $=$ Kent State University Libben Paleoindian collection; NMNH = the National Museum of Natural History (Smithsonian Institution) Terry Collection; SAS = School of Anatomical Sciences, University of the Witwatersrand; DM = Ditsong Museum in Pretoria, South Africa; KNM = Kenya National Museum, Nairobi; MCZ = Harvard Museum of Comparative Zoology; $\mathrm{CMNH}=$ Cleveland Museum of Natural History; NMZ = National Museum of Zoology, University of Munich; PCSC = Primatological Collection and Shultz Collection,University of Zurich-Irchel; AMNH = American Museum of Natural History; CFM = Chicago Field Museum; UM = University of Michigan; ESI = Evolutionary Studies Institute, University of the Witwatersrand. ${ }^{\mathrm{b}}$ Includes specimens commonly classified as Paranthropus

${ }^{\mathrm{c}}$ Ward et al., 2012

${ }^{\mathrm{d}}$ Pontzer et al., 2010 
Table S3. Comparative tibia and femur samples used in the resampling analysis.

\begin{tabular}{|c|c|c|c|c|}
\hline Species & $\begin{array}{c}\text { Tibia sample } \\
\qquad(n)\end{array}$ & $\begin{array}{l}\text { Tibial length } \\
\text { mean } \pm \text { SD } \\
(\text { min-max })\end{array}$ & $\begin{array}{c}\text { Femur sample } \\
(n)\end{array}$ & $\begin{array}{c}\text { Femoral head } \\
\text { diameter } \\
\text { mean } \pm \mathrm{SD} \\
(\min -\mathrm{max})\end{array}$ \\
\hline Homo sapiens & 122 & $\begin{array}{l}372.2 \pm 27.1 \\
(306-435)\end{array}$ & 308 & $\begin{array}{l}44.0 \pm 4.0 \\
(34.4-55.8)\end{array}$ \\
\hline Gorilla gorilla & 16 & $\begin{array}{l}294.4 \pm 26.7 \\
(247-335)\end{array}$ & 112 & $\begin{array}{l}44.6 \pm 5.7 \\
(35.6-56.0)\end{array}$ \\
\hline Pan troglodytes & 24 & $\begin{array}{l}250.8 \pm 18.3 \\
(218-293)\end{array}$ & 125 & $\begin{array}{l}33.3 \pm 2.4 \\
(28.6-40.0)\end{array}$ \\
\hline Pongo pygmaeus & 12 & $\begin{array}{l}222.0 \pm 14.9 \\
(206-258)\end{array}$ & 23 & $\begin{array}{l}32.7 \pm 3.3 \\
(29.0-40.3)\end{array}$ \\
\hline
\end{tabular}




\section{Supplementary Figure}
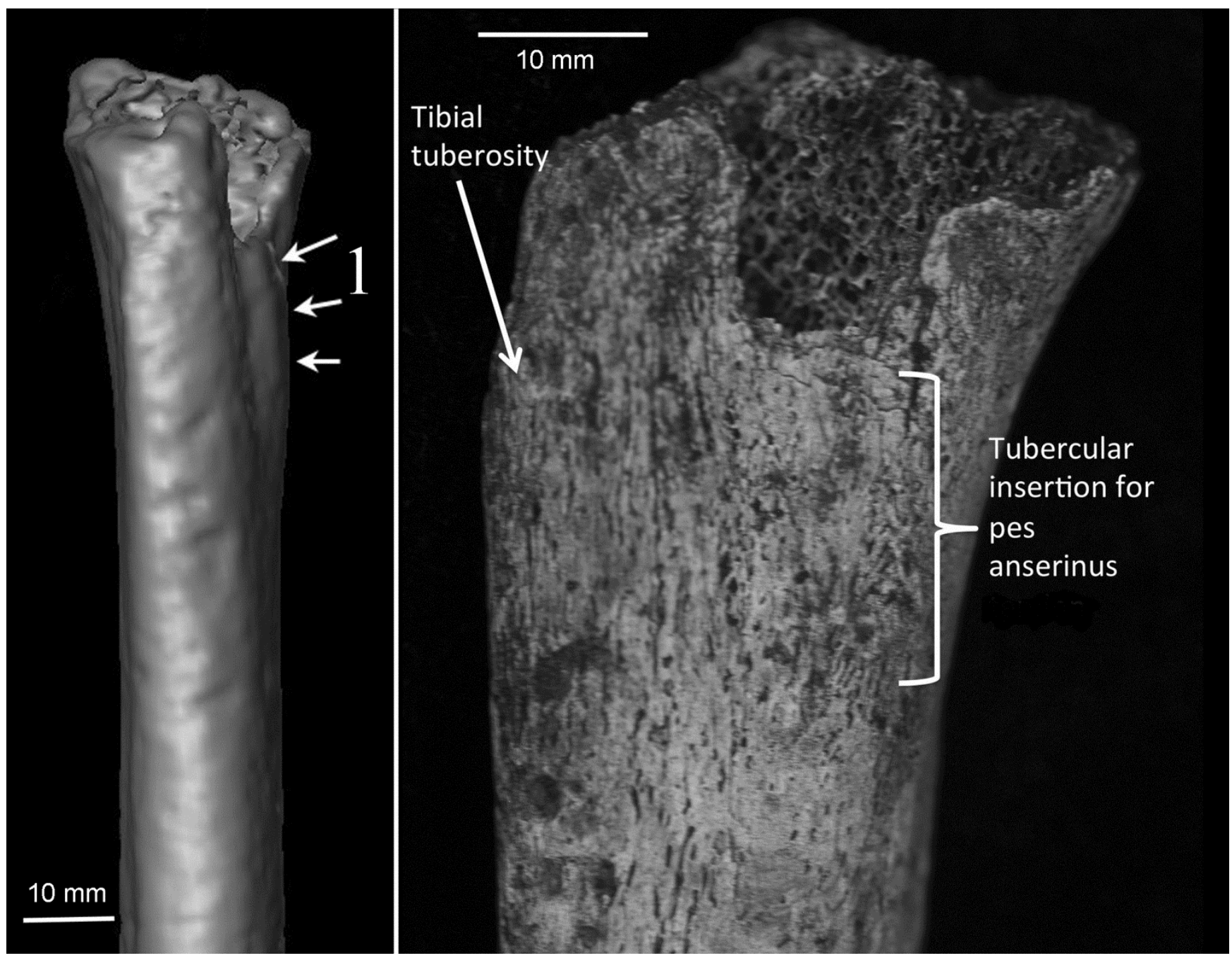

Figure S1. To the left is a surface rendering of the proximal half of the U.W. 101-484 tibia of Homo naledi showing the well-developed insertion of the pes anserinus (1). To the right is a photograph of the same area of U.W. 101-484 showing the enlarged pes anserinus insertion medial to the tibial tuberosity and a groove running between the tibial tuberosity and the pes anserinus tubercle. 


\section{Description of the thigh and leg material}

In this section detailed descriptions of the least informative elements of the femur, patella, tibia, and fibula from Homo naledi are provided. A full list of all thigh and leg material found in the Dinaledi chamber is listed in Table 1 of the main text.

\subsection{Femora}

U.W. 101-014 is an unsided potentially immature (due to small size) partial femoral shaft. A prominent linea aspera is visible along its length. A parallel groove running immediately alongside the linea aspera is palpable for approximately $34 \mathrm{~mm}$. The medullary cavity is partially obstructed by sediment on both ends, but appears AP elongated. Cortical bone is thickest posteriorly and thinnest anteriorly. The anterior surface is significantly longer than the posterior surface due to a complete, oblique break extending $34 \mathrm{~mm}$.

U.W.101-143 is a right proximal femoral shaft. Proximally, the break is just distal to the lesser trochanter. At the level of the proximal break the shaft is platymeric. Here, the medial cortex is thicker $(6.7 \mathrm{~mm})$ than the lateral cortex $(5.5 \mathrm{~mm})$. At the distal break the shaft dimensions are $19.0 \mathrm{~mm}$ AP and $17.3 \mathrm{~mm}$ ML. Here, the medial cortex is thicker $(6.2 \mathrm{~mm})$ than the lateral cortex $(5.5 \mathrm{~mm})$.

Posteromedially, a pectineal line is visible. It merges with what looks like a spiral line $43 \mathrm{~mm}$ distal to the proximal break. The spiral line and pectineal lines merge with the gluteal line $49 \mathrm{~mm}$ distal to the proximal break. Proximally, the gluteal line is well-developed. Lateral to the gluteal line is a palpable grooved depression identifiable as the hypotrochanteric fossa. In medial and lateral views, there is some anteroposterior curvature to the shaft.

U.W. 101-341 is an unsided femoral shaft fragment, preserving either the lateral or medial side of the diaphysis. The maximum thickness of the cortex is $7 \mathrm{~mm}$.

U.W. 101-857 is a left distal femoral shaft. The anterior part of the shaft is stripped away proximally and distally, leaving only a portion $15.1 \mathrm{~mm}$ SI. The posterior part of the shaft is preserved. Medially the shaft is convex and laterally it is concave. A linea aspera is present superiorly that proceeds distally for $27 \mathrm{~mm}$ before diverging into the lateral and medial supracondylar lines that gradually diverge down the shaft to the point of break inferiorly. At the point of origin of the supracondylar lines, the ML breadth is $18.7 \mathrm{~mm}$ and the minimum AP breadth is $23.2 \mathrm{~mm}$, though there is some damage posteriorly in this region. This specimen has been temporarily exported for radiocarbon dating, which requires minimal destructive sampling. The destructive sampling study was approved by the ESI curator and a temporary export and destructive sampling permit (Permit ID 2182, Case No 9088) issued.

U.W. 101-863 is the proximal end of a very small, fragmentary immature long bone measuring $36 \mathrm{~mm}$ from the damaged proximal end to a break in the shaft. Owing to multiple affinities with other immature femora in the assemblage, this bone was originally identified as a proximal femur and has been presented as such elsewhere (e.g., Walker, 2015). Recent analyses, however, have cast doubt on 
this assignment and the specimen may actually be a heavily eroded proximal humerus. Due to this uncertainty, U.W. 101-863 is omitted from this overview of the Dinaledi thigh and leg assemblage. Internal study is underway to properly identify this immature fragment.

U.W.101-898 is a small unsided fragment of femoral condyle. The ML breadth from the preserved surface of the condylar notch to exposed trabecular bone is $10.5 \mathrm{~mm}$. The SI breadth is $21.5 \mathrm{~mm}$; the AP breadth from the condyle surface to the posterior exposed trabecular bone is $18.0 \mathrm{~mm}$.

U.W.101-1284 is right distal femoral shaft (3D surface scan at www.morphosource.org). At the proximal break, the shaft is $21.7 \mathrm{~mm}$ AP and $21.1 \mathrm{~mm}$ ML. Here, the medial cortex is thicker $(7.3 \mathrm{~mm})$ than the lateral cortex $(6.0 \mathrm{~mm})$. A considerable portion of the anterodistal part of the cortex has been stripped away exposing trabecular bone. At the distal anterior break, the shaft is $23.0 \mathrm{~mm}$ AP and 19.4 $\mathrm{mm}$ ML, demonstrating some distal waisting of the shaft. Posteriorly, the linea aspera is welldeveloped superiorly before diverging into the medial and lateral supracondylar lines. The medial surface of the bone is convex. The lateral surface is concave. In medial and lateral views, the shaft is slightly AP bowed. In the anterior view, the shaft is convex and somewhat bowed mediolaterally.

U.W. 101-1434 is a gracile left proximal femoral shaft fragment preserved from a break in the shaft inferior to the lesser trochanter to a break in the midshaft region. The subtrochanteric region is platymeric. Proximally, in lateral and medial view, the medial shaft shows a weak flare, which is the distal part of the lesser trochanter. Flaking of the cortex from the shaft is present proximally. A rough area corresponding to the gluteal line is present laterally. Medial to the gluteal line is a faint pectineal line and medial to it a spiral line is visible. The three lines merge $44.2 \mathrm{~mm}$ distal from the proximal break. Distally, a linea aspera descends the length of the preserved shaft. At the distal break in the shaft, the bone is $15.8 \mathrm{~mm}$ AP and $15.3 \mathrm{~mm}$ ML. Here, the medial cortex is thicker $(5.4 \mathrm{~mm})$ than the lateral cortex $(4.6 \mathrm{~mm})$. Anteriorly, the shaft is convex and has longitudinal cracking throughout.

U.W. 101-1523 is a right distal femoral shaft fragment preserved from a break in the shaft to the unfused lateral metaphyseal surface (3D surface scan at www.morphosource.org). There is very little preserved of the metaphyseal surface save for a $14.3 \mathrm{~mm}$ AP and $14.9 \mathrm{~mm}$ ML patch of unfused metaphyseal surface. U.W. 101-1523 is likely the antimere to U.W. 101-938, given size and developmental congruence along with a similar patina. There is some cortical erosion around the perimeter of the bone, particular along the distal rim. The medial aspect of the distal metaphysis is not preserved. At the proximal point of break, the shaft is $16.9 \mathrm{~mm}$ AP and $14.9 \mathrm{~mm}$ ML. In cross-section, there is a prominent pilaster, but externally only a weakly developed linea aspera that weakly splits into barely palpable supracondylar lines.

U.W. 101-1555 is an immature femoral neck fragment with an unfused (but affixed) partial head, altogether measuring $48.6 \mathrm{~mm}$ ML (3D surface scan at www.morphosource.org). The inferior and anterior surfaces of the head retain large areas of subchondral bone, though near the lateral break and metaphyseal plate trabeculae are exposed. The minimum SI height of the head is $24.3 \mathrm{~mm}$. The entire posterior surface of the fragment is badly damaged, with only a small patch of cortical bone extending 
inferiorly from the superior surface of the neck. The posterior $\sim 1 / 3$ of the femoral head and nearly $1 / 2$ of the posterolateral neck is missing. Posteriorly as well, the femoral head preserves a small patch of the fovea. The superior surface of the neck and head is also badly damaged. The AP neck width at the level where cortical surface is preserved is $14.3 \mathrm{~mm}$. The orthogonal SI dimension cannot be measured due to significant erosion, but is a minimum of $17.5 \mathrm{~mm}$.

U.W. 101-1694 is a right distal lateral femoral epiphysis measuring $36.0 \mathrm{~mm}$ AP and preserving only $18.9 \mathrm{~mm}$ ML. There is considerable erosion around the lateral and medial perimeters of the bone. The subchondral bone of the condyle is slightly eroded around its edges and quite eroded anteriorly. The condyle is moderately convex.

\subsection{Patellae}

U.W. 101-1512 is a partial unsided patella, consisting of three fragments, two of which conjoin. It is $23.7 \mathrm{~mm}$ SI, $17.8 \mathrm{~mm} \mathrm{ML}$, and $10.2 \mathrm{~mm} \mathrm{AP}$, though all of these measurements are minimums given damage around the perimeter of the bone. In the anterior view, the cortex is exfoliated and cracked throughout. The medial part of the bone is not preserved at all, exposing the underlying trabeculae.

U.W. 101-1639 is a right patella preserving some of the base, the anteromedial surface, and the posteromedial contact with the distal femur. Features of the anterior part of the bone are not detectable because of surface erosion. The lateral side of the bone is not preserved. The preserved SI diameter is $23 \mathrm{~mm}$ and the ML width is $17.2 \mathrm{~mm}$, though the patella would have been taller and wider. The bone is about $14.9 \mathrm{~mm}$ thick AP. Posteriorly, the facet for the distal femur is preserved only medially. The medial facet preserves $12.1 \mathrm{~mm}$ ML and $16.8 \mathrm{~mm}$ SI. It strongly slopes anteriorly and is weakly concave at the most medial point. Internally, the patella is filled with trabeculae that are exposed laterally. Proximally, the base is deflected posteriorly relative to the anterior aspect of the bone.

\subsection{Tibiae}

U.W. 101-013 is a distal tibial shaft. Proximally, the bone is sheared cleanly and is $20.9 \mathrm{~mm}$ by approximately $17 \mathrm{~mm}$. Distally, trabeculae are exposed and the diameter is $26.8 \mathrm{~mm}$ by $20.9 \mathrm{~mm}$.

U.W. 101-017 is a right proximal tibial shaft. At the proximal break, the shaft is $21.5 \mathrm{~mm}$ AP and 16.6 $\mathrm{mm}$ ML. The anterior border is straight and well-marked. The posterior border is rounded. The lateral surface is convex.

U.W. 101-042 is an unsided tibial shaft fragment. A prominent crest is present, but it is difficult to establish if it is anteriorly or posteriorly located, as other tibiae in the Dinaledi assemblage have crests on both the anterior and posterior aspects of the shaft. The side of the fragment opposite from the preserved crest is worn, preventing assessment of the morphology on that side. The fragment has oblique breaks both superiorly and inferiorly. 
U.W. 101-072 is a left tibial shaft fragment. It is missing the posterior and part of the lateral surface of the diaphysis. The preserved anterior border runs proximolaterally to distomedially. It is marked proximally and becomes rounded distally. The lateral surface is convex.

U.W. 101-085 is an unsided tibial shaft fragment. The cortical thickness of the fragment is $8.1 \mathrm{~mm}$.

U.W. 101-136 is a right proximal tibial shaft fragment constituted by the association of three fragments: U.W. 101-136, U.W. 101-137, and U.W. 101-360. The diaphysis is very robust for the Dinaledi assemblage. Shaft dimensions just distal to the tibial tuberosity at the level of the distal soleal line are $29.3 \mathrm{~mm}$ AP and 17.2 mm ML. The interosseous border is well-marked and runs from proximoanteriorly to distoposteriorly.

U.W. 101-237 is a left proximal tibial shaft fragment. The diaphysis is platycnemic. Proximally and anteriorly the tibial tuberosity is missing and there is cortical damage where the characteristic vertical striation distal to the tuberosity would be. Posteriorly a soleal line is present. The lateral surface is damaged but flat. The medial surface is convex. At the distal break the dimensions are $27.9 \mathrm{~mm}$ AP and $15.9 \mathrm{~mm}$ ML.

U.W. 101-239 is a proximal anterior tibial shaft fragment. The cortex is partially eroded throughout especially at the distal break where it has been completely eroded and no cortex can be seen. The interosseous border is well-marked and runs from proximoanteriorly to distoposteriorly. Much of the lateral surface of the bone is missing but the surface between the anterior border and the interosseous border is present and shows a depression (for $\mathrm{m}$. tibialis anterior). The anterior border is well-marked and curves proximomedially to distolaterally. Only about one-third (medial view) of the lateral surface is present and is flat.

U.W. 101-313 is a posterior fragment of proximal left tibial shaft. Only the posterior surface is preserved and a well-marked soleal line is present, running from superolaterally to inferomedially. In lateral view, the diaphysis flares posteriorly toward the proximal break.

U.W. 101-402 is a right distal tibial shaft fragment. The anterior border for the interosseous ligament is palpable laterally. Proximally, the cortex is $5.8 \mathrm{~mm}$ thick. The dimensions at the distal break are 19.8 $\mathrm{mm}$ AP and $20.2 \mathrm{~mm}$ ML.

U.W. 101-567 is a tibial shaft fragment. The cortical thickness of the preserved fragment is $6.1 \mathrm{~mm}$.

U.W. 101-586 is a tibial shaft fragment. The cortical thickness of the fragment is $5.9 \mathrm{~mm}$.

U.W. 101-848 is a fragment of a right tibial shaft. The anterior border is well marked, the lateral surface is flat, and the medial surface is convex.

U.W. 101-1210 is a distal tibial shaft fragment. The anterior border is rounded. The medial surface is convex; the lateral surface is flat, especially distally. In anterior and posterior view the distal shaft flares. At the proximal break the dimensions are $15.9 \mathrm{~mm}$ AP and $15.6 \mathrm{~mm}$ ML. 
U.W. 101-1214 is a right midshaft tibial fragment. The proximal and distal breaks are sheared cleanly. The anterior border is rounded and the interosseous border is well-marked. A slight depression is present between the two aforementioned borders. The medial surface is convex. A border runs proximo-distally on the medial surface of the bone. Three fragments in the same box conjoin anteriorly and proximally to the fragment described above and additional fragments collected with this specimen should conjoin the others.

U.W. 101-1220 consists of many fragments of nondiagnostic tibial cortex.

U.W. 101-1241 is a left distal shaft of a tibia. The anterior border is rounded. The medial surface is convex and the lateral surface is flat, especially distally. In anterior and posterior view, the distal shaft flares. At the proximal break, the shaft dimensions are $16.3 \mathrm{~mm}$ AP and $15.1 \mathrm{~mm} \mathrm{ML}$.

U.W. 101-1262 is a fragmentary right distal tibia, preserved in two pieces. One is part of the lateral shaft preserving $36.5 \mathrm{~mm}$. The other fragment is a piece of the distal tibia preserving $11.9 \mathrm{~mm} \mathrm{SI}$ of the anterior rim and a small part of the talar facet. None of the medial or posterior shaft is preserved, nor is the medial malleolus. The metaphysis flares distally, but metrics are difficult to assess. The talar facet preserves only $16.7 \mathrm{~mm}$ ML and $16.1 \mathrm{~mm}$ AP; the rest is damaged. Medially, the facet is bordered by a slight inferior lip that delineates the beginning of the medial malleolus. Anteriorly, the talar facet is bordered by the anterior rim of the tibia, which preserves a small depression that is likely a squatting facet. Laterally and posteriorly, the talar facet is bordered by exposed trabeculae.

U.W. 101-1288 is a small right distal tibial shaft. At the proximal break (roughly midshaft) the bone is jagged and $23.5 \mathrm{~mm}$ AP and $16.2 \mathrm{~mm}$ ML. The diaphysis is platycnemic. Medially a sharp ridge for the medial insertion of the flexor digitorum longus $\mathrm{m}$. is present, as occurs in U.W. 101-484. Laterally the ridge for the interosseous ligament is well-developed distally. This bone shows the same complex of traits observed for U.W. 101-484/588. Distally the shaft flares in anterior and posterior view. Trabecular bone is exposed at the distal break, which is $19.1 \mathrm{~mm} \mathrm{ML}$ and $16.7 \mathrm{~mm}$ AP.

U.W. 101-1295 is a fragment of tibial shaft. The cortical thickness of the fragment is $5.6 \mathrm{~mm}$.

U.W. 101-1518 is a small fragment of a left distal tibia, preserving the lateral part of the shaft and the anterolateral part of the talar facet. The lateral shaft is concave, preserving a patch of cortex that is 19.7 $\mathrm{mm} \mathrm{ML}$ and $17.1 \mathrm{~mm}$ SI. It is surrounded by exposed trabeculae and, distally, what appears to be crushed cortex. Anteriorly and posteriorly, trabeculae are exposed. The bone is sheared, removing the entire medial portion of the bone. A patch of the talar facet that is $15.4 \mathrm{~mm} \mathrm{ML}$ and $15.3 \mathrm{~mm}$ AP is preserved. It is concave both AP and ML.

\subsection{Fibulae}


U.W. 101-181 is a robust distal fibular shaft fragment. The proximal and distal breaks are jagged. The diaphysis is triangular in cross-section. The dimensions at the distal break are $9.1 \mathrm{~mm}$ AP, $7.1 \mathrm{~mm} \mathrm{ML}$, and $27.6 \mathrm{~mm}$ in circumference. The anterolateral and the anteromedial borders run parallel and are only $2.7 \mathrm{~mm}$ apart.

U.W. 101-416 is a left proximal fibular shaft fragment. The shaft is damaged along the posteromedial and anterolateral borders. The proximal and distal breaks are sheared, cleanly exposing a triangular cross-section. At the proximal break the diaphysis is compressed AP. At the distal break the diaphysis is compressed ML. The shaft exhibits the same traits observed in the most complete specimen, U.W. 101-1037.

U.W. 101-449 is a proximal fibular shaft fragment.

U.W. 101-508 is a well-preserved right fibular midshaft fragment. The proximal break is sheared cleanly and triangular in cross-section. The distal break is jagged and elliptical in cross-section. The dimensions at the proximal break are $9.8 \mathrm{~mm} \mathrm{AP,} 7.8 \mathrm{~mm} \mathrm{ML}$, and $27.8 \mathrm{~mm}$ in circumference. The anterolateral border is well-marked and sharp. The lateral curve of the anterolateral border indicates this bone is from the midshaft region. The anteromedial border is not visible. The posteromedial border is well-marked and sharp. The posteromedial border is eroded for most of its length, but appears rounded. The medial surface is flat. The lateral and posterior surfaces are convex.

U.W. 101-580 is a well-preserved fragment of a left distal fibular shaft. The proximal and distal breaks are jagged. The dimensions at the proximal break are $10.5 \mathrm{~mm} \mathrm{AP,} 7.5 \mathrm{~mm} \mathrm{ML}$, and $29.3 \mathrm{~mm}$ in circumference. The shaft exhibits the same traits observed in the most complete specimens, particularly U.W. 101-1037.

U.W. 101-675 is a small, proximal fibular fragment. Some damage is present along the posterior surface and the anterolateral border. The proximal break is jagged, the distal break is sheared cleanly; both breaks are triangular in cross-section. The diaphysis is compressed mediolaterally. The anterolateral border is well-defined and sharp. The anteromedial border is not visible. The posteromedial and posterolateral borders are well-defined and rounded. The medial surface is slightly grooved. The posterior and lateral borders are slightly convex.

U.W. 101-702 is a left proximal fibular shaft. The proximal and distal breaks are triangular in crosssection and clearly defined. The proximal break of the fragment is at the level of the fibular neck. The medullary cavity is filled with sediment. Some flaking along the posterior surface of the bone and erosion midway on the anterolateral border is present. The shaft at the point of distal break is $8.7 \mathrm{~mm}$ $\mathrm{AP}$ and $7.6 \mathrm{~mm} \mathrm{ML}$. The anterolateral border is well-defined and sharp. The anteromedial border is not visible. The posteromedial border is well-defined and sharp and runs straight down the shaft. The posterolateral border shows some damage, but is still well-defined and blunt. The medial surface is slightly grooved. The lateral surface shows light grooving for the proximal attachment of $\mathrm{m}$. peroneus longus. The posterior surface is slightly convex. 
U.W. 101-719 is an eroded, small, left proximal fibular shaft comprised of two glued fragments. The proximal break is jagged. The distal break is sheared cleanly, exposing a quadrangular cross section. At the level of the distal fracture the dimensions are $9.2 \mathrm{~mm}$ AP and 6.1 mm ML. This shaft is compressed ML, similar to U.W. 101-925. The anterolateral border is well-defined and sharp. The anteromedial border is not visible. The posterolateral border is blunt. The posteromedial border is well-defined and sharp. The medial surface is flat proximally and eroded distally. The lateral and posterior surfaces are convex, though there is a considerable amount of erosion on both surfaces.

U.W. 101-722 is an eroded proximal fibular fragment.

U.W. 101-737 is right distal fibular shaft constituted by the union of two fragments, U.W. 101-737 and U.W. 101-774. The proximal and distal breaks are sheared cleanly. The proximal break is triangular in cross-section. The distal break is elliptical in cross-section. The anterolateral border is well-marked and sharp. Posteromedial and posterolateral borders are well-marked and rounded.

U.W. 101-778 is a distal fibular shaft.

U.W. 101-782 is a heavily eroded distal fibular shaft fragment, constituted by the union of two fragments, U.W. 101-782 and U.W. 101-783. Four borders are visible marking the point at which the anteromedial border runs parallel to the anterolateral border, around midshaft. Both proximal and distal breaks are sheared cleanly and triangular in cross-section.

U.W. 101-806 is a fibular shaft fragment.

U.W. 101-813 is a small, heavily damaged fibular shaft fragment.

U.W. 101-876 is a proximal fibular shaft fragment. The distal break is sheared cleanly; the proximal break is jagged. The dimensions at the distal break are $7.8 \mathrm{~mm}$ AP and 7.0 mm ML.

U.W. 101-892 is an unsided distal fibular shaft constituted by the union of two fragments, U.W. 101892 and U.W. 101-1049. Only two borders are visible and well-marked, though it is unclear precisely which borders these are. One break in the diaphysis is sheared cleanly (dimensions: $7.7 \mathrm{~mm} \mathrm{AP,5.6}$ $\mathrm{mm} \mathrm{ML}$ ). The other break is jagged.

U.W. 101-902 is a small, left proximal fibular shaft fragment. The proximal and distal breaks are jagged and there is some flaking proximally along the posteromedial border. The rest of the shaft is well-preserved. At the level of the distal break the dimensions are $6.1 \mathrm{~mm}$ AP and 4.2 $\mathrm{mm}$ ML. The anterolateral border is moderately defined proximally and becomes less defined distally, though there is some cortical erosion here. The anteromedial border is not visible. The posteromedial border is welldefined and sharp, especially proximally. The posterolateral border shows signs of erosion so it is difficult to characterize its morphology. The medial surface does not show the characteristic grooving present on other Dinaledi fibulae: it is flat proximally and becomes slightly convex distally. The lateral surface is slightly convex. The posterior surface is slightly convex proximally and becomes flatter distally. 
U.W. 101-925 is a proximal right fibular shaft. It comprises four conjoining fragments. The distal break is sheared cleanly and the proximal break is jagged. The cortex of the shaft exhibits erosional damage. At the distal break, the diaphysis is $9.2 \mathrm{~mm}$ AP and $6.3 \mathrm{~mm}$ ML. Proximally trabecular bone is present, indicating that the break is near the fibular head. The diaphysis is triangular in cross-section along its entire length and ML compressed. The diaphysis gradually flares proximally. The minimum circumference of the bone is $\sim 20 \mathrm{~mm}$ distal to the flaring, which corresponds to the neck of the fibula. The anterolateral border is well-marked and runs down the length of the anterior diaphysis. The anteromedial border is not visible. The posterolateral border is present and blunt. The posteromedial border is well-marked and prominent. The medial surface is rather flat and presents slight grooving (origin of $\mathrm{m}$. tibialis posterior). The other surfaces of the shaft are too damaged to discern any features.

U.W. 101-968 is a right distal fibular shaft. The diaphysis is eroded along much of its surface, however the main features of the bone can be highlighted. The proximal and distal breaks are jagged. The cross section at the level of the proximal break is triangular, while at the level of the distal break it is elliptical. The anterolateral border is eroded proximally. Distally it is well-marked and sharp. The anteromedial border is well-marked and sharp. The posteromedial border is well-marked proximally. The posterolateral border is rounded. The anterior surface is flat and well-defined distally (maximum ML breadth $8.3 \mathrm{~mm}$ ). The medial surface is nearly flat. The lateral and posterior surfaces are convex.

U.W. 101-987 is a small proximal fibular shaft. The dimensions at the proximal break are $8.1 \mathrm{~mm}$ AP, $5.6 \mathrm{~mm} \mathrm{ML}$, and $22.3 \mathrm{~mm}$ in circumference. The anterolateral border is well-marked and sharp. The anteromedial border is not visible. The posterolateral and posteromedial borders are rounded. The lateral surface is slightly grooved, the medial surface is flat, and the posterior surface is convex.

U.W. 101-1046 is a left distal fibular shaft. The proximal and distal breaks are triangular in crosssection and sheared cleanly. At the level of the proximal break the dimensions are $8.8 \mathrm{~mm}$ AP and 6.2 $\mathrm{mm}$ ML. At the level of the distal break the dimensions are $7.5 \mathrm{~mm}$ AP and $6.8 \mathrm{~m} \mathrm{ML}$. The anteromedial, anterolateral, and posteromedial borders are well-defined. The posterolateral border is well-defined and sharp. The medial surface is convex. The lateral and posterior surfaces are flat.

U.W. 101-1066 is a fragment of a fibular midshaft. It is smaller than the average fibular diaphysis found in the Dinaledi assemblage, but it is difficult to assess if it is an immature individual. Erosional damage is visible on the lateral border. Both proximal and distal breaks are triangular in cross-section. The proximal break is sheared cleanly, the distal break is jagged. At the level of the proximal break the dimensions are $7.5 \mathrm{~mm} \mathrm{AP,} 7.2 \mathrm{~mm} \mathrm{ML}$, and $23.7 \mathrm{~mm}$ in circumference. The anterolateral border is well-marked and rounded in the superior part and becomes sharp distally. The anteromedial border is visible but not marked. The posteromedial border is well-marked and moderately sharp. The posterolateral border is well-marked and rounded. The anterior surface is narrow proximally and widens distally to a maximum ML breadth of $6.5 \mathrm{~mm}$. It is flat along its whole length. The lateral surface is flat. The medial surface is slightly grooved proximally and slightly convex distally. The posterior surface is flat. 
U.W. 101-1071 is a distal fibular shaft fragment. It is smaller than the average fibular diaphysis found in the Dinaledi assemblage, but it is difficult to assess if it is an immature individual. Where the cortex is preserved, the shaft dimensions are $8.8 \mathrm{~mm} \mathrm{AP}$ and $7.7 \mathrm{~mm} \mathrm{ML}$. Both the proximal and distal breaks are elliptical in cross-section. Because of cortical erosion, only two borders are visible, one anterior and one posterior, though these borders are not identifiable.

U.W. 101-1094 is a fibular shaft fragment.

U.W. 101-1113 is a fragment of a proximal right fibula lacking the articular surface. Partial flaking of the cortex is present posteriorly $(9.5 \mathrm{~mm} \mathrm{SI}, 5.9 \mathrm{~mm} \mathrm{ML})$. The breaks are sheared cleanly both proximally and distally. Proximally, the bone flares. The posterior portion extends more proximally than the anterior portion due to irregular breakage. Anteriorly, just distal to the break, there is a small tubercle. The level of the distal break corresponds to the level of the neck of the fibula. The anterolateral border is visible but not pronounced. The anteromedial border is not visible. The posteromedial border is well-marked and prominent. The posterolateral border is visible, but not welldefined.

U.W. 101-1114 is a distal fibular shaft fragment. The proximal and distal breaks are elliptical in crosssection. At the distal break the dimensions are $9.6 \mathrm{~mm}$ AP and $6.9 \mathrm{~mm} \mathrm{ML}$. The shaft exhibits the same traits observed in the most complete fragments, such as U.W. 101-1037.

U.W. 101-1115 is a fibular midshaft fragment. It is smaller than the average fibular diaphysis found in the Dinaledi assemblage, but it is difficult to assess if it is an immature individual. Both the proximal and distal breaks are jagged. The dimensions in the center of the fragment are $9.3 \mathrm{~mm} \mathrm{AP,} 7.2 \mathrm{~mm} \mathrm{ML}$, and $26.1 \mathrm{~mm}$ in circumference.

U.W. 101-1122 is a fibular shaft fragment. It is smaller than the average fibular diaphysis found in the Dinaledi assemblage, but it is difficult to assess if it is an immature individual. The diaphysis is wellpreserved and ML compressed. One of the breaks is jagged, the other sheared cleanly.

U.W. 101-1138 is a proximal fibular shaft fragment. It is smaller than the average fibular diaphysis found in the Dinaledi assemblage, but it is difficult to assess if it is an immature individual. One break is jagged, the other is sheared cleanly. Both breaks are triangular in cross-section. The dimensions at the center of the fragment are $5.8 \mathrm{~mm} \mathrm{AP}$ and $4.4 \mathrm{~mm}$ ML.

U.W. 101-1143 is a right fibular shaft fragment. The proximal and distal breaks are sheared cleanly. The shaft at the distal point of break is triangular. At the proximal point of break, the shaft is more elliptical. The proximal break corresponds to the level of the neck of the fibula. The dimensions at the distal break are $8.6 \mathrm{~mm} \mathrm{AP,} 8.7 \mathrm{~mm} \mathrm{ML}$, and $28.7 \mathrm{~mm}$ in circumference. The lateral surface shows signs of erosion. The anterolateral and posteromedial borders are palpable. The anteromedial border is not visible. The posterolateral border is present and round in cross-section.

U.W. 101-1231 includes several conjoining fragments of distal fibula. 
U.W. 101-1254 is a proximal right fibular shaft. Additional fragments were collected with this specimen and may refit distally. The proximal break is triangular in cross-section and sheared cleanly. The distal break is jagged. The anterolateral border is partially eroded. Some erosion is also present on the posterior surface. The proximal break is at the level of the neck. The proximal part of the anterolateral border is eroded; distally it is well-marked and sharp. The anteromedial border is not visible. It may be present, but because of the erosion on the anterior part of the bone it cannot be evaluated. The posterolateral border is rounded and directed laterally. The posteromedial border is rounded. The medial surface is slightly grooved proximally and flat distally. The lateral surface is grooved proximally and slightly convex distally. The posterior surface is convex.

U.W. 101-1259 is a fibular shaft fragment. The bone is heavily damaged and only two borders can be seen, both of which are rounded.

U.W. 101-1260 is a left proximal fibular shaft fragment. Both the proximal and distal ends are sheared cleanly. At the level of the proximal break the dimensions are $7.9 \mathrm{~mm} \mathrm{AP,} 8.8 \mathrm{~mm} \mathrm{ML}$, and $27.1 \mathrm{~mm}$ in circumference. The bone shows an unusual proximal curvature that may be the consequence of a healed fracture. The anterolateral border is dull. The anteromedial border is not visible. The posteromedial and posterolateral borders are rounded. The medial surface is moderately grooved. The lateral surface is flat. The posterior surface is convex.

U.W. 101-1313 is a proximal fibular shaft fragment. It is smaller than the average fibular diaphysis found in the Dinaledi assemblage, but it is difficult to assess if it is an immature individual. The dimensions at the level of the proximal break are $7.6 \mathrm{~mm} \mathrm{AP,} 4.9 \mathrm{~mm} \mathrm{ML}$, and $20.4 \mathrm{~mm}$ in circumference; and at the level of the distal break $8.5 \mathrm{~mm}$ AP, $5.6 \mathrm{~mm} \mathrm{ML}$, and $23.1 \mathrm{~mm}$ in circumference. The shaft exhibits the same traits observed in most complete fragments, such as U.W. 101-1037.

U.W. 101-1436 is a fibular midshaft fragment. The diaphysis shows evidence of erosion. The distal break is jagged; the proximal break is sheared cleanly. The dimensions at the level of the proximal break are $9.2 \mathrm{~mm}$ AP, $7.8 \mathrm{~mm} \mathrm{ML}$, and $27.5 \mathrm{~mm}$ in circumference. The anterolateral border is welldefined, but dull. The anteromedial border is barely visible because of cortical erosion. The posteromedial and the posterolateral borders are well-marked, the former sharp and the latter rounded. The anterior surface is flat. The medial surface is slightly convex, but the presence of erosion in this area makes it difficult to determine. The lateral surface is flat. The posterior surface is convex.

U.W. 101-1451 is a left proximal fibular shaft. The bone is partially eroded laterally. The breaks are sheared cleanly both proximally and distally. Proximally the bone flares gradually until the break, where trabeculae are visible and well-preserved. This level is just distal to the proximal articulation of the fibula. Anteriorly, just distal to the proximal break there is a small bony tubercle. The shaft is triangular in cross-section. The anterior side that defines the triangular cross section is constituted by a well-marked and prominent anterolateral border. The most proximal part of the border flares anteriorly. 
The anteromedial border is not visible. The posteromedial border is well-marked and sharp. The posterolateral border is weakly developed.

U.W. 101-1520 is a fibula shaft fragment. It is smaller than the average fibular diaphysis found in the Dinaledi assemblage, but it is difficult to assess if it is an immature individual. The dimensions at the center of the fragment are $6.9 \mathrm{~mm} \mathrm{AP}$ and $6.9 \mathrm{~mm} \mathrm{ML}$.

U.W. 101-1679 is a right proximal fibular shaft fragment. The breaks are sheared cleanly both proximally and distally. The proximal break corresponds to the level of the neck of the fibula. The anterolateral border is well-marked, but not sharp as in other fibulae in the assemblage. The anteromedial border is not visible. The posterolateral and posteromedial borders are rounded. The medial surface is very slightly grooved. The lateral surface is flat and the posterior surface is slightly convex. 


\section{References}

DeGusta D.A., 2004. Pliocene hominid postcranial fossils from the Middle Awash, Ethiopia,

Ph.D. Dissertation, University of California, Berkeley 2004.

Domínguez-Rodrigo M., Pickering T.R., Baquedano E., Mabulla A., Mark D.F., Musiba C.,

Bunn H.T., Uribelerrea D., Smith V., Diez-Martin F. and Pérez-González A., 2013.

First partial skeleton of a 1.34-million-year-old Paranthropus boisei from Bed II,

Olduvai Gorge, Tanzania, PLoS One 8, 2013, e80347.

Gilbert W.H., 2008. Daka member hominid postcranial remains, In: Gilbert W.H. and Asfaw

B., (Eds.), Homo erectus: Pleistocene evidence from the Middle Awash, Ethiopia Vol.

1, 2008, University of California Press; Cambridge, Berkeley, 373-396.

Grine F.E., Jungers W.L., Tobias P.V. and Pearson O.M., 1995. Fossil Homo femur from

Berg Aukas, northern Namibia, Am. J. Phys. Anthropol. 97, 1995, 151-185.

Johanson D.C., Lovejoy C.O., Kimbel W.H., White T.D., Bush M.E., Latimer B.M. and

Coppens Y., 1982. Morphology of the Pliocene partial hominid skeleton (A.L. 288-1)

from the Hadar formation, Ethiopia, Am. J. Phys. Anthropol. 57, 1982, 403-451.

Jungers W.L., Larson S.G., Harcourt-Smith W., Morwood M.J., Sutikna T., Awe R.D. and

Djubiantono T., 2009. Descriptions of the lower limb skeleton of Homo floresiensis,

J. Hum. Evol. 57, 2009, 538-554

Lordkipanidze D., Jashashvili T., Vekua A., Ponce de León M., Zollikofer C.P.E., Rightmire

G.P., Pontzer H., Ferring R., Oms O., Tappen M., Bukhsianidze M., Agusti J., Kahlke

R., Kiladze G., Martinez-Navarro B., Mouskhelishvili A., Nioradze M. and Rook L.,

2007. Postcranial evidence from early Homo from Dmanisi, Georgia, Nature 449,

2007, 205-310.

Lovejoy C.O., 1975. Biomechanical perspectives on the lower limb of early hominids, In:

Tuttle R., (Ed), Primate Functional Morphology and Evolution, 1975, Mouton; The 
Hague, 291-326.

Lovejoy C.O., Johanson D.C. and Coppens Y., 1982. Hominid lower limb bones recovered from the Hadar formation: 1974-1977 collections, Am. J. Phys. Anthropol. 57, 1982, $679-700$.

Lovejoy C.O., Meindl R.S., Ohman J.C., Heiple K.G. and White T.D., 2002. The Maka femur and its bearing on the antiquity of human walking: Applying contemporary concepts of morphogenesis to the human fossil record, Am. J. Phys. Anthropol. 119, 2002, $97-$ 133.

Partridge T.C., Granger D.E., Caffee M.W. and Clarke R.J., 2003. Lower Pliocene hominid remains from Sterkfontein, Science 300, 2003, 607-612.

Pickering T.R., Heaton J.L., Clarke R.J., Sutton M.B., Brain C.K. and Human K., 2012. New hominid fossils from Member 1 of the Swartkrans formation, South Africa, J. Hum. Evol. 62, 2012, 618-628.

Pickford M., Senut B., Gommery D. and Treil J., 2002. Bipedalism in Orrorin tugenensis revealed by its femora, C.R. Palevol. 1, 2002, 191-203.

Pontzer H., Rolian C., Rightmire G.P., Jashashvili T., Ponce de León M.S., Lordkipanidze D. and Zollikofer C.P., 2010. Locomotor anatomy and biomechanics of the Dmanisi hominins, J. Hum. Evol. 58, 2010, 492-504.

Reed K.E., Kitching J.W., Grine F.E., Jungers W.L. and Sokoloff L., 1993. Proximal femur of Australopithecus africanus from Member 4, Makapansgat, South Africa, Am. J. Phys. Anthropol. 92, 1993, 1-15.

Walker C.S., 2015. Ontogeny of lower limb morphology and proportions in the Dinaledi hominins, Ph.D. Dissertation, Duke University2015.

Walker A.C. and Leakey R.E.F., 1993. The postcranial bones, In: Walker A.C. and Leakey R.E.F., (Eds.), The Nariokotome Homo erectus skeleton, 1993, Harvard University Press; Cambridge, 95-160. 
Ward C.V., Kimbel W.H., Harmon E.H. and Johanson D.C., 2012. New postcranial fossils of Australopithecus afarensis from Hadar, Ethiopia (1990-2007), J. Hum. Evol. 63, 2012, 1-51. 